NOTE TO USERS

This reproduction is the best copy available. 
$=$ 


\title{
Molecular adaptations of skeletal and cardiac muscle in the hibernating thirteen-lined ground squirrel, Spermophilus tridecemlineatus
}

\author{
By \\ Shannon Noëlla Tessier \\ B.Sc. Carleton University, 2007
}

A thesis submitted to the Faculty of Graduate Studies and Research in partial fulfillment of the requirements for the degree of

\author{
Master of Science \\ Department Biology \\ Carleton University \\ Ottawa, Ontario, Canada
}




$\begin{array}{ll}\begin{array}{l}\text { Library and Archives } \\ \text { Canada }\end{array} & \begin{array}{l}\text { Bibliothèque et } \\ \text { Archives Canada }\end{array} \\ \begin{array}{l}\text { Published Heritage } \\ \text { Branch }\end{array} & \begin{array}{l}\text { Direction du } \\ \text { Patrimoine de l'édition }\end{array} \\ \begin{array}{l}\text { 395 Wellington Street } \\ \text { Ottawa ON K1A ON4 } \\ \text { Canada }\end{array} & \begin{array}{l}\text { 395, rue Wellington } \\ \text { Ottawa ON K1A ON4 } \\ \text { Canada }\end{array}\end{array}$

Your file Votre référence
ISBN: $978-0-494-71673-1$
Our file Notre référence
ISBN: $978-0-494-71673-1$
NOTICE:

The author has granted a nonexclusive license allowing Library and Archives Canada to reproduce, publish, archive, preserve, conserve, communicate to the public by telecommunication or on the Internet, loan, distribute and sell theses worldwide, for commercial or noncommercial purposes, in microform, paper, electronic and/or any other formats.

The author retains copyright ownership and moral rights in this thesis. Neither the thesis nor substantial extracts from it may be printed or otherwise reproduced without the author's permission.
AVIS:

L'auteur a accordé une licence non exclusive permettant à la Bibliothèque et Archives Canada de reproduire, publier, archiver, sauvegarder, conserver, transmettre au public par télécommunication ou par l'Internet, prêter, distribuer et vendre des thèses partout dans le monde, à des fins commerciales ou autres, sur support microforme, papier, électronique et/ou autres formats.

L'auteur conserve la propriété du droit d'auteur et des droits moraux qui protège cette thèse. Ni la thèse ni des extraits substantiels de celle-ci ne doivent être imprimés ou autrement reproduits sans son autorisation.
In compliance with the Canadian Privacy Act some supporting forms may have been removed from this thesis.

While these forms may be included in the document page count, their removal does not represent any loss of content from the thesis.
Conformément à la loi canadienne sur la protection de la vie privée, quelques formulaires secondaires ont été enlevés de cette thèse.

Bien que ces formulaires aient inclus dans la pagination, il n'y aura aucun contenu manquant.

\section{Canadä}




\section{Abstract}

Many small mammals face severe problems during the winter - little or no food supply and yet huge energy costs for keeping their bodies warm. To escape these problems, they hibernate, entering states of deep torpor where metabolic rate falls to just $2-4 \%$ of euthermic and body temperature falls to near $0^{\circ} \mathrm{C}$. Remarkably, skeletal muscle cell size and strength are sustained despite extended periods of disuse during torpor whereas cell growth (hypertrophy) is promoted in cardiac muscle to support the stronger cardiac contractions needed in the cold. Despite overall suppression of transcription and translation during hibernation, the present research identified and analyzed selected muscle genes and their products that were up-regulated during torpor in striated muscle of thirteen-lined ground squirrels (Spermophilus tridecemlineatus). These changes in mRNA/protein levels of myocyte enhancer factor-2 (MEF2A, MEF2C) transcription factor as well as altered expression of selected downstream targets (e.g. glucose transporter 4, myogenic differentiation protein) aid skeletal and cardiac muscle in meeting metabolic challenges associated with hibernation. MEF2 transcription factors were significantly elevated (both mRNA and protein) at various points in the torporarousal cycle suggesting a significant role for MEF2-mediated gene transcription in the selective adjustment of striated muscle proteins. Muscle plasticity in the hibernator was also evidenced by torpor-responsive changes in the protein levels of important contractile (troponin I, $\alpha / \beta$-tropomyosin), sarcomeric (myomesin) and cytoskeleton proteins (desmin, and vimentin). These data provide new insights into muscle remodeling during hibernation and the role of selected genes/proteins in balancing programs of atrophy, stasis and myogenesis. 


\section{Acknowledgements}

I would first like to sincerely thank my thesis supervisor Dr. Kenneth B. Storey for maximizing my learning experience, pushing me to higher levels of achievement, and encouraging me to follow my own unique path of scientific curiosity. Ken, I have learnt (and will continue to learn) so much from you and feel tremendously grateful for your great advice in both my scientific career and personal life. I would also like to give thanks to Janet Storey for her incredible patience and countless hours spent reviewing and editing my manuscripts and thesis. Janet, your "colourful" commentary and detailed instructions have helped me improve my communication skills enormously. I thank you both for the confidence and motivation you have instilled in me as both a scientist and an individual.

I would also like to thank my family for their constant support. To my mother, thank you for making me "power snacks" as I studied throughout the night. To my father, thank you for allowing me to take over the house and create a quiet and comfortable study area. A special thanks to my brothers, Chris and Darren, for always looking out for my best interest while also making sure I never take myself too seriously. To Denis, I

thank you for our endless science talks and words of encouragement when I need it most.

A huge thanks to my childhood friends who never missed a moment throughout my life and supported everything about my "nerdy" ways. Thank you for sitting through endless talks about hibernation, muscle disorders, and everything in the lab. Finally, I would like to thank all Storey lab members who have made everyday enjoyable. 


\section{Table of Contents}

Title Page $\quad$ i

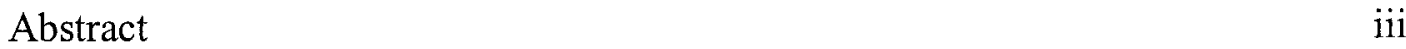

Acknowledgements $\quad$ iv

Table of Contents $\quad \mathrm{V}$

List of Abbreviations $\quad$ vi

List of Figures viii

Chapter 1 General Introduction 1

$\begin{array}{lll}\text { Chapter } 2 & \text { General Materials and Methods } & 10\end{array}$

Chapter $3 \quad$ Expression of myocyte enhancer factor-2 and 22 downstream genes in ground squirrel skeletal muscle during hibernation

Chapter 4 Myocyte enhancer factor-2 and cardiac muscle gene expression during hibernation in thirteenlined ground squirrels.

Chapter 5 Molecular adaptations of structural proteins in striated muscle of the thirteen-lined ground squirrel during hibernation

Chapter $6 \quad$ General Discussion 85

$\begin{array}{ll}\text { Publication List } & 100\end{array}$

$\begin{array}{ll}\text { Appendix I } & 102\end{array}$

$\begin{array}{ll}\text { References } & 103\end{array}$ 


\section{List of Abbreviations}

ACR

APS

ATP

bHLH

BLAST

bp

cDNA

DEPC

DNA

DTT

EAR

EDTA

EHIB

ENT

$\mathrm{EtBr}$

ETOH

FOXO

HDAC

Hepes

HRP

$\mathrm{kDa}$

LAR

LHIB
Active in the cold room

ammonium persulfate

Adenosine triphosphate

basic helix-loop-helix

Basic Local Alignment Search Tool

Base pair

complementary deoxyribonucleic acid

Diethylpyrocarbonate

Deoxyribonucleic acid

Dithiolthreitol

Early arousal

Ethylenediamine tetraacetic acid

Early hibernation

Entrance into torpor

Ethidium bromide

Ethanol

Forkhead box, class O proteins

Histone deacetylase

4-(2-hydroxyethyl)-1-piperazineethanesulfonic acid

Horse radish peroxidase

Kilodalton

Late arousal

Late hibernation 


\begin{tabular}{|c|c|}
\hline MADS-box & MCM1, Agamous, Deficiens, SRF \\
\hline MAFbx & Muscle atrophy $\mathrm{F}$ box \\
\hline MAPK & Mitogen-activated protein kinase \\
\hline MEF2 & Myocyte enhancer factor- 2 \\
\hline mRNA & messenger ribonucleic acid \\
\hline MyHC & Myosin heavy chain \\
\hline MyoD & Myogenic differentiation \\
\hline OD & Optical density \\
\hline PAGE & polyacrylamide gel electrophoresis \\
\hline PCR & polymerase chain reaction \\
\hline PGC-1 $\alpha$ & PPAR $\gamma$ coactivator 1-alpha \\
\hline PMSF & Phenylmethanesulfonylfluoride \\
\hline $\operatorname{PPAR} \gamma$ & Peroxisome proliferator-activated receptor gamma \\
\hline PVDF & Polyvinylidine fluoride \\
\hline rRNA & ribosomal RNA \\
\hline RT & Room temperature \\
\hline SDS & Sodium dodecyl sulfate/ lauryl sulphate \\
\hline $\mathrm{T}_{\mathrm{b}}$ & Body temperature \\
\hline TEMED & $\mathrm{N}, \mathrm{N}, \mathrm{N}^{\prime}, \mathrm{N}^{\prime}$-tetramethylethylenediamine \\
\hline Tris & Tris(hydroxymethyl)aminomethane \\
\hline $\mathrm{Tf}$ & Transcription factor \\
\hline TMB & Tetramethylbenzidine \\
\hline
\end{tabular}




\section{List of Figures}

Fig. 1.1 Habitat range of the thirteen-lined ground squirrel,

Fig. 2.1 Body temperature $\left(\mathrm{T}_{\mathrm{b}}\right)$ of a thirteen-lined ground squirrel as a function of time over one torpor-arousal cycle.

Fig. 3.1 Changes in the protein levels of MEF2 Tfs over the course of a torpor-arousal cycle in skeletal muscle of $S$. tridecemlineatus.

Fig. 3.2 Representative Western blot of thirteen-lined ground squirrel skeletal muscle extract from ACR and EHIB conditions immunoblotted with anti-MEF2A antibody. The antibody cross-reacted with a single band at the expected molecular weight of $44 \mathrm{kDa}$.

Fig. 3.3 Changes in the distribution of total MEF2 protein and phosphorylated MEF2 content in nuclear and cytoplasmic fractions over the course of a torpor-arousal cycle in skeletal muscle of $S$. tridecemlineatus.

Fig. 3.4 Changes in glucose transporter isoforms 4 protein and mRNA transcript levels in skeletal muscle of $S$. tridecemlineatus over the torpor-arousal cycle.

Fig. 3.5 Changes in myogenic differentiation protein and mRNA transcript levels in skeletal muscle of $S$. tridecemlineatus over the torpor-arousal cycle.

Fig. 3.6 Changes in the levels of Mef2a and Mef2c mRNA transcript levels in skeletal muscle of $S$. tridecemlineatus over the torpor-arousal cycle.

Fig. 3.7 Changes in the DNA binding of MEF2 Tfs over the course of a torpor-arousal cycle in skeletal muscle of $S$. tridecemlineatus.

Fig. 4.1 Changes in the protein levels of MEF2 Tfs over the course of the torpor-arousal cycle in cardiac muscle of $S$. tridecemlineatus. 
Fig. 4.2 Changes in the distribution of total MEF2 protein and

phosphorylated MEF2 content in nuclear and cytoplasmic fractions over the course of a torpor-arousal cycle in cardiac muscle of $S$. tridecemlineatus.

Fig. 4.3 Changes in glucose transporter isoforms 4 protein and mRNA transcript levels in cardiac muscle of $S$. tridecemlineatus over the torpor-arousal cycle.

Fig. 4.4 Changes in myogenic differentiation protein and mRNA transcript levels in cardiac muscle of $S$. tridecemlineatus over the torpor-arousal cycle.

Fig. 4.5 Changes in the levels of Mef2a and Mef2c mRNA transcript levels in cardiac muscle of $S$. tridecemlineatus over the torpor-arousal cycle.

Fig. 4.6 Changes in the DNA binding of MEF2 Tfs over the course of a torpor-arousal cycle in cardiac muscle of $S$. tridecemlineatus.

Fig. 5.1 Changes in the protein levels of troponin I, $\alpha / \beta-$ tropomyosin, and myomesin over the course of a torporarousal cycle in skeletal muscle of $S$. tridecemlineatus.

Fig. 5.2 Changes in the protein levels of desmin and vimentin in skeletal muscle of $S$. tridecemlineatus over the torporarousal cycle.

Fig. 5.3 Changes in the protein levels of troponin I, $\alpha / \beta-$ tropomyosin, and myomesin in cardiac muscle of $S$. tridecemlineatus over the torpor-arousal cycle.

Fig. 5.4 Changes in the protein levels of desmin and vimentin in cardiac muscle of $S$. tridecemlineatus over the torporarousal cycle. 


\section{Chapter 1}

\section{General Introduction}


All animal life requires energy to fuel vital processes at the cellular, tissue and whole organism level. This necessity of life has staged the evolution of organisms which may rely on daily feeding habits, a migration to more fruitful grazing lands, or a mechanism to conserve energy under unfavorable conditions. One highly successful adaptation for surviving prolonged seasonal exposures to stressful environments (e.g. little or no food, cold temperatures) is hibernation. Torpor-arousal bouts are characterized by prolonged periods of torpor where animals strongly suppress their metabolic rate (often to just 2-4\% of euthermic) and drop body temperature $\left(\mathrm{T}_{\mathrm{b}}\right)$ to near ambient (often to $<5^{\circ} \mathrm{C}$ ), interspersed with brief periods of arousal back to euthermia [Wang \& Lee, 1996; Geiser, 2004; Storey, 2010]. This hypometabolic state has effectively countered the pressure associated with large environmental fluctuations and has led to the successful expansion of ecological ranges, that would otherwise be largely inhospitable to smallbodied non-hibernating endotherms. For small mammals, such as ground squirrels, hibernation can conserve up to $88 \%$ of the energy that would otherwise be needed to remain euthermic over the winter months [Wang \& Lee, 1996]. Although part of the energy savings in torpor comes from the reduction in $\mathrm{T}_{\mathrm{b}}$, strong regulatory controls are needed both to impose global controls that coordinate the suppression of metabolic rate (and thereby cause $\mathrm{T}_{\mathrm{b}}$ to fall) and to readjust metabolism to support long term viability in the torpid state. The present research focuses on thirteen-lined ground squirrels, Spermophilus tridecemlineatus, which are native to the central prairies of North America and survive the winter by hibernating in underground burrows (Fig. 1.1).

The fluctuation of $T_{b}$ associated with the hibernation season represents a dramatic $30^{\circ} \mathrm{C}$ change in core $\mathrm{T}_{\mathrm{b}}$ and results in important adaptations for dealing with the cold 
[Tabarean et al, 2010]. Furthermore, hibernating ground squirrels also experience dramatic reductions in organ perfusion rates $(<10 \%$ of normal) and respiration rates $(2.5$ $\%$ of normal) [Frerichs \& Hallenbeck 1998; Storey \& Storey, 2010]. In anticipation of the winter season, ground squirrels enter a phase of hyperphagia where excessive eating results in body mass gains of up to $40 \%$ [Martin, 2008; Storey, 2010]. This is matched with a sharp shift in the metabolic profile of the animals which moves from a heavy reliance on carbohydrate catabolism to dependence on $\beta$-oxidation [Buck \& Barnes, 2000]. The central nervous system also requires distinct adaptations where overall activity is reduced with only specific regions of the brain demonstrating active neuronal firing during torpor [Bratincsák et al, 2007]. Finally, ground squirrels are able to sustain skeletal muscle strength and cell size in the face of extended periods of disuse during torpor whereas cardiac muscle becomes hypertrophic to meet the higher force required to pump cold, viscous blood to vital organs [Rourke et al, 2004; Storey, 2010].

The dramatic adaptations of physiology and biochemistry shown by hibernators make them elegant model systems with which to study many issues of medical relevance to humans including hypothermia tolerance, inducible torpor, organ preservation, ischemia resistance, and selected myopathies. Using thirteen-lined ground squirrels as a model organism, studies in our lab have examined many aspects of hypometabolism in hibernators [Woods \& Storey, 2005; Mamady \& Storey, 2006; Morin \& Storey, 2006; Eddy \& Storey, 2007; MacDonald \& Storey, 2007; Morin \& Storey, 2007; Morin et al, 2008; Morin \& Storey, 2009; Tessier \& Storey, 2010]. Key molecular adjustments during torpor include the following; global suppression of transcription [Morin \& Storey, 2006] and translation [Morin et al, 2008], elevated antioxidant defenses [Morin \& Storey, 
2007], differential regulation of enzymes by mechanisms such as reversible protein phosphorylation [MacDonald \& Storey, 2007], and modulation of gene expression by transcription factors [Eddy \& Storey, 2007], amongst other notable changes [Woods \& Storey, 2005; Mamady \& Storey, 2006; Morin \& Storey, 2009].

\section{Skeletal Muscle}

Skeletal muscle is a highly plastic organ which is primarily used for postural support and movement, but also plays roles in other physiological processes [Postnikova et al, 1999]. For example, thermogenesis is crucial to arousal from torpor and is driven initially by nonshivering thermogenesis in brown adipose tissue, with subsequent contributions from shivering thermogenesis in skeletal muscle once the animal is partially rewarmed [Geiser, 2004; Storey, 2010]. Nonhibernating species, including humans, typically experience significant muscle wasting during prolonged periods of inactivity but, remarkably, hibernators show very little atrophy over the winter months spent largely in deep torpor [Musacchia et al, 1989; Rourke et al, 2004; Bassel-Duby \& Olson, 2006; Lee et al, 2008; Malatesta et al, 2009]. One proposed method of adapting to long bouts of inactivity during hibernation is altered expression of myosin heavy chain (MyHC) isoforms including greater expression of slow isoforms, which presumably provides a more optimal mix of isoforms to adapt the muscles to the reduced work load and thermal conditions of the torpid state [Caiozzo, 2002; Zuikova et al, 2005; Bassel-Duby \& Olson, 2006; Rourke et al, 2006; Choi et al, 2009]. Hibernators can also show selective remodeling of their skeletal muscles, possibly as an aid to low temperature life and/or to optimize the capacity for shivering thermogenesis during arousal [Caiozzo, 2002; Rourke et al, 2004; Zuikova et al, 2005; Bassel-Duby \& Olson, 2006]. 


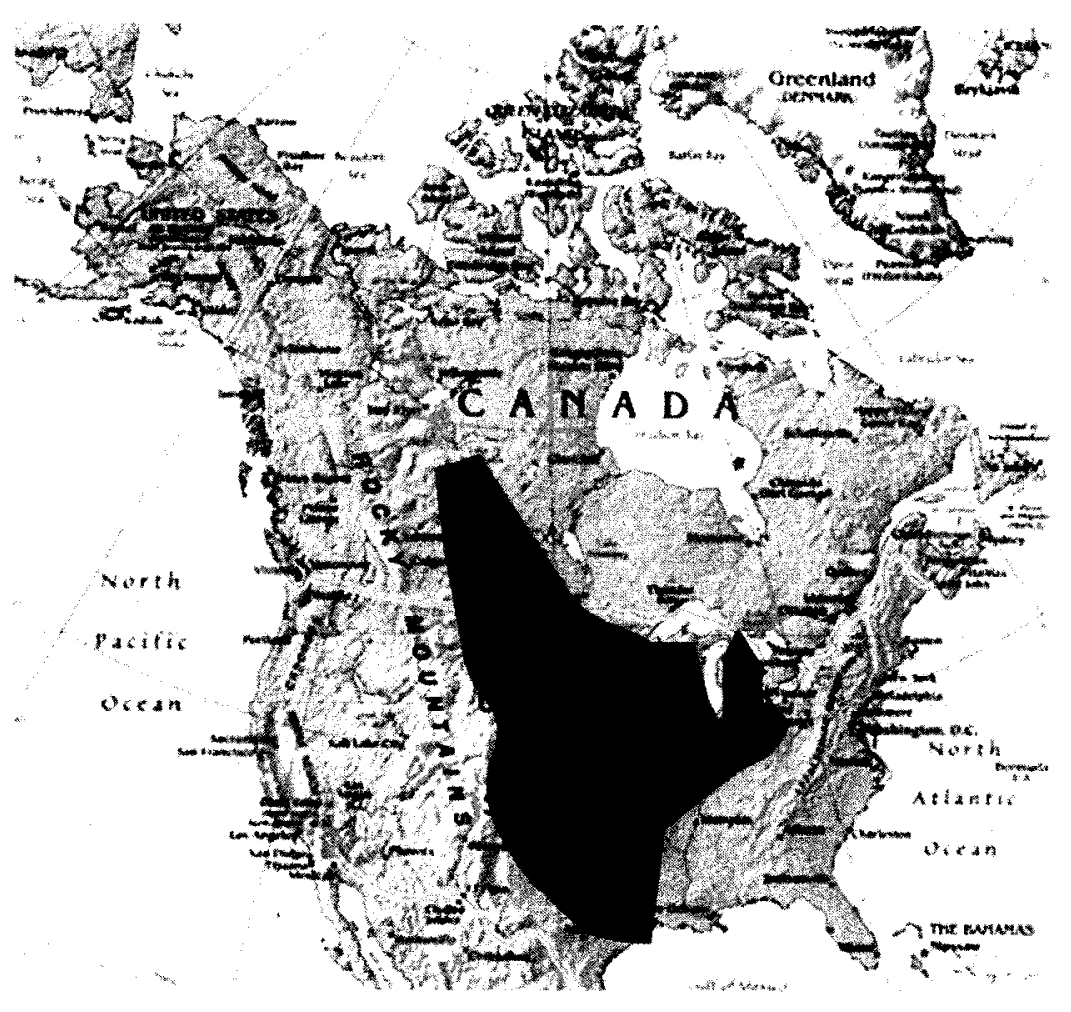

Fig. 1.1. The range of the thirteen-lined ground squirrel, Spermophilus tridecemlineatus, extends north-south from central Alberta, Manitoba, and Saskatchewan to Texas and New Mexico, and east-west from central Ohio to Colorado.

North American map taken from:

http://www.lib.utexas.edu/maps/americas/north america ref02.jpg 


\section{Cardiac Muscle}

Cardiac muscle shares similarities with skeletal muscle with regard to its striated appearance and method of contraction. However, during hibernation cardiomyocytes undergo distinct physiological changes. Whereas heart rate is reduced to just 5-10 beats/min (compared to euthermic values of $350-400$ beats/min), the force of contraction needs to increase significantly in order to pump cold, viscous blood through the hibernator body [Dawe \& Morrison, 1955; Storey \& Storey, 2004]. This leads to cardiac hypertrophy. In humans, cardiomyocyte hypertrophy is characterized by an increase in cell size, enhanced protein synthesis, and heightened organization of the sarcomere with effects that are generally deemed to be detrimental [Frey et al, 2004]. However, in hibernators, such hypertrophy is a necessary strategy for life during cold torpor and analysis of hibernator heart could identify those mechanisms that allow nondeleterious and reversible cardiomyocyte hypertrophy. One such adaptation could be myosin heavy chain (MyHC) restructuring that may play a role in adapting cardiac muscle to both cold temperature and the contractile demands of the torpid state [Morano et al, 1992; Fahlman et al, 2000; Brauch et al, 2005]. Different ratios of MyHC isoforms can contribute to the differing contractile properties of cardiac muscles [Brauch et al, 2005, Kuzman et al, 2005]. Indeed, hibernating mammals show a preference for $\alpha$-MyHC proteins in heart

during hibernation which confer a higher shortening velocity and greater ATPase activity than $\beta$-MHC proteins [Brauch et al, 2005, Kuzman et al, 2005].

\section{OBJECTIVES AND HYPOTHESIS}

Metabolic rate depression is characterized by strong global suppression of all ATP-expensive cell functions including transcription and translation. Against this 
background, instances of positive up-regulation of selected genes/proteins can be highly instructive for identifying responses that are critical to the torpor-arousal process. In fact, various gene-screening approaches have identified selected protein targets that are upregulated during torpor [Storey \& Storey, 2010]. As a refinement of this approach, I have focused on the responses of selected transcription factors (Tfs) and proteins related to the structural apparatus of striated muscle over the torpor-arousal cycle. Since each Tf regulates the expression of a group of genes/proteins that serve common cell functions, identification of the Tfs that show enhanced expression during torpor and/or arousal, with follow-up to analyze the expression of their downstream genes, can provide insights into the cell functions that need particular attention for hibernation success [Storey \& Storey, 2010]. Additionally, analysis of the extent and nature of muscle remodeling under strong environmental pressures will help unravel important mechanisms of muscle plasticity and resiliency that may be applicable to all mammals.

\section{The regulation of Myocyte Enhancer Factor-2 (MEF2)}

Accumulating evidence has thrust various transcription factors (and the regulatory control that they impose on cells) to the forefront of research on the molecular mechanisms that direct the cellular profile of myocytes [Akazawa \& Komuro, 2003; Muñoz et al, 2009; Black \& Olson, 1998]. One such candidate, is the myocyte enhancer factor-2 (MEF2) family of transcription factors [Molkentin \& Markham, 1993; Lin et al, 1997; Naya et al, 2002; Czubryt \& Olson, 2004; Potthoff \& Olson, 2007; Muñoz et al, 2009]. MEF2 transcription factors are extremely dynamic, representing a group of proteins that are able to integrate information from diverse signaling pathways [Kato $e t$ al, 2000; Yang et al, 1999; Lynch et al, 2005; Muñoz et al, 2009], show altered 
regulatory properties as a result of numerous posttranslational modifications [Kang et al, 2006; Ornatsky et al, 1999; Wei et al, 2008], and undergo interactions with multiple cofactors and other transcription factors to elicit specific responses [Black \& Olson, 1998; Maeda et al, 2002; Amat et al, 2009]. Although, MEF2 has been implicated in diverse cellular responses, its highest expression levels are in striated muscle and the conserved MEF2 DNA binding sequence is found in the control region of the most muscle-specific genes [Black \& Olson, 1998; Potthoff \& Olson, 2007].

\section{Hypothesis 1: Skeletal muscle must undergo molecular changes in order to} function properly at reduced body temperatures and minimize muscle disuse atrophy. MEF2 transcription factors, that are regulators of important muscle specific genes, will be differentially expressed during hibernation.

Chapter 3 tests this hypothesis by examining the protein and mRNA expression (via immunoblotting and reverse transcriptase PCR analysis) of MEF2A and MEF2C in ground squirrel skeletal muscle over the course of torpor and arousal. In addition, nuclear localization and DNA binding assays were utilized to obtain a multi-dimensional view of MEF2A and MEF2C transcription factor regulation. The data reveal that MEF2 genes are positively regulated during hibernation and that expression of known downstream genes under MEF2 control, GLUT4 and MyoD, is also enhanced.

Hypothesis 2: Cardiac muscle must function properly at cold $\mathrm{T}_{\mathrm{b}}$ when heart rate is reduced and the force of cardiac contraction is enhanced. MEF2 transcription factors will play a significant role cardiac remodeling in the hibernator with responses that may differ substantially from those of skeletal muscle. 
Chapter 4 tests this hypothesis by examining responses of MEF2A and MEF2C and selected downstream targets (GLUT4 and MyoD) in ground squirrel heart over the course of torpor-arousal. Mirroring the methods of Chapter 3, the data suggest that MEF2 transcription factors, and the downstream genes that they control, play a role in adapting cardiomyocytes to cold temperatures and changing functional demands of the torpid state.

\section{Adaptations of Structural Proteins}

Troponin and tropomyosin proteins play an integral role in skeletal and cardiac muscle contraction. Once the muscle has been excited by an action potential, calcium ions bind to troponin leading to the removal of the blocking action of tropomyosin, and the subsequent exposure of actin sites for the binding of myosin cross-bridges [Watkins et al, 1995]. Myomesin is an end line protein, attaching myosin thick filaments to the $\mathrm{M}$ line and maintaining the thick filament lattice [Agarkiva \& Perriard, 2005]. Intermediate filaments, such as desmin and vimentin, interconnect myofibrils through the Z-disk and link the contractile apparatus to the sarcolemma as well as to the nucleus [Capetanaki et al, 2007; Ivaska et al, 2007].

Hypothesis 3: Adaptive changes in the amounts of muscle contractile proteins, sarcomeric proteins and intermediate filaments will aid skeletal and cardiac muscle to meet the physiological demands of the cold torpor state.

Chapter 5 tests this hypothesis by evaluating five proteins related to the structural apparatus of striated muscle (troponin, tropomyosin, myomesin, desmin, vimentin) using immunoblot techniques to assess expression over a time course of torpor and arousal in 13-lined ground squirrels. The data reveal that myocytes undergo structural changes during hibernation and this response differs between skeletal and cardiac muscle. 
Chapter 2

General Materials and Methods 


\section{Animals}

Male and female thirteen-lined ground squirrels, S. tridecemlineatus, weighing 130-180 g were wild-captured annually in August by licensed trappers (TLS Research, Michigan) and transported to the Animal Hibernation Facility, National Institute of Neurological Disorders and Stroke, NIH, Bethesda, MD. Hibernation experiments were conducted by the laboratory of Dr. J.M. Hallenbeck as previously described [30] and briefly summarized as follows. Animals were kept in shoebox cages at $21^{\circ} \mathrm{C}$ and fed $\mathrm{ad}$ libitum until they gained sufficient lipid stores (mass rose to 220-240 g) to enter hibernation. Animals were fitted with a sensor chip (IPTT-200; Bio Medic Data Systems) injected subcutaneously while the squirrels were anesthetized with 5\% isofluorane. To induce hibernation, animals were transferred to cold chambers at $4-6^{\circ} \mathrm{C}$ in cages containing wood shavings. $\mathrm{T}_{\mathrm{b}}$, time and respiration rate were monitored and used to determine the stage of hibernation. Experiments were carried out during the months of December-February. All animals had been through multiple hibernation bouts prior to sampling in order to ensure constant torpor-arousal cycles. Most animals settled into torpor after 2-3 days, and were sacrificed by decapitation at various points over torporarousal bouts; tissue samples were quickly excised and immediately frozen in liquid nitrogen. Samples were delivered to Carleton University on dry ice and stored at $-80^{\circ} \mathrm{C}$ until use. Tissue samples were collected from animals under the following conditions: (1) 'active' in the cold room (ACR): at least three days at a stable $\mathrm{Tb}\left(36-37^{\circ} \mathrm{C}\right)$ and high metabolic rate. ACR animals were capable of entering torpor but had not re-entered hibernation in the past 72 hours. In addition, ACR animals display the slow-wave sleep characteristic of all sampling animals. These animals were chosen as the reference group to eliminate compounding variables of environmental light, temperature, feeding as well 
as time/season. (2) Early entrance into torpor (ENT): characterized by decreasing $\mathrm{T}_{\mathrm{b}}$ ranging from 31 to $18^{\circ} \mathrm{C}$ (at least two successive temperature readings showed a decreasing $T_{b}$ ), (3) early-hibernation (EHIB): animals showed a stable $T_{b}$ of $5-8^{\circ} \mathrm{C}$ for 24 hours, (4) late-hibernation (LHIB): animals were in continuous torpor for at least 3 days with a stable $\mathrm{T}_{\mathrm{b}}$ of $5-8^{\circ} \mathrm{C}$, (5) early-arousal (EAR): squirrels exhibited a rising $\mathrm{T}_{\mathrm{b}}\left(\sim 12^{\circ} \mathrm{C}\right)$ and increased respiration rate $\geq 60 / \mathrm{min}$, and (6) late-arousal (LAR): these animals had previously been in deep torpor before a full interbout arousal where $\mathrm{T}_{\mathrm{b}}$ was stable at 34$37^{\circ} \mathrm{C}$ for less than 1 day (Fig. 2.1). The skeletal muscle tissue collected and used for analysis was a mixture of hind limb muscles whereas the cardiac muscle was a mixture of atrial and ventricular tissue.

\section{Total RNA isolation and quality assessment.}

Frozen tissue samples from the six time points of the torpor-arousal cycle were separately extracted ( $\mathrm{N}=4$ for each). All materials and solutions were treated with $0.1 \%$ v/v diethylpyrocarbonate (DEPC) and autoclaved prior to use. Total RNA was extracted from muscle $(\sim 100 \mathrm{mg})$ using Trizol $^{\mathrm{TM}}$ reagent (Tri-Reagent, Invitrogen), according to manufacturer's instructions. Briefly, $1 \mathrm{~mL}$ of Trizol ${ }^{\mathrm{TM}}$ was added to frozen tissue followed by homogenization using a Polytron PT10 homogenizer. After a brief incubation ( $5 \mathrm{~min}$; RT), $200 \mu \mathrm{l}$ of chloroform was added followed by centrifugation at $12,000 \times \mathrm{g}\left(15 \mathrm{~min}, 4^{\circ} \mathrm{C}\right)$. Total RNA was removed, precipitated in $500 \mu \mathrm{l}$ of isopropanol (10 $\mathrm{min}, \mathrm{RT}$ ), and centrifuged a second time at $12,000 \times \mathrm{g}\left(15 \mathrm{~min}, 4^{\circ} \mathrm{C}\right)$. The total RNA pellet was washed with $1 \mathrm{ml}$ of $70 \%$ ethanol and centrifuged as above. The supernatant was removed and the pellet was air dried for $15 \mathrm{~min}$. The final RNA pellet was re- 
suspended in 25-50 $\mu \mathrm{l}$ of DEPC water. RNA concentration was determined by reading the absorbance at $260 \mathrm{~nm}$ on the GeneQuant Pro spectrophotometer (Pharmacia), and the ratio of absorbance at $260 / 280 \mathrm{~nm}$ was used as an indicator of RNA purity. All samples were diluted to a final concentration of $1 \mu \mathrm{g} / \mu \mathrm{l}$ using DEPC water. RNA quality was examined by $1 \%(\mathrm{w} / \mathrm{v})$ native agarose gel electrophoresis with ethidium bromide staining to check the integrity of $18 \mathrm{~S}$ and $28 \mathrm{~S}$ ribosomal RNA (rRNA) bands. 


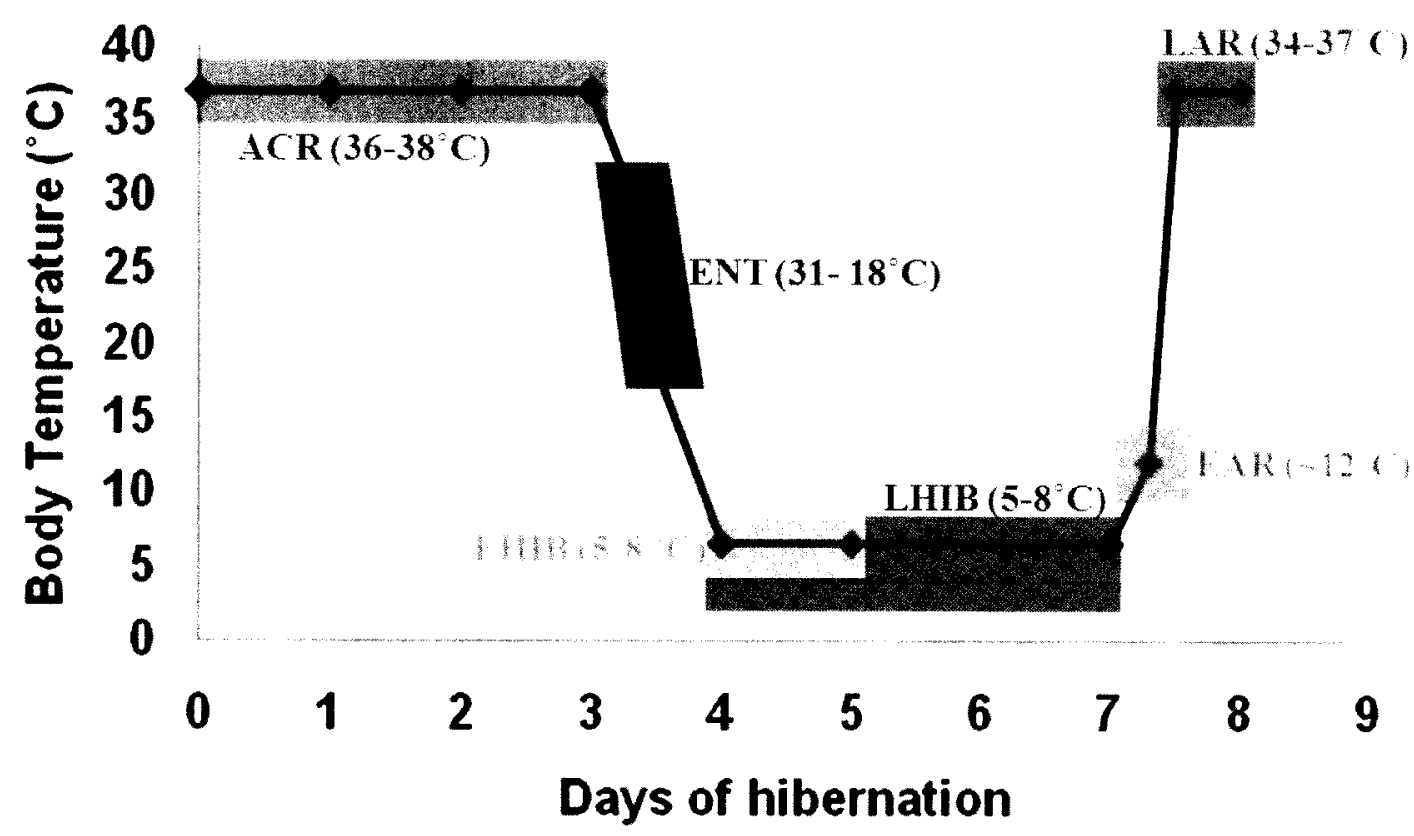

Fig. 2.1. Body temperature $\left(T_{b}\right)$ of a thirteen-lined ground squirrel as a function of time over one torpor-arousal cycle. The different stages are: (1) active in the cold room (ACR), (2) early entrance into torpor (ENT), (3) early-hibernation (EHIB), (4) latehibernation (LHIB), (5) early-arousal (EAR), and (6) late-arousal (LAR). 


\section{Primer Design and Synthesis}

Primers were designed using alignments created by DNAMAN and the Primer Designer Program, v3.0 (Scientific and Educational Software) based on consensus sequences for the genes derived from several mammalian species. The primers (purchased from Sigma Genosys) were designed based on the following parameters; primer length between 18 and 24 bases, primer annealing temperature greater than $50^{\circ} \mathrm{C}$, and GC content of $40-60 \%$.

\section{cDNA synthesis and PCR amplification.}

For first strand cDNA synthesis, $3 \mu \mathrm{g}$ aliquots of total RNA $(1 \mu \mathrm{g} / \mu \mathrm{l})$ from muscle were mixed with $7 \mu \mathrm{l}$ of DEPC treated water and $1 \mu \mathrm{l}$ oligo-dT $(200 \mathrm{ng} / \mu \mathrm{l})$. Samples were then placed in a PCR machine (Mastercycler, Eppendorf) for $5 \mathrm{~min}$ at $65^{\circ} \mathrm{C}$ to promote the annealing of oligo-dT (5'-TTTTTTTTTTTTTTTTTTTTTTV-3'; V=A or G or C; Sigma Genosys) to the mRNA polyA tail. Samples were briefly held on ice before the addition of $4 \mu \mathrm{l}$ X first strand buffer, $2 \mu \mathrm{l} 10 \mathrm{mM}$ DTT, $1 \mu \mathrm{l} 10 \mathrm{mM}$ dNTPs and $1 \mu \mathrm{l}$ Superscript II reverse transcriptase (all from Invitrogen) for a total volume of $19 \mu 1$. The mixture was incubated at $42^{\circ} \mathrm{C}$ for $45 \mathrm{~min}$ and then held at $4{ }^{\circ} \mathrm{C}$. The resulting cDNA samples were serial diluted $\left(10^{-1}, 10^{-2}, 10^{-3}, 10^{-4}\right)$ and PCR amplified using primers specific to Mef2a, Mef2c, Glut4, MyoD or $\alpha$-tubulin (used for normalization). Tubulin is the appropriate normalization gene as multiple experiments have demonstrated the levels remain constant throughout the torpor-arousal cycle. During hibernation, the majority of genes do not change and only select loci are either activated or repressed (Appendix I).

PCR was performed by mixing $5 \mu$ of each cDNA dilution with $1.25 \mu$ of primer 
mixture $(0.3 \mathrm{nmol} / \mu \mathrm{l}$ forward and $0.3 \mathrm{nmol} / \mu \mathrm{l}$ reverse $), 13.5 \mu \mathrm{l}$ of DEPC treated water, $2.5 \mu \mathrm{l}$ of $10 \mathrm{X}$ PCR buffer (Invitrogen), $1.25 \mu \mathrm{l}$ of $50 \mathrm{mM} \mathrm{MgCl}, 0.5 \mu \mathrm{l}$ of $10 \mathrm{mM}$ $\mathrm{dNTPs}$, and $1 \mu \mathrm{l}$ of Taq Polymerase (Invitrogen) for a total volume of $25 \mu \mathrm{l}$. The appropriate PCR conditions were optimized based on cycle tests and cDNA serial dilutions for quantification purposes to ensure that the products had not reached amplification saturation. The cycles performed for amplification consisted of an initial step of $7 \mathrm{~min}$ at $95^{\circ} \mathrm{C}$; followed by 37 cycles of denaturation at $95^{\circ} \mathrm{C}$ for $1 \mathrm{~min}$, annealing at $53-68.1^{\circ} \mathrm{C}$ for $1 \mathrm{~min}$, extension at $72^{\circ} \mathrm{C}$ for $1 \mathrm{~min}$; the final step was $72^{\circ} \mathrm{C}$ for $10 \mathrm{~min}$. Products were separated on a $1.0 \%(\mathrm{w} / \mathrm{v})$ agarose gel, stained with ethidium bromide. Briefly, gels were prepared by adding $2 \mathrm{~g}$ of agarose to $200 \mathrm{ml}$ of $1 \times$ TAE buffer prepared by mixing $4 \mathrm{ml}$ of $50 \times$ TAE buffer stock $(242 \mathrm{~g}$ Tris base, $57.1 \mathrm{ml}$ concentrated acetic acid, $100 \mathrm{ml}$ of $0.5 \mathrm{M}$ EDTA in 1 liter of water, adjusted to $\mathrm{pH} 8.5$ ) with $196 \mathrm{ml}$ of $\mathrm{ddH}_{2} \mathrm{O}$. The mixture was heated and $2 \mu \mathrm{l}$ of ethidium bromide $(0.3 \mathrm{mg} / 300 \mathrm{ml})$ was added to the solution. The heated solution was allowed to cool in a gel tray until solidified. A $2 \mu \mathrm{g}$ aliquot of xylene blue loading dye was added to each PCR reaction and $12 \mu \mathrm{l}$ samples were then loaded onto agarose gels followed by electrophoresis in $1 \times$ TAE buffer for $20 \mathrm{~min}$ at 120 volts. In addition, PCR products were excised and purified using the freeze-squeeze method. Samples were cycled through two freeze-thaw cycles in liquid nitrogen, followed by centrifugation at 7,000 x $\mathrm{g}(7 \mathrm{~min}, \mathrm{RT})$ while passed through a filter cup. Purified cDNA was sequenced by Bio Basic Inc., Markham, Ontario. Sequences were verified using the BLASTN and BLASTP (using deduced amino acid sequences) programs at the NCBI. 


\section{Total protein extraction and cytoplasmic/nuclear extract preparation.}

Samples of frozen tissues from six time points in the torpor-arousal cycle were separately extracted $(\mathrm{N}=4)$. Samples of skeletal and cardiac muscle were quickly weighed, crushed into small pieces under liquid nitrogen, and then homogenized 1:3 w:v using a Polytron PT10 in ice-cold homogenizing buffer (20 mM Hepes, $200 \mathrm{mM} \mathrm{NaCl}$, $0.1 \mathrm{mM}$ EDTA, $10 \mathrm{mM} \mathrm{NaF}, 1 \mathrm{mM} \mathrm{Na} \mathrm{VO}_{4}, 10 \mathrm{mM} \beta$-glycerophosphate) with $1 \mathrm{mM}$ phenylmethylsulfonyl fluoride (Bioshop), and $1 \mu$ l protease inhibitor cocktail (Sigma Genosys) added immediately before homogenization. Each sample was centrifuged at $10,000 \times \mathrm{g}\left(10 \mathrm{~min}, 4^{\circ} \mathrm{C}\right)$ before removing the supernatant containing soluble proteins. Protein concentration was quantified by the Coomassie blue dye-binding method using the BioRad reagent (BioRad Laboratories, Hercules, CA) with absorbance read at $595 \mathrm{~nm}$ on a MR5000 microplate reader. Samples were adjusted to a constant $10 \mu \mathrm{g} / \mu \mathrm{l}$ by addition of small amounts of homogenizing buffer and then aliquots were combined 1:1 $\mathrm{v} / \mathrm{v}$ with $2 \mathrm{X}$ SDS loading buffer (100 mM Tris-base pH 6.8, 4\% w/v SDS, $20 \% \mathrm{v} / \mathrm{v}$ glycerol, $0.2 \% \mathrm{w} / \mathrm{v}$ bromophenol blue, $10 \% \mathrm{v} / \mathrm{v} 2$-mercaptoethanol) and boiled. Final protein samples $(5 \mu \mathrm{g} / \mu \mathrm{l})$ were stored at $-20^{\circ} \mathrm{C}$ until use.

Separate tissue samples were used to prepare cytoplasmic and nuclear extracts for use in western blot and ELISA protocols. Samples of skeletal and cardiac muscle $(\sim 500$ mg) were homogenized using a Dounce homogenizer with 20 piston strokes and $1 \mathrm{~mL}$ of homogenization buffer (10 mM HEPES, pH 7.9, 10 mM KCl, 10 mM EDTA, $20 \mathrm{mM} \beta-$ glycerol phosphate) with $10 \mu \mathrm{l} 100 \mathrm{mM}$ DTT and $10 \mu$ l protease inhibitor cocktail (Sigma) added immediately before homogenization. Samples were centrifuged $(10,000 \mathrm{x}$ $\mathrm{g}, 10 \mathrm{~min}, 4^{\circ} \mathrm{C}$ ) and the cytoplasmic fractions were removed. Pellets were re-suspended 
in $147 \mu \mathrm{l}$ of extraction buffer (20 mM HEPES, pH 7.9, $400 \mathrm{mM} \mathrm{NaCl}, 1 \mathrm{mM}$ EDTA, $10 \% \mathrm{v} / \mathrm{v}$ glycerol, $20 \mathrm{mM} \beta$-glycerol phosphate) with $1.5 \mu \mathrm{l} 100 \mathrm{mM}$ DTT and $1.5 \mu \mathrm{l}$ protease inhibitor cocktail added (a total of $150 \mu$ per gram of starting material). The tubes were then allowed to incubate in a bucket of ice on a rocking platform for $1 \mathrm{~h}$ with mixing every $10 \mathrm{~min}$. After another centrifugation $\left(10,000 \mathrm{x} \mathrm{g}, 10 \mathrm{~min}, 4^{\circ} \mathrm{C}\right)$ supernatants containing soluble nuclear proteins were transferred to a sterile Eppendorf tubes. Protein concentration was determined using the Bio-Rad assay and then adjusted to $5 \mu \mathrm{g} / \mu \mathrm{l}$. Only nuclear extracts were required in the ELISA protocol and were stored at $-80^{\circ} \mathrm{C}$ until use. For western blots, aliquots of both nuclear and cytoplasmic extracts were combined 1:1 v/v with $2 X$ SDS loading buffer as described previously. The efficiency of nuclear extraction was validated using antibodies for a protein located only in nuclei (histone H3; Cell Signaling) at a dilution of 1:2000 (v/v) with anti-rabbit secondary antibody (Bioshop) at a dilution of 1:4000 (v/v).

\section{Western blotting.}

The BioRad Mini Protean III system was used. Equal amounts of protein from each sample (10-25 $\mu \mathrm{g}$ depending on the protein to be detected) were loaded onto $8-12 \%$ SDS-polyacrylamide gels and run at $180 \mathrm{~V}$ for 45-60 min. Polyacrylamide gels were made based on a discontinuous gel system; stacking gel pH $6.8(130 \mu \mathrm{l} 1.0 \mathrm{M}$ Tris- $\mathrm{HCl}$, $170 \mu \mathrm{l} 30 \%$ acrylamide, $680 \mu \mathrm{l}$ water, $10 \mu \mathrm{l} 10 \%$ SDS, $10 \mu \mathrm{l} 10 \%$ APS, $1 \mu 1$ TEMED) and conditions for a $10 \%$ resolving gel $\mathrm{pH} 8.8(1.3 \mathrm{ml} 1.5 \mathrm{M}$ Tris-base, $1.7 \mathrm{ml} 30 \%$ acrylamide, $2.0 \mathrm{ml}$ water, $50 \mu \mathrm{l} 10 \% \mathrm{SDS}, 50 \mu \mathrm{l} 10 \%$ APS, $2 \mu 1$ TEMED). The running buffer was diluted 10-fold from the stock solution (25.5 g Tris-base, $460 \mathrm{~g}$ glycine, $25 \mathrm{~g}$ 
SDS, adjusted to $2.5 \mathrm{~L}$ with water) before use. Proteins were then transferred to PVDF membrane by electroblotting at $320 \mathrm{~mA}$ for $1.5 \mathrm{~h}$ using a transfer buffer containing 25 $\mathrm{mM}$ Tris ( $\mathrm{pH} 8.5$ ), $192 \mathrm{mM}$ glycine and $10 \% \mathrm{v} / \mathrm{v}$ methanol at room temperature.

Membranes were blocked with either milk or polyvinyl alcohol (PVA), made up in TBST (20 mM Tris base, $\mathrm{pH} 7.6,140 \mathrm{mM} \mathrm{NaCl}, 0.05 \% \mathrm{v} / \mathrm{v}$ Tween-20) to prevent nonspecific binding of antibodies. Milk was prepared 2-5\%(w/v) in TBST and incubated with the membrane on a rocker for 30-40 min. When PVA was used, incubation was with $1 \mu \mathrm{g} / \mathrm{ml}$ PVA (30-70 kDa) in TBST for 30-45 sec. Membranes were probed with specific primary antibodies, diluted in TBST, at $4^{\circ} \mathrm{C}$ for $12-48 \mathrm{~h}$. After washing briefly, the membranes were then incubated with HRP-conjugated secondary antibodies for 30-45 min at room temperature. Bands were visualized by enhanced chemiluminescence $\left(\mathrm{H}_{2} \mathrm{O}_{2}\right.$ and Luminol) and then blots were restained using Coomassie blue $(0.25 \% \mathrm{w} / \mathrm{v}$ Commassie brilliant blue, $7.5 \% \mathrm{v} / \mathrm{v}$ acetic acid, $50 \%$ methanol) to visualize all protein bands (Appendix I). Several optimization strategies highlighted above ensure the primary antibody reacts with the protein of interest and eliminates unspecific binding. Notably, primary antibodies derived from the human peptide sequence may show up to $100 \%$ sequence similarity to the hibernating ground squirrel and thus ensure proper antigen: antibody recognition.

\section{Enzyme-linked immunosorbent assay (ELISA).}

DNA-transcription factor binding was evaluated for 5 time points (ACR, ENT, EHIB, LHIB, EAR) and all experimental samples were always run together. Nuclear extracts were prepared as above, with the exception that following quantification the concentration of extracts was adjusted to $5 \mu \mathrm{g} / \mu \mathrm{l}$ using extraction buffer with no further 
manipulation. DNA oligonucleotides are biotinylated and react with streptavidin coated micro-plates. Equal amounts of protein were aliquoted from each sample and used to assess the amount of binding by transcription factor to its response element.

DNA oligonucleotides were designed based on the DNA binding element of MEF2 transcription factors and produced by Sigma Genosys. The biotinylated probe (MEF2 5'-Biotin-GATCGCGCTAAAAATAACCCTGTCG -3') and the complement probe (MEF2 5'-c-CGACAGGGTTATTTTTAGCGCGATC-3') were first diluted in sterile water to a final concentration of $500 \mathrm{pmoles} / \mu \mathrm{l}$ and subsequently mixed $1: 1(\mathrm{v} / \mathrm{v})$ for a total volume of $20 \mu \mathrm{l}$. Probes were then placed in a thermocycler for $10 \mathrm{~min}$ at $95^{\circ} \mathrm{C}$ and the temperature of the block was slowly cooled to room temperature. Double stranded probe was diluted in PBS (137 mM NaCl, $2.7 \mathrm{mM} \mathrm{KCl}, 10 \mathrm{mM} \mathrm{Na}_{2} \mathrm{HPO}_{4}, 2$ $\mathrm{mM} \mathrm{KHPO}$, $\mathrm{pH} 7.4$ ), vortexed and $50 \mu 1$ added to each well (40 pmoles DNA/well). Following a $1 \mathrm{~h}$ incubation, unbound probe was discarded by washing three times in wash buffer (PBS containing 0.1\% Tween-20) and a fourth time with PBS. Nuclear extracts, containing equal amounts of protein from each sample, were combined with the complete transcription factor binding buffer (10 mM HEPES, $50 \mathrm{mM} \mathrm{KCl,} 0.5 \mathrm{mM}$ EDTA, $3 \mathrm{mM} \mathrm{MgCl} 2,10 \%$ glycerol, $0.5 \mathrm{mg} / \mathrm{ml}$ bovine serum albumin, $0.05 \% \mathrm{NP}-40,20$ mM DTT, pH 7.9), vortexed, and $50 \mu \mathrm{l}$ was aliquoted into each microplate well. Only binding buffer, without protein samples, was added to the negative control wells. Following $1 \mathrm{~h}$ incubation at room temperature with mild agitation, the sample was discarded and the plate was washed three times with wash buffer. Primary antibody was then added ( $60 \mu \mathrm{l} /$ well) and allowed to incubate for $1 \mathrm{~h}$. Following incubation, excess primary antibody was discarded, the wells were washed three times in wash buffer, and 
$60 \mu 1 /$ well of secondary antibody was added to each well. The same primary and secondary antibodies used in the western blot procedure were utilized in the ELISA protocol. After a final round of washing, bound antibody was detected with tetramethylbenzidine (TMB), purchased from BioShop. TMB was aliquoted into each well $(60 \mu \mathrm{l})$ and colour was allowed to develop. Then $60 \mu \mathrm{l}$ of STOP solution $(1 \mathrm{M} \mathrm{HCl})$ was added to each well to halt the reaction and absorbance was measured at $450 \mathrm{~nm}$ (with a reference wavelength of $655 \mathrm{~nm}$ ) using a Multiskan spectrophotometer.

\section{Quantification and statistics.}

Band densities on both ethidium bromide stained agarose gels and chemiluminescent immunoblots were visualized using a Chemi-Genius BioImaging system (Syngene, Frederick, MD) and quantified using the associated Gene Tools software. Bands corresponding to PCR products of the gene of interest were normalized against the corresponding band intensity of $\alpha$-tubulin amplified from the same cDNA sample. Immunoblot band density in each lane was normalized against the summed intensity of a group of Coomassie stained protein bands in the same lane; these were chosen because they did not show variation between different experimental states and were not located close to the protein bands of interest. Relative binding using the ELISA based protocol was calculated using the corrected optical density (sample OD minus OD in blank wells containing no protein) calculated by the Multiskan spectrophotometer (read at $450 \mathrm{~nm}$, reference wavelength of $655 \mathrm{~nm}$ ). Data are expressed as means $\pm S E M, n=4-5$ independent samples from different animals. Statistical testing of normalized band intensities used one-way ANOVA and a post-hoc test (Student-Newman-Keuls). 


\section{Chapter 3}

Expression of myocyte enhancer factor-2 and downstream genes in ground squirrel skeletal muscle during hibernation 


\section{Introduction}

As mentioned in chapter 1 , hibernation is a strategy that allows many small mammals to deal with the metabolic problems generated by limited food supply and the energetic costs of maintaining a high body temperature during the winter season [Wang \& Lee, 1996; Storey, 2010]. The suppression of metabolic rate must be a controlled process in order to maintain cellular homeostasis at cold $T_{b}$ while simultaneously reprioritizing ATP use by different cell functions, enhancing cell preservation. Each organ of the hibernator has challenges that must be addressed either on a seasonal timeframe or over the course of a torpor-arousal bout using mechanisms of metabolic regulation and macromolecular restructuring. Specific issues for skeletal muscle include the potential for disuse atrophy over many months spent in inactive torpor and the need for a well-developed capacity for shivering thermogenesis that is an important contributor (along with brown adipose tissue) to rewarming the body during arousal from torpor.

Skeletal muscle cells are remarkable for their ability to adapt to changing functional demands through changes in their composition and metabolic capacity [Joanisse, 2004]. The myofibers that make up muscle cells are classified based on the myosin heavy chain (MyHC) isoforms they contain; type I and type IIa MyHC isoforms are associated with muscle fibers that contain more capillaries, myoglobin, and mitochondria, making them well-suited for aerobic activities (slow twitch) [Joanisse, 2004]. In contrast, type IIb and type IIx MyHC isoforms are associated with glycolytic muscle fibers that are more appropriate for short bursts of speed and power (fast twitch) [Joanisse, 2004]. During periods of reduced use, muscle typically remodels itself in a process called atrophy that can include a reduction of muscle mass, strength, and 
oxidative characteristics, as well as a reduction of slow MyHC expression [Rourke et al, 2004; Bassel-Duby \& Olson, 2006; Choi et al, 2009; Malatesta et al, 2009]. Interestingly, selected studies with hibernators have found very little atrophy of skeletal muscles despite the mechanical unloading that occurs over the weeks of inactivity [Yacoe, 1983; Musacchia et al, 1989; Wickler et al, 1991; Rourke et al, 2004; Rourke et al, 2006; Lee et al, 2008; Choi et al, 2009]. Furthermore, other studies have reported selective changes to skeletal muscle proteins of hibernators that may serve to retain and/or remodel muscle on either a long term seasonal basis or over the course of individual torpor-arousal bouts [Storey \& Storey, 2010]. Taken together, these findings indicate that hibernators may have unusual or enhanced mechanisms of muscle mass retention as compared with nonhibernating mammals and that hibernators could provide effective model systems for discovering mechanisms of muscle retention that could have application for human use. One method of adapting to long bouts of inactivity during hibernation could be the maintenance of slower MyHC expression which presumably provides a more optimal mix of isoforms to adapt the muscles to the reduced work load and thermal conditions of the torpid state [Caiozzo, 2002; Rourke et al, 2004; Zuikova et al, 2005; Choi et al, 2009]. However, given the highly variable composition of contractile and metabolic proteins within a muscle cell, adaptations involving the control of muscle mass and fiber type shifts during hibernation are extremely complex with many aspects of the regulatory control of muscle metabolism incompletely understood [Joanisse, 2004; Rourke et al, 2004; Rourke et al, 2006; Choi et al, 2009; Lee et al, 2009].

This chapter explores the responses of myocyte enhancer factor-2 (MEF2) proteins during hibernation in 13-lined ground squirrels. MEF2 Tfs are critical regulators 
of structural and contractile proteins in striated muscles with well known roles in skeletal muscle myogenesis [Black \& Olson, 1998; Kim et al, 2008]. Genes under MEF2 control include structural proteins such as desmin and dystrophin and proteins of the contractile apparatus including troponin, tropomyosin, and myosin heavy and light chain isoforms [Black \& Olson, 1998]. MEF2 also regulates proteins with key supporting roles in muscle function such as sarcoplasmic reticulum $\mathrm{Ca}^{2+}$-ATPase and glucose transporter 4 (GLUT4) and as well as other Tfs involved in muscle growth and differentiation such as myogenic differentiation (MyoD) and myogenin [Black \& Olson, 1998]. Four isoforms of MEF2 (MEF2A, -B, $-\mathrm{C},-\mathrm{D})$ occur in mammals and all are regulated by reversible phosphorylation [Black \& Olson, 1998; Bassel-Duby \& Olson, 2006]. The family members impose both positive and negative controls on muscle remodeling, serving to adjust the molecular attributes of skeletal muscle [Black \& Olson, 1998]. The data reveal that MEF2 genes are positively regulated during hibernation and that expression of known downstream genes under MEF2 control, GLUT4 and MyoD, is also enhanced.

\section{Material and Methods}

\section{Animals}

All animals were captured, treated and organs harvested following the same protocol as previously described in Chapter 2 . The skeletal muscle used was a mixture of several hind limb muscles.

\section{Total RNA isolation and quality assessment}

Total RNA was separately extracted $(\mathrm{N}=4)$ from different skeletal muscle samples $(\sim 100 \mathrm{mg}$ each) from six time points in the torpor-arousal cycle; ACR, ENT, EHIB, 
LHIB, EAR, LAR. The protocol followed the manufacturer's directions as previously described in Chapter 2.

Primer Design and Synthesis

Primers for Mef2a, Mef2c, Glut4 and MyoD were designed using the Primer Designer Program, v3.0 (Scientific and Educational Software) based on consensus sequences for these genes derived from comparisons of several mammalian species (human, rat, cattle) and as previously described in Chapter 2. The Mef2a product was 310 base pairs and encoded 103 amino acids (GenBank accession \#: GU434270), the Mef2c product was 352 bp (117 amino acids; GenBank accession \#: GU434272), the Glut4 product was 290 bp (96 amino acids; GenBank accession \#: GU434271) and the MyoD product was 337 bp (111 amino acids; GenBank accession \#: GU434273). The primer sequences were as follows:

(1) Mef2a: forward 5'-TTGCCACCTCAGAACTTCTC-3' reverse 5'-TTCATTCCAAGAYTGCCACC-3',

(2) Mef2c: forward 5'-CCAGTGTCCAGCCAYAACAG-3' reverse 5'-TGTAGGTGYTGCTGTTGCCA-3',

(3) Glut4: forward 5'-CCCGMTACCTCTAYATCATC-3' reverse 5'-TTGACCACACCAGCTCCTAT-3',

(4) MyoD: forward 5'-GACCCGTGTTTCGACTCCCC-3' reverse 5'-TCGATRTAGCGGATGGCGTT-3', (5) $\alpha$-tubulin: forward 5'-AAGGAAGATGCTGCCAATAA-3' reverse 5'-GGTCACATTTCACCATCTG-3'. 
cDNA was synthesized as described in Chapter 2. The resulting cDNA samples from 6 time points in the torpor-arousal cycle were serially diluted $\left(10^{-1}, 10^{-2}, 10^{-3}\right)$ and PCR amplified using primers specific for Mef2a, Mef2c, Glut4, and MyoD. The cycles performed for amplification consisted of an initial step of $7 \mathrm{~min}$ at $95^{\circ} \mathrm{C}$, followed by $36-$ 38 cycles at $95^{\circ} \mathrm{C}$ for $1 \mathrm{~min}$, and annealing at $53-68.1^{\circ} \mathrm{C}$ for $1 \mathrm{~min} 72^{\circ} \mathrm{C}$ for $1 \mathrm{~min}$; the final step was $72^{\circ} \mathrm{C}$ for 10 min. Annealing temperature was $53.8,68.1,60,53.2,53^{\circ} \mathrm{C}$ for Mef2a, Mef2c, Glut4, MyoD, and $\alpha$-tubulin, respectively. All genes required 36 cycles for PCR amplification, except Mef2c which required 38 cycles.

Products were separated on a $1 \%$ agarose gel, stained with ethidium bromide. The bands from the most dilute cDNA sample were used for quantification purposes to make sure that the products had not reached amplification saturation. For skeletal muscle, all genes were quantified from the $10^{-3}$ cDNA dilution. Samples of Mef2a, Mef2c, Glut4 and MyoD PCR products were sequenced as previously described and verified using the BLASTN and BLASTP (using deduced amino acid sequences) programs.

\section{Total protein extraction and cytoplasmic/nuclear extract preparation}

Extracts of frozen hind leg skeletal muscle $(\sim 500 \mathrm{mg})$ were made as previously described. Separate tissue samples were used to prepare cytoplasmic and nuclear extracts for use in the western blot and ELISA protocols, essentially as described previously.

\section{Western Blotting}

Western blotting was performed as in Chapter 2. Equal amounts of protein from each sample were loaded onto $10 \%$ polyacrylamide gels and run at $180 \mathrm{~V}$ for 45 minutes. 
To evaluate relative protein levels of MEF2A, p-MEF2A, MEF2C, and p-MEF2C, $25 \mu \mathrm{g}$ of protein was loaded into each well whereas $10 \mu \mathrm{g}$ was used for MyoD. Membranes to be probed with antibodies for MEF2A, p-MEF2A, and p-MEF2C were blocked with $2.5 \% \mathrm{w} / \mathrm{v}$ non-fat dried milk dissolved in TBST (0.05\% Tween-20) for $30 \mathrm{~min}$. MEF2C and MyoD were blocked with 30-70 kDa PVA ( $1 \mu \mathrm{g} / \mathrm{ml}$ in TBST) for $45 \mathrm{sec}$.

Antibodies specific for mammalian MEF2A and p-MEF2A (Thr312) were purchased from GenScript whereas antibodies for MEF2C, p-MEF2C (Ser387) and GLUT4 were from Santa Cruz Biotechnologies and MyoD antibodies were from Developmental Studies Hybridoma Bank (University of Iowa). MEF2A, p-MEF2A, MEF2C, p-MEF2C and GLUT4 antibodies were used at 1:4000 v/v dilution in TBST (20 $\mathrm{mM}$ Tris base, $\mathrm{pH} 7.6,140 \mathrm{mM} \mathrm{NaCl}, 0.05 \% \mathrm{v} / \mathrm{v}$ Tween-20) whereas MyoD antibodies were used at 1:500 v/v dilution in TBST $(0.05 \%$ Tween-20). All membranes were probed with primary antibody for $12 \mathrm{~h}$ at $4^{\circ} \mathrm{C}$ except for MyoD which was probed for $24 \mathrm{~h}$ at $4^{\circ} \mathrm{C}$. Membranes that had been probed with $\mathrm{MEF} 2 \mathrm{C}$ were then incubated with HRPlinked anti-goat IgG secondary antibody (1:4000 v:v dilution), MyoD antibodies were detected with HRP-linked anti-mouse IgG secondary antibody (1:2000 v:v dilution) and all other antibodies were detected using HRP-linked anti-rabbit IgG secondary antibody (1:4000 v:v dilution). All membranes were washed three times between incubation periods in $1 \mathrm{X}$ TBST $(0.05 \%$ Tween-20) for $\sim 5 \mathrm{~min} /$ wash. MEF2C and MyoD required more washes after probing with secondary antibody ranging from $\sim 40 \mathrm{~min}$ to $2 \mathrm{~h}$, respectively. Signal detection and quantification were as described in Chapter 2.

Enzyme-linked immunosorbent assay (ELISA)

ELISA was performed as described in Chapter 2. Probes for MEF2 were 
purchased from Sigma Genosys including both the biotinylated probe (MEF2 5'-BiotinGATCGCGCTAAAAATAACCCTGTCG -3') and the complement probe (MEF2 5'-cCGACAGGGTTATTTTTAGCGCGATC-3'). The quantitative run for MEF2A utilized the following conditions; $15 \mu \mathrm{g}$ of protein/well, $1 \mu \mathrm{g}$ of salmon sperm/well, $60 \mathrm{mM} \mathrm{NaCl}$, $1 / 1000 \mathrm{v} / \mathrm{v}$ MEF2A primary antibody in TBST $(0.05 \%$ Tween-20), 1/2000 v/v anti-rabbit secondary antibody in TBST (0.05\% Tween-20). The quantitative run for MEF2C utilized the following conditions: $20 \mu \mathrm{g}$ protein/well, $2 \mu \mathrm{g}$ of salmon sperm/well, $60 \mathrm{mM}$ $\mathrm{NaCl}, 1 / 1000 \mathrm{v} / \mathrm{v} \mathrm{MEF} 2 \mathrm{C}$ primary antibody in TBST $(0.05 \%$ Tween-20), 1/2000 v/v antigoat secondary antibody in TBST $(0.05 \%$ Tween-20). Absorbance was calculated as described in Chapter 2.

\section{Quantification and statistics}

Band densities for Mef2a, Mef2c, Glut4 and MyoD on ethidium bromide stained agarose gels and band densities for MEF2A, p-MEF2A, MEF2C, p-MEF2C, GLUT4 and MyoD on chemiluminescent immunoblots were visualized and quantified as described in Chapter 2. Relative binding affinity for the ELISA protocol was quantified as described in Chapter 2. Data are expressed as means $\pm S E M, n=4$ independent samples.

\section{Results}

Analysis of MEF2 protein levels and nuclear localization

MEF2 protein levels in skeletal muscle were measured by immunoblotting comparing a pre-hibernation control condition (ACR) and five time points on the torporarousal cycle: ENT, EHIB, LHIB, EAR, LAR (Fig. 3.1). The antibodies used cross- 
reacted with a single band on the immunoblots at the expected molecular mass for MEF2 of $44 \mathrm{kDa}$ (Fig. 3.2). As compared with ACR controls, MEF2A total protein increased significantly in EHIB (by 2.8 fold higher, $\mathrm{p}<0.01$ ) and LHIB (2.2 fold higher, $\mathrm{p}<0.01$ ) and then levels fell again during arousal; protein levels in EAR and LAR were just 19\% and $26 \%$ of the EHIB maximum, respectively (p<0.01) (Fig. 3.1a). MEF2C total protein increased during entrance into torpor (ENT values were 2 fold higher than $A C R, p<0.01$ ) and remained high in EHIB (1.5 fold higher than ACR, $\mathrm{p}<0.01)$. Levels decreased again to control values in LHIB and EAR and in LAR were just $22 \%$ of the ENT maximum $(\mathrm{p}<0.01)$ (Fig. 3.1a)

MEF2 can be phosphorylated on several sites, each of which affects protein function. Antibodies recognizing phosphorylated MEF2A Thr312 or MEF2C Ser387 (phosphorylation on these sites enhances transcriptional activity) were used to monitor changes in the phosphorylation state of MEF2 over the torpor-arousal cycle. The amount of p-MEF2A protein increased significantly during entrance into torpor ( 1.5 fold higher than ACR, $\mathrm{p}<0.05$ ), and was also 1.4-fold higher than ACR during LHIB ( $<<0.05)$ (Fig. 3.1b). Phospho-MEF2C total protein levels also increased during entrance into torpor (1.4 fold higher than ACR, $\mathrm{p}<0.05$ ) but fell again during torpor and remained low thereafter; during EAR and LAR levels were just 50\% of the maximum in ENT (p<0.01) (Fig. 3.1b).

Figure 3.3 depicts MEF2 and p-MEF2 distribution between cytoplasmic and nuclear fractions. MEF2A and MEF2C protein levels were significantly higher (by 1.6 and 2.1 fold, respectively) in the nuclear fraction of muscle from the LHIB group compared with nuclear levels in ACR ( $p<0.01$ ) (Fig. 3.3a). Correlated with this, the amount of $\mathrm{MEF} 2 \mathrm{C}$ in the cytoplasmic fraction was strongly reduced during hibernation to 
just one-third of the ACR value $(\mathrm{p}<0.01)$. The amount of phosphorylated MEF2A and MEF2C protein was also significantly higher in the nuclear fraction of the LHIB group (by 1.3 and 1.6 fold; $\mathrm{p}<0.01$ ) as compared with ACR (Fig. 3.3b).

\section{Analysis of GLUT4 and MyoD protein levels}

The genes for GLUT4 and MyoD are two important downstream targets of MEF2. Antibodies for GLUT4 and MyoD cross-reacted with single bands on immunoblots at the expected molecular masses of 50 and $45 \mathrm{kDa}$, respectively. Figure 3.4a shows that GLUT4 total protein levels increased significantly in the skeletal muscle of ground squirrels while in torpor. GLUT4 increased significantly in EHIB (2 fold higher than ACR, p<0.01), and remained high through LHIB (1.8 fold higher than ACR, $\mathrm{p}<0.01)$ and EAR (1.7 fold higher than ACR, $\mathrm{p}<0.01)$ periods. Levels fell again in fully aroused animals. Figure 3.5a shows that MyoD protein levels were elevated over ACR values only during the early arousal period (1.5 fold greater than ACR, $\mathrm{p}<0.05)$.

cDNA cloning of Mef2, Glut4 and MyoD

Primers were designed from the consensus sequence of the genes from four other mammalian species (human, mouse, rat and cow), and then PCR products were amplified from total RNA prepared from skeletal muscle of ground squirrels. Products were confirmed as encoding portions of the Mef2a, Mef $2 c$, Glut4 or MyoD sequences using BLASTN. The Mef2a product was 310 base pairs and encoded 103 amino acids (GenBank accession \#: GU434270), the Mef2c product was 352 bp (117 amino acids; GenBank accession \#: GU434272), the Glut4 product was 290 bp (96 amino acids; 
GenBank accession \#: GU434271) and the MyoD product was 337 bp (111 amino acids;

GenBank accession \#: GU434273). This compares with values for the full length mRNA sequences in humans which are 1,290 bp for Mef $2 a$ (429 amino acids), 1,392 bp for Mef2c (463 amino acids), 1,530 bp for Glut4 (509 amino acids) and $963 \mathrm{bp}$ for MyoD (320 amino acids). Hence, the amplified products represent $24 \%, 25 \%, 19 \%$, and $35 \%$ of the full length human sequences for Mef2a, Mef2c, Glut4 and MyoD, respectively.

Analysis of Mef2, Glut4 and MyoD transcript levels

The primers for Mef2a, Mef2c, Glut4 and MyoD were used in RT-PCR to assess relative mRNA transcript levels in skeletal muscle over the torpor-arousal course. Figure 3.6 shows $M e f 2$ expression levels. Mef $2 a$ transcripts were unchanged from ACR values in ENT and EHIB but increased in the LHIB condition $(2.3$ fold higher than EHIB, $\mathrm{p}<0.01$ ) and peaked during early arousal (3.0 fold higher than EHIB, $\mathrm{p}<0.01)$. Levels remained elevated in late arousal ( 1.5 fold higher than ACR, $\mathrm{p}<0.01)$ although reduced by $50 \%$ as compared with EAR $(\mathrm{p}<0.05)$. Transcript levels of Mef $2 c$ steadily decreased during ENT and EHIB through to LHIB (to $40 \%$ of ACR, p<0.05) but then sharply increased again during early arousal (3.2 fold higher than LHIB, $\mathrm{p}<0.05)$ and returned to near control levels in LAR. Figure $3.4 \mathrm{~b}$ shows that Glut4 transcript levels remained relatively stable over the torpor-arousal course except for a significant increase during in EHIB (1.2 fold higher than $\mathrm{ACR}, \mathrm{p}<0.05) . M y o D$ transcript levels decreased rapidly during entrance into torpor (reduced by $50 \%$ as compared with ACR, $\mathrm{p}<0.05$ ), and remained low in EHIB and LHIB phases (Figure 3.5b). Transcript levels rose again during arousal to levels that were $\sim 2.5$ fold higher than LHIB $(\mathrm{p}<0.05)$. 
Analysis of MEF2 relative DNA binding

Relative DNA binding by MEF2 in skeletal muscle was measured by an enzymelinked immunosorbent assay (ELISA) comparing a pre-hibernation control condition (ACR) with four time points on the torpor-arousal cycle: ENT, EHIB, LHIB, EAR (Figure 3.7). The probes for MEF2 DNA binding were designed based on the specific DNA binding element of the Tf. As compared with ACR controls, nuclear extracts from ENT showed 1.8-fold higher ( $\mathrm{p}<0.01$ ) MEF2A binding to DNA whereas binding levels returned to control values from EHIB to EAR (Figure 3.7a). Similarly, MEF2C total protein binding in nuclear extracts was 2.3-fold in ENT $(\mathrm{p}<0.01)$ and 2.2-fold higher in EHIB ( $p<0.01)$ as compared with ACR. Subsequently, MEF2C-DNA binding decreased in LHIB and EAR to $27 \%$ and $32 \%$ of the ACR value, respectively (Fig. 3.7b). 

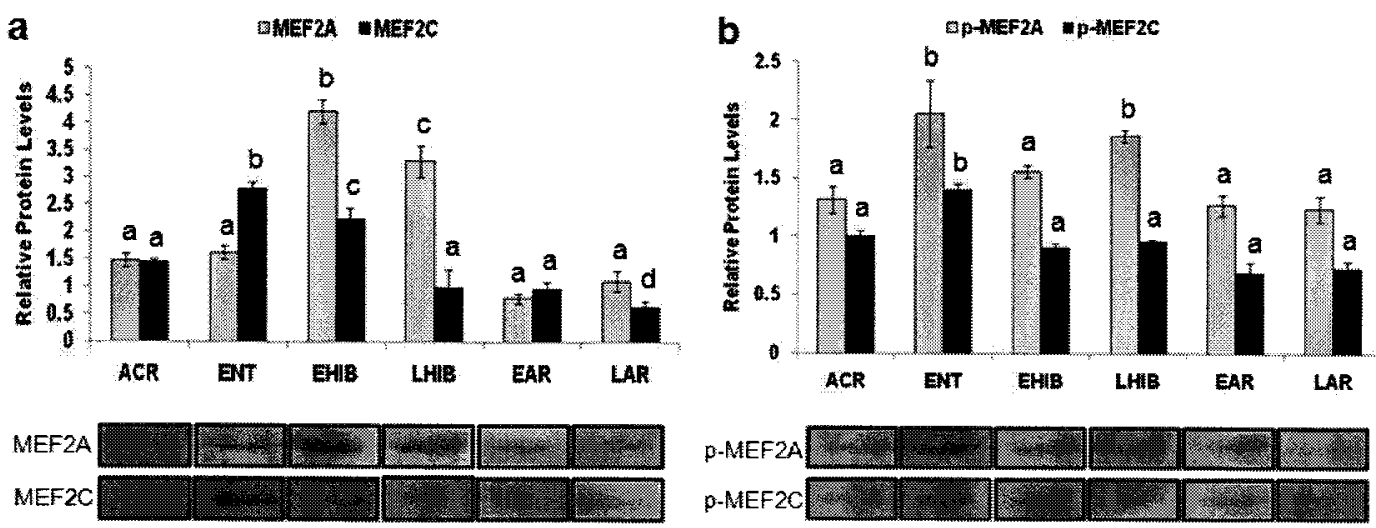

Fig. 3.1. Changes in the protein levels of MEF2 Tfs over the course of a torpor-arousal cycle in skeletal muscle of $S$. tridecemlineatus. Sampling points are: active in the cold room (ACR), entrance into torpor (ENT), early hibernation (EHIB), late hibernation (LHIB), early arousal (EAR) and late arousal (LAR). See the Materials and Methods for more extensive definitions. (a) MEF2A and MEF2C total protein expression at six sampling points. (b) Levels of phosphorylated MEF2A (Thr 312) and MEF2C (Ser 387). Representative Western blots are shown along with histograms showing mean normalized band densities ( \pm S.E.M., $n=4$ independent trials on tissue from different animals). Data were analyzed using analysis of variance with a post hoc Student-Newman-Keuls test; different letters denote values are significantly different from each other, $\mathrm{P}<0.05$. 


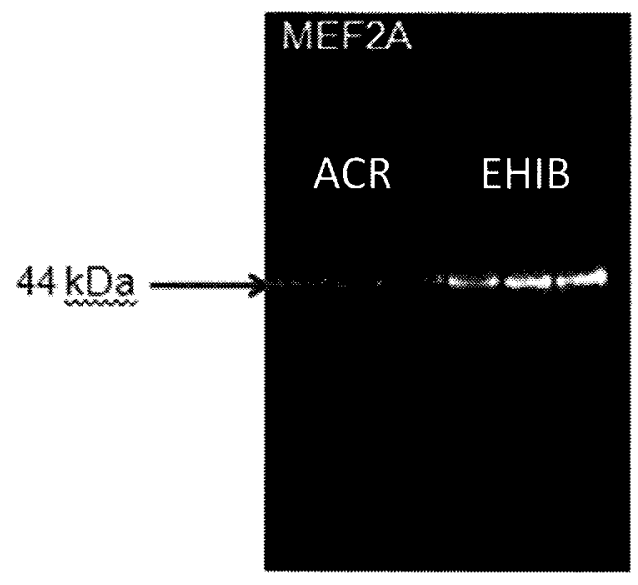

Fig. 3.2. Representative Western blot of thirteen-lined ground squirrel skeletal muscle extract from ACR and EHIB conditions immunoblotted with anti-MEF2A antibody. The antibody cross-reacted with a single band at the expected molecular weight of $44 \mathrm{kDa}$. 

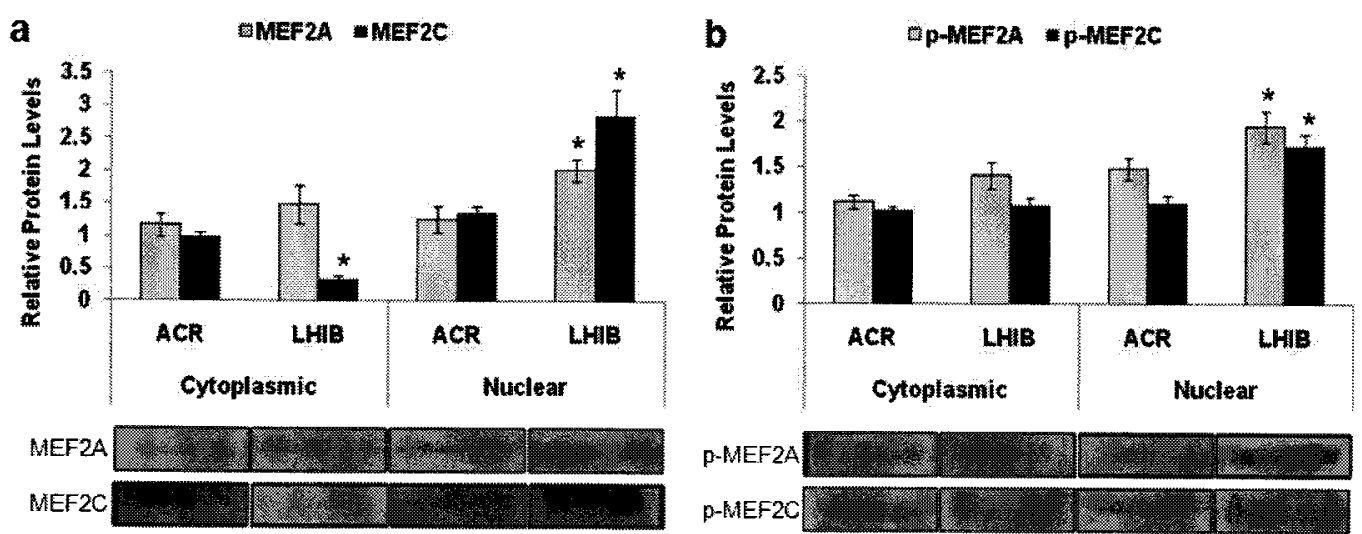

Fig. 3.3. Changes in the distribution of total MEF2 protein and phosphorylated MEF2 content in nuclear and cytoplasmic fractions over the course of a torpor-arousal cycle in skeletal muscle of $S$. tridecemlineatus. Representative Western blots show the distribution of (a) MEF2A and MEF2C between cytoplasm and nucleus, and (b) pMEF2A (Thr 312) and p-MEF2C (Ser 387) between cytoplasm and nucleus between control (ACR) and long-term torpor (LHIB) conditions. Histograms show mean normalized band densities $( \pm$ S.E.M., $n=4$ independent trials on tissue from different animals). * - Significantly different from the corresponding ACR value for the same cell fraction using the Student's t-test, $\mathrm{P}<0.01$. 

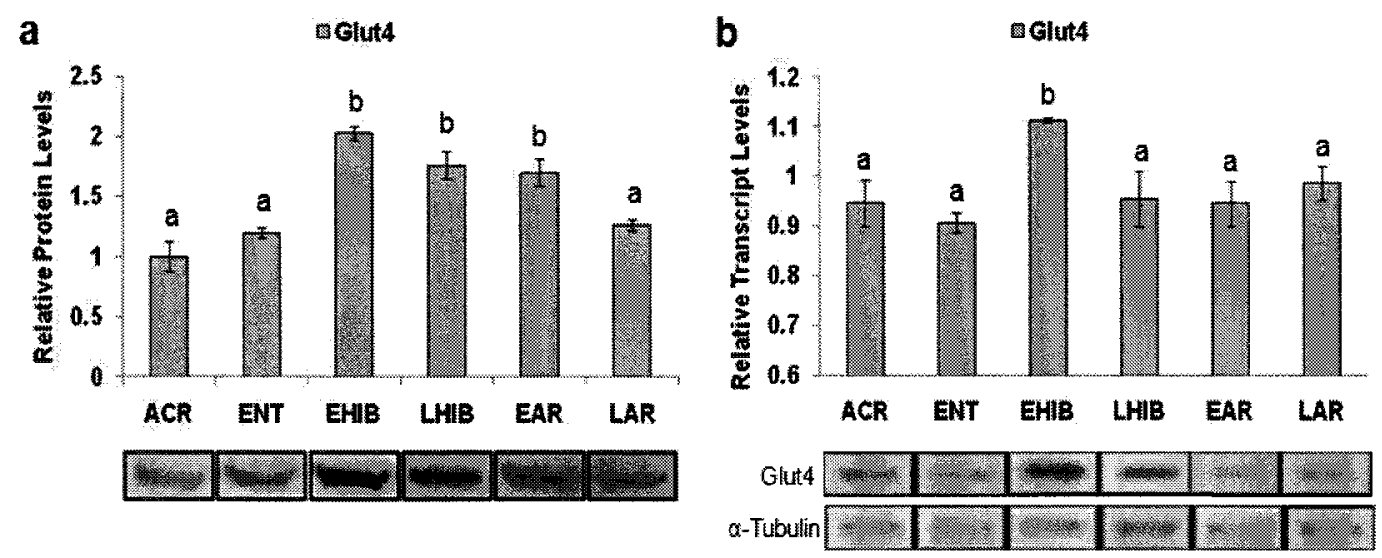

Fig. 3.4. Changes in glucose transporter isoform 4 protein and mRNA transcript levels in skeletal muscle of $S$. tridecemlineatus over the torpor-arousal cycle. (a) Representative Western blots and histogram showing mean GLUT4 protein levels. (b) Representative transcript bands on agarose gels and histogram showing mean normalized glut 4 transcript levels. Glut 4 bands were normalized against tubulin bands amplified from the same sample. Data are means ( \pm S.E.M., $n=4$ samples from different animals). Other information as in Fig. 3.1. 

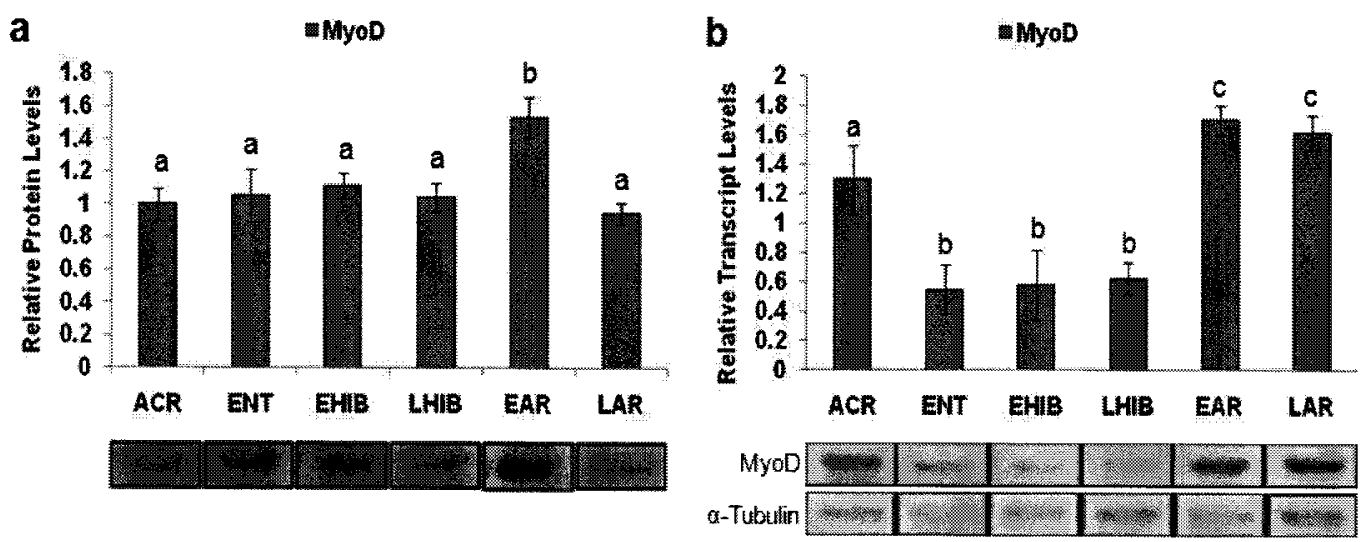

Fig. 3.5. Changes in myogenic differentiation protein and mRNA transcript levels in skeletal muscle of $S$. tridecemlineatus over the torpor-arousal cycle. (a) Representative Western blots and histogram showing mean MyoD protein levels. (b) Representative transcript bands on agarose gels and histogram showing mean normalized $M y o D$ transcript levels. $M y o D$ bands were normalized against tubulin bands amplified from the same sample. Data are means ( \pm S.E.M., $n=4$ samples from different animals). Other information as in Fig. 3.1. 


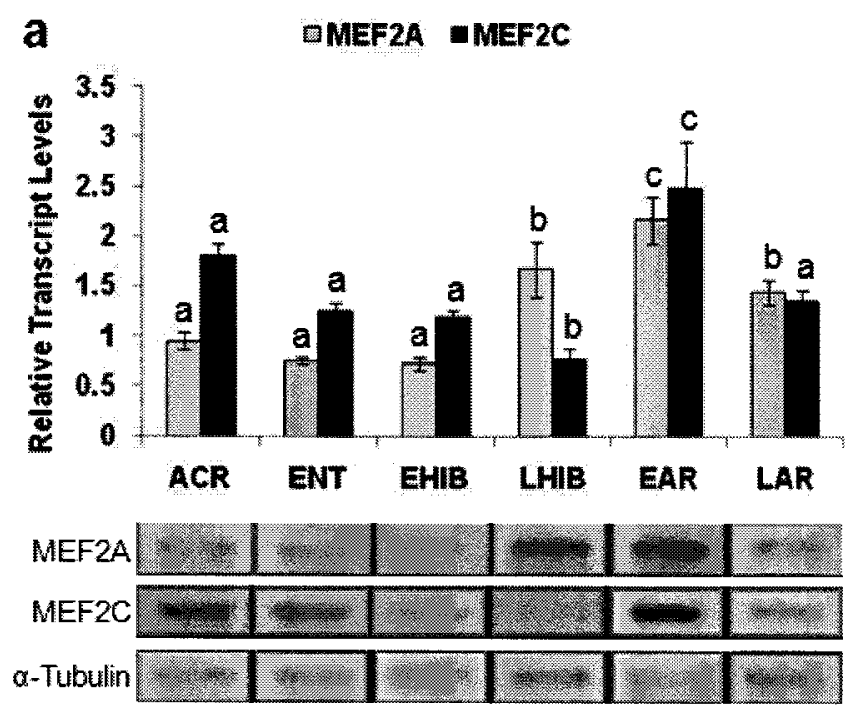

Fig. 3.6. Changes in the levels of Mef2a and Mef2c mRNA transcript levels in skeletal muscle of $S$. tridecemlineatus over the torpor-arousal cycle. Shown are representative bands on agarose gels (and bands for $\alpha$-tubulin that was used for normalization) and histograms of means $( \pm$ S.E.M., $n=4$ independent trials on separate RNA isolations from different animals) for six sampling points. Other information as in Fig. 3.1. 

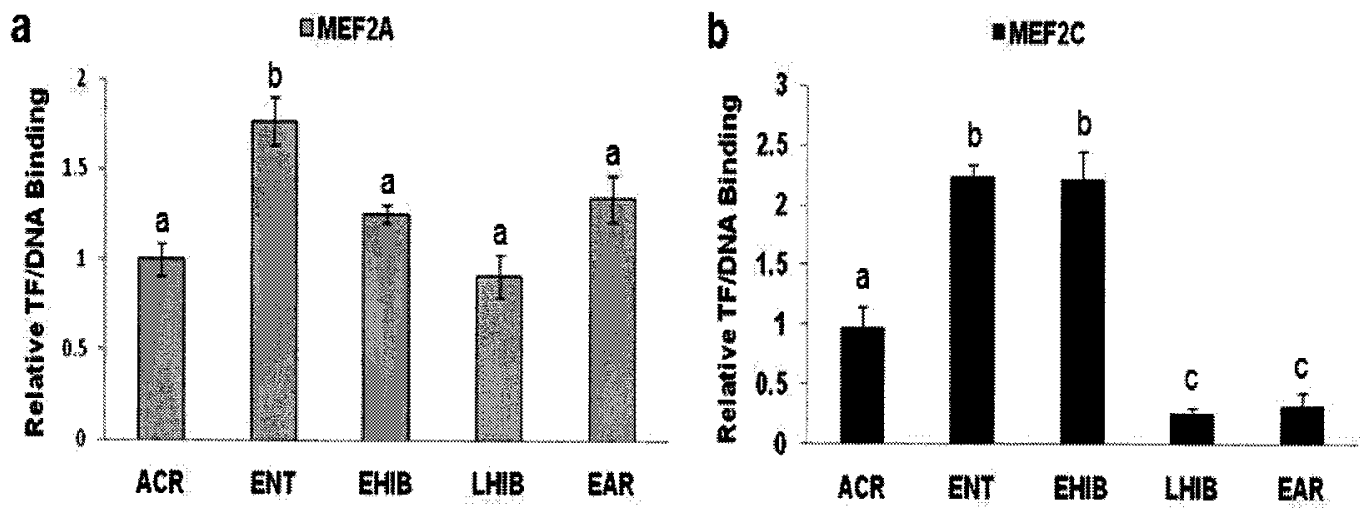

Fig. 3.7. Changes in the DNA binding of MEF2 Tfs over the course of a torpor-arousal cycle in skeletal muscle of $S$. tridecemlineatus. Sampling points are: active in the cold room (ACR), entrance into torpor (ENT), early hibernation (EHIB), late hibernation (LHIB), and early arousal (EAR). (a) MEF2A relative DNA binding at five sampling points. (b) MEF2C relative DNA binding at five sampling points. Other information as in Fig. 3.1. 


\section{Discussion}

Studies of a number of hibernating species, including ground squirrels, have reported minimal loss or size reduction of skeletal muscle cells over the hibernating season [Choi et al, 2009; Rourke et al, 2004; Rourke et al, 2006; Musacchia et al, 1989; Wickler et al, 1991; Harlow et al, 2001; Tinker et al, 1998; Cotton \& Harlow, 2010]. Moreover, oxidative capacity is preserved, and muscle strength is only slightly reduced [Choi et al, 2009; Rourke et al, 2004; Rourke et al, 2006; Harlow et al, 2001; Tinker et $a l, 1998]$. Skeletal muscle is highly plastic, allowing it to adapt to mechanical and neural stimuli [Joanisse, 2004]. However, the molecular mechanisms that are responsible for preservation and/or change of muscle structure/function during hibernation are not well known. This chapter was aimed at elucidating the response of key muscle $\mathrm{Tfs}$ and selected downstream genes in thirteen-lined ground squirrels to evaluate their possible involvement in adjusting and preserving muscle metabolism for long-term cold torpor.

MEF2 is activated by a variety of extracellular stimuli that are transmitted from the cell membrane to the nucleus via multiple signaling cascades [Black \& Olson, 1998; Ishikawa et al, 2010; Sun et al, 2003; Chandran et al, 2007]. The best characterized pathways in MEF2 regulation involve mitogen-activated protein kinases (MAPKs) [Olson, 2004; Cox et al, 2003]; indeed, MEF2A and MEF2C proteins are known to be activated by ERK5 and p38 [Rampalli et al, 2007; Ma et al, 2005; Sun et al, 2003; Kato et al, 1997]. Previous studies by our lab have shown that selected MAPKs are activated during hibernation [Eddy \& Storey, 2007; MacDonald \& Storey, 2005]; for example, the amount of phospho-p38 MAPK rose by 6.8 fold in skeletal muscle of hibernating Richardson's ground squirrels, $S$. richardsonii (equivalent to the LHIB condition) 
[MacDonald \& Storey, 2005]. In addition, the calcium/calmodulin-dependent protein kinase (CaMK) and phosphatase (calcineurin) also activate MEF2 [Bassel-Duby \& Olson, 2006; Sun et al, 2003; McKinsey et al, 2000]. Differential phosphorylation by kinases allows MEF2 isoforms to respond to diverse signals in a tissue-specific manner [Cox et al, 2003]. For example, phosphorylation at Thr-312 and Thr-319 on MEF2A strongly increases transcriptional activity as does phosphorylation of Ser387 on MEF2C [Cox et al, 2003; Yoon et al, 2005]. Once activated, MEF2 enters the nucleus and enhances the transcription of many muscle specific genes whose protein products contribute to modifying muscle including protecting cells from responses associated with disuse [Black \& Olson, 1998]. Phosphorylation at other sites has different effects; for example, phosphorylation of MEF2A at Ser-255 targets the protein for degradation whereas phosphorylation at Ser-289, which is in a region known to be alternately spliced in different tissues, may function in tissue specific regulation of MEF2 [Cox et al, 2003].

In the present chapter, the responses of MEF2A and MEF2C and selected phosphorylated forms were examined over the course of a torpor-arousal cycle in skeletal muscle of 13-lined ground squirrels. There was a strong elevation of both MEF2A and C total protein expression from ENT through LHIB periods (Fig. 3.1a) and furthermore, enhanced levels of phosphorylation of MEF2A Thr-312 and MEF2C Ser-387 indicated activation of these Tfs. Hence, signals that control MEF2 were clearly triggering a twofold response - both enhanced MEF2 protein levels and increased phosphorylation (activation) of the proteins. In addition, both total MEF2 protein and the levels of the phosphorylated species were elevated in the nuclear fraction of muscle from torpid squirrels (LHIB stage) as compared with nonhibernating (ACR) animals. This indicates 
that greater amounts of activated (phosphorylated) MEF2 migrate to the nucleus when squirrels enter torpor. Finally, DNA binding by MEF2A was enhanced during ENT whereas MEF2C DNA binding was elevated during both ENT and EHIB (Fig. 3.7a,b). These data indicate that not only is the amount active phosphorylated MEF2A and C increased as an early response to torpor (Fig. 3.1b) but the Tfs both localize to the nucleus and show increased binding capacity for binding to DNA. The above is strong evidence of enhanced transcriptional activity.

Interestingly, the present study also demonstrates that differences in MEF2A and $\mathrm{MEF} 2 \mathrm{C}$ regulation exist; thus, $\mathrm{MEF} 2 \mathrm{C}$ total protein levels increased earlier than $\mathrm{MEF} 2 \mathrm{~A}$ protein whereas DNA binding activity of $\mathrm{MEF} 2 \mathrm{C}$ remained elevated later in the torporarousal cycle (EHIB). MEF2 Tfs are exposed to complex alternate splicing patterns and display differences in their temporal pattern of expression [Black \& Olson, 1998; Cox et $a l, 2003]$. Therefore, whereas members of the MEF2 family may exhibit overlapping roles, they may also elicit independent responses during hibernation. Curiously, Mef $2 a$ and $M e f 2 c$ transcript levels showed a late response in LHIB/EAR; this was not well correlated with protein expression levels which were elevated in ENT. This incongruence merits more investigation but overall the data show that MEF2 Tfs are activated during hibernation in skeletal muscle and thus suggests that they have significant roles to play in muscle during torpor.

Further evidence of MEF2 transcriptional activity during hibernation comes from the increased expression of selected MEF2 downstream targets, MyoD and GLUT4. This also suggests that these proteins may have important roles to play in adjusting skeletal muscle for stresses faced during a torpor bout. MyoD is a Tf in the basic helix-loop-helix 
(bHLH) family of proteins; members of this family form homo- and hetero-dimers that bind to a DNA consensus sequence called an E box (CANNTG) [Berkes \& Tapscott, 2005]. MyoD was selected as a candidate downstream gene under MEF2 regulation because previous research demonstrated that MEF2 and MyoD work in concert to initiate the signals involved in skeletal muscle gene activation [Naya \& Olson, 1999; Legerlotz \& Smith, 2008]. The partnership between MEF2 and MyoD mediates the response to multiple signaling pathways that control myogenesis, myoblast differentiation, cell cycle control and apoptosis [Berkes \& Tapscott, 2005; Naya \& Olson, 1999; Legerlotz \& Smith, 2008; De Falco et al, 2006]. MEF2 and MyoD interact directly, as evidenced by the close proximity of MEF2 DNA binding sites and E boxes in the promoter and enhancer regions of muscle specific genes [Berkes \& Tapscott, 2005]. The coordinated upregulation of MEF2 and MyoD mRNA transcripts during arousal from torpor (EAR, LAR) (Fig. 3.5b; Fig.3.6) and the corresponding upregulation of MyoD protein levels in EAR (Fig. 3.5a) illuminate the interaction between MEF2 and MyoD. A partnership between MEF2 and MyoD during arousal might be involved in optimizing thermogenic capacity to support arousal and/or ameliorating any symptoms of atrophy that accrued during the torpor period. Previous research has identified an involvement of MEF2 and MyoD in the determination of muscle-specific Myosin Heavy Chain (MHC) and Myosin Light Chain profile transitions [Fahlman \& Storey, 2000; Black \& Olson, 1998; Naya \& Olson, 1999]. One documented phenomenon of hibernation is MHC restructuring [Rourke et al, 2004; Rourke et al, 2006]. During hibernation there is selection for the formation of slow-twitch (type I) muscle fibers and previous research has suggested that a key feature in preventing muscle atrophy in small mammals is maintaining slow MHC 
expression [Rourke et al, 2004; Rourke et al, 2006]. Slow-twitch muscle fibers have enhanced oxidative capacity and are suited for endurance. These characteristics enable Type I muscle fibers to fatigue slowly and perhaps allow the skeletal muscle of hibernating mammals to resist atrophy during extended periods of disuse. Additionally, high rates of lipid oxidation in mitochondria-rich Type 1 muscle fibers is critical for shivering thermogenesis during arousal.

Enhanced levels of GLUT4 during hibernation probably contribute to controlling glucose transport in order to maintain energetic homeostasis. Glut4 is an exerciseresponsive gene that encodes an insulin-regulated glucose transporter that is highly expressed in skeletal muscle [Wright, 2007; McGee \& Hargreaves, 2006]. The data show that enhanced glut4 gene expression is an early response in the hibernation cycle (occurring in EHIB) and correlates well with enhanced GLUT4 protein levels that are sustained through torpor and into the arousal period (Fig. 3.4a,b). The reason for enhanced GLUT4 levels in hibernator muscle requires further investigation, particularly since lipids are the primary fuel used during torpor by most tissues. However, evidence suggests that GLUT4 levels rise in tissues that contain proliferating mitochondria [Holloszy, 2008] and, therefore, it may be involved in optimizing the aerobic capacity of cells for function in cold torpor and thermogenesis during arousal. GLUT4 was selected as a downstream target for evaluation because of a known synergy between MEF2 and another coactivator, the peroxisome proliferator-activated receptor gamma coactivator $1 \alpha$ (PCG-1 $\alpha$ ) [Wright, 2007; Lin et al, 2002]. MEF2 and PGC-1 $\alpha$ have been shown to associate with and initiate the transcription of Glut4, promoting slow-twitch fiber formation [Bassel-Duby \& Olson, 2006; Wright, 2007; McGee \& Hargreaves, 2006]. 
PCG- $1 \alpha$ is preferentially expressed in type I fibers emphasizing its role in the activation of oxidative metabolism [McGee \& Hargreaves, 2006]. PCG-1 $\alpha$ also interacts with the nuclear receptor, peroxisome proliferator-activated receptor gamma (PPAR $\gamma$ ) that is well known to regulate proteins involved in lipid oxidation [McGee \& Hargreaves, 2006]. Previous research in our lab has shown a strong increase in PCG-1 $\alpha$ transcript (3.1 fold) and protein (1.7 fold) levels in the skeletal muscle of hibernating ground squirrels [Eddy et al, 2005].

In summary, the present chapter provides a molecular and biochemical view of some of key proteins involved in muscle metabolism during hibernation. Although more details remain to be elucidated, these data suggest that MEF2A and MEF2C and their downstream targets, MyoD and GLUT4, are important to the retention and/or remodeling of skeletal muscle during hibernation to meet multiple goals that may include optimization of aerobic capacity for shivering thermogenesis, limitation of atrophy, and adjustments for low temperature function. Discovery of the mechanisms that promote muscle plasticity during hibernation in 13-lined ground squirrels will not only contribute significantly to our understanding of skeletal muscle metabolism, and could potentially lead to applications for limiting muscle atrophy in humans arising from conditions such as prolonged bed rest, paralysis, or long term space flight. 


\section{Chapter 4}

Myocyte enhancer factor-2 and cardiac muscle gene expression during hibernation in thirteen-lined ground squirrels. 


\section{Introduction}

Of particular interest in this chapter are the molecular mechanisms which remodel cardiac cells during hibernation to meet the demands of the animal. Although heart rate is lowered to just $1.5-2.5 \%$ of euthermic levels during cold torpor, the force of cardiac contraction is actually increased to meet the greater force needed to pump cold viscous blood [Liu et al, 1993; Zakharova et al, 2008]. Furthermore, hearts of hibernators continue to beat at temperatures far below those that cause hypothermic cardiac arrest in most mammals, partly due to altered calcium cycling by hibernator cardiomyocytes [Liu et al, 1993; Wang et al, 2002]. All of these capabilities make hibernator hearts elegant model systems for studies of various cardiomyopathies including the effects of heart attack.

The term cardiomyocyte hypertrophy is defined as the enlargement of individual cardiac cells accompanied by enhanced protein synthesis, changes in the structural proteins of the sarcomere and changes in gene transcription [Molkentin et al, 1998; Frey et al, 2004; Czubryt \& Olson, 2004]. In humans, increased demands placed on the body drive the changes which characterize cardiomyocyte hypertrophy resulting in beneficial compensation strategies; however, over time these changes often become harmful and ultimately result in impaired cardiac function and heart failure [Akazawa \& Komuro, 2003; Frey et al, 2004; Czubryt \& Olson, 2004; Taegtmeyer et al, 2010]. In addition, acute events such as myocardial infarction may also initiate downstream events that result in cardiac hypertrophy [Akazawa \& Komuro, 2003; Czubryt \& Olson, 2004]. In contrast, the accompanying changes that occur in cardiomyocytes during hibernation represent an adaptive change which ensures the survival of the ground squirrel during the winter 
months, and, subsequently, a return to normal cardiac function during summer active months. Therefore, it is of interest to evaluate the molecular attributes of cardiac cells from hibernating mammals to uncover the mechanisms that govern their ability to adapt to extreme fluctuations in physiological demands.

Whereas the response of MEF2 transcription factors has been evaluated thoroughly in skeletal muscle during hibernation, MEF2 has also been shown to play an important role in the regulation of cardiac hypertrophy [Molkentin \& Markham, 1993; Lin et al, 1997; Naya et al, 2002; Streitcher et al, 2010;]. For example, Mef2a null mice die shortly after birth with dilated right ventricles and myofribrillar disorganization [Naya et al, 2002] whereas Mef2c null mice have altered cardiac gene expression [Lin et al, 1997]. Moreover, signaling pathways that are activated in hypertrophy, such as the Ras/mitogen-activated protein kinase (MAPK), lie directly upstream of MEF2 and impose regulatory control via reversible protein phosphorylation [Streitcher et al, 2010; Czubryt \& Olson, 2004]. Recent evidence has also shown that activated p38 and its downstream target MAPK-activated protein kinase-2 (MK2) led to rapid onset of cardiomyocyte hypertrophy [Streitcher et al, 2010]. Indeed, MEF2A and MEF2C are preferentially phosphorylated and activated by p38 family members [Yang et al, 1999]. This finding was substantiated in Richardson's ground squirrels where active, phosphorylated p38MAPK was elevated in heart during torpor and MK2 activity was approximately doubled in both heart and skeletal muscle [MacDonald \& Storey, 2005]. Furthermore, MEF2 DNA binding activity has been shown to be elevated in myopathic hearts [Molkentin \& Markham, 1993]. Therefore, MEF2 transcription factors represent a focal point in cardiac muscle metabolism and place MEF2 in the spotlight as a master 
regulator of cardiac muscle specific genes.

I hypothesized, therefore, that MEF2 transcription factors would have a significant role to play in cardiac metabolism of hibernating species. Utilizing reverse transcriptase PCR and immunoblotting analysis, the responses of MEF2A and MEF2C were analyzed over the torpor-arousal cycle in cardiac muscle of thirteen-lined ground squirrels, $S$. tridecemlineatus. The data revealed that MEF2 genes are positively regulated during torpor and that expression of known downstream genes under MEF2 control, glucose-transporter 4 (GLUT4) and myogenic differentiation (MyoD), is also enhanced.

\section{Materials \& Methods}

Animals.

All animals were captured, treated and organs harvested following the same protocol as previously described in Chapter 2. The cardiac muscle used was a mixture of atrial and ventricular tissue.

Total RNA isolation and quality assessment.

Total RNA was separately extracted $(\mathrm{N}=5)$ from cardiac muscle $(\sim 100 \mathrm{mg})$ from six time points in the torpor-arousal cycle; ACR, ENT, EHIB, LHIB, EAR, LAR. Protocol followed the manufacturer's directions as previously described in Chapter 2. Primer Design and Synthesis.

Primers for Mef2a, Mef2c, Glut4 and $M y o D$ were designed using the Primer Designer Program, v3.0 (Scientific and Educational Software) based on consensus sequences for these genes derived from comparisons of several mammalian species and 
as previously described in Chapter 2 . The primer sequences were as follows:

(1) Mef2a forward 5' -TTGCCACCTCAGAACTTCTC-3' and reverse 5'TTCATTCCAAGAYTGCCACC-3',

(2) $M e f 2 c$ forward 5'-CCAGTGTCCAGCCAYAACAG-3' and reverse 5'TGTAGGTGYTGCTGTTGCCA-3',

(3) Glut4 forward 5'-CCCGMTACCTCTAYATCATC-3' and reverse 5'TTGACCACACCAGCTCCTAT-3',

(4) MyoD forward 5'-GACCCGTGTTTCGACTCCCC-3' and reverse 5'TCGATRTAGCGGATGGCGTT-3', (5) $\alpha$-tubulin forward 5'-AAGGAAGATGCTGCCAATAA-3' and reverse 5'GGTCACATTTCACCATCTG-3'

cDNA synthesis and PCR amplification.

cDNA was synthesized as described in Chapter 2. The resulting cDNA from 6 time points in the torpor-arousal cycle; ACR, ENT, EHIB, LHIB, EAR, LAR were serial diluted $\left(10^{-1}, 10^{-2}, 10^{-3}, 10^{-4}\right)$ and PCR amplified using primers specific to Mef2a, Mef2c, Glut4, and MyoD. The cycles performed for amplification consisted of an initial step of $7 \mathrm{~min}$ at $95^{\circ} \mathrm{C}$, followed by 37 cycles at $95^{\circ} \mathrm{C}$ for $1 \mathrm{~min}$, annealing at $53-68.1^{\circ} \mathrm{C}$ for $1 \mathrm{~min}$ $72^{\circ} \mathrm{C}$ for $1 \mathrm{~min}$; the final step was $72^{\circ} \mathrm{C}$ for $10 \mathrm{~min}$. Annealing temperature was 53.8 , $68.1,60,58,53^{\circ} \mathrm{C}$ for Mef2a, Mef2c, Glut4, MyoD, and $\alpha$-tubulin, respectively. Products were separated on a $1 \%$ agarose gel, stained with ethidium bromide. The bands from the most dilute cDNA sample were used for quantification purposes to make sure that the products had not reached amplification saturation. For cardiac muscle, 
all genes were quantified from the $10^{-3}$ cDNA dilution. Samples of Mef2a, Mef $2 c$, Glut4 and $M y o D$ PCR products were sequenced as previously described and verified using the BLASTN and BLASTP (using deduced amino acid sequences) programs.

Total protein extraction and cytoplasmic/nuclear extract preparation.

Samples of frozen cardiac muscle $(\sim 500 \mathrm{mg})$ were homogenized as previously described. Separate tissue samples were used to prepare cytoplasmic and nuclear extracts for use in the western blot and ELISA protocol, essentially as described previously.

\section{Western Blotting.}

Western blotting was performed as described in Chapter 2. Equal amounts of protein from each sample was loaded onto $10 \%$ polyacrylamide gels and run at $180 \mathrm{~V}$ for 45 minutes. To evaluate relative protein levels of MEF2A, p-MEF2A, MEF2C, and p$\mathrm{MEF} 2 \mathrm{C}, 25 \mu \mathrm{g}$ of protein was loaded into each well. To evaluate the relative protein levels of MyoD only $10 \mu \mathrm{g}$ of protein was loaded into each well. PVDF membranes to be probed with antibodies specific for MEF2A, p-MEF2A, and p-MEF2C were blocked with $5 \% \mathrm{w} / \mathrm{v}$ non-fat dried milk dissolved in TBST (0.05\% Tween-20) for 40 minutes. MEF2C and MyoD were blocked with 30-70 kDa PVA [ $1 \mu \mathrm{g} / \mathrm{ml}$ w/v in TBST $(0.05 \%$ Tween20)] for 45 seconds.

Antibodies specific for proteins of interest were purchased as explained in Chapter 3 (Materials and Methods, Western blotting). MEF2A, p-MEF2A, MEF2C, pMEF2C and GLUT4 antibodies were used at 1:2000 v/v dilution in TBST (20 mM Tris base, $\mathrm{pH} 7.6,140 \mathrm{mM} \mathrm{NaCl}, 0.05 \% \mathrm{v} / \mathrm{v}$ Tween-20) whereas MyoD antibodies were used at $1: 250 \mathrm{v} / \mathrm{v}$ dilution in TBST $(0.05 \%$ Tween-20). All membranes were probed with primary antibody for 12 hours at $4^{\circ} \mathrm{C}$ except for MyoD which was probed for 24 hours at 
$4^{\circ} \mathrm{C}$. Membranes that had been probed with MEF2C were then incubated with HRPlinked anti-goat IgG secondary antibody (1:4000 v:v dilution), MyoD antibodies were detected with HRP-linked anti-mouse IgG secondary antibody (1:2000 v:v dilution) and all other antibodies were detected using HRP-linked anti-rabbit IgG secondary antibody (1:4000 v:v dilution). All membranes were washed three times between incubation periods in $1 \mathrm{X}$ TBST $(0.05 \%$ Tween-20) for approximately 5 minutes/wash. MEF2C and MyoD required more washes in TBST $(0.5 \%$ Tween-20) after probing with secondary antibody ranging from $\sim 40$ minutes to 2 hours, respectively. Signal detection and quantification were as described in Chapter 2.

Enzyme-linked immunosorbent assay (ELISA).

ELISA was performed as described in Chapter 2. Probes for MEF2 were purchased from Sigma Genosys including both the biotinylated probe MEF2 5'-BiotinGATCGCGCTAAAAATAACCCTGTCG -3' and the complement probe (MEF2 5'-cCGACAGGGTTATTTTTAGCGCGATC-3'). The quantitative run for MEF2A utilized the following conditions; $30 \mu \mathrm{g}$ of protein/well, $2 \mu \mathrm{g}$ of salmon sperm/well, $60 \mathrm{mM} \mathrm{NaCl}$, $1 / 2000 \mathrm{v} / \mathrm{v}$ MEF2A primary antibody in TBST $(0.05 \%$ Tween-20), 1/2000 v/v anti-rabbit secondary antibody in TBST $(0.05 \%$ Tween-20). The quantitative run for MEF2C utilized the following conditions: $35 \mu \mathrm{g}$ protein/well, $3 \mu \mathrm{g}$ of salmon sperm/well, $60 \mathrm{mM}$ $\mathrm{NaCl}, 1 / 2000 \mathrm{v} / \mathrm{v}$ MEF2C primary antibody in TBST $(0.05 \%$ Tween-20), 1/2000 v/v antigoat secondary antibody in TBST $(0.05 \%$ Tween-20). Absorbance was calculated as described in Chapter 2.

Quantification and statistics.

Band densities, for Mef2a, Mef2c, Glut4 and MyoD, on ethidium bromide stained 
agarose gels and band densities, for MEF2A, p-MEF2A, MEF2C, p-MEF2C, GLUT4, and MyoD, on chemiluminescent immunoblots were visualized and quantified as described in Chapter 2. Relative binding affinity for the ELISA protocol were quantified as described in Chapter 2. Data are expressed as means $\pm \mathrm{SEM}, \mathrm{n}=5$ independent samples for cDNA quantification and $n=4$ independent samples for chemiluminescent immunoblots.

\section{Results}

Analysis of MEF2 protein levels and nuclear localization

MEF2 protein levels in cardiac muscle were measured by immunoblotting, comparing hearts from animals that had not yet entered a torpor cycle in the cold room (ACR) with five time points on the torpor-arousal cycle: ENT, EHIB, LHIB, EAR, LAR (Fig. 4.1). The antibodies used cross-reacted with a single band on the immunoblots at the expected molecular mass for MEF2 of $44 \mathrm{kDa}$. As compared with ACR controls, MEF2A total protein levels increased during entry into torpor and peaked during torpor (values in ENT, EHIB and LHIB were 2, 2.4 and 2.6 fold higher, respectively, $\mathrm{p}<0.05$ ). Levels remained elevated over ACR values during early and late arousal (by 1.7 and 1.6 fold higher in EAR and LAR, respectively, $\mathrm{p}<0.05$ ) although they were reduced from the peak values in torpor. $\mathrm{MEF} 2 \mathrm{C}$ total protein showed a similar pattern; levels were $1.3,1.6$ and 2.0 fold higher than ACR during ENT, EHIB and LHIB, respectively $(\mathrm{p}<0.05)$. MEF2C decreased again during EAR (to a level 1.4 fold higher than ACR, $\mathrm{p}<0.05$ ) before returning to control levels during LAR (Fig. 4.1a). 
MEF2 transcriptional activity is regulated by posttranslational modifications such as protein phosphorylation at several distinct sites. Transcriptional activity is enhanced when MEF2A is phosphorylated at Thr312 and MEF2C at Ser387 and, therefore, antibodies that recognize these phosphorylation sites were used to monitor changes in the activity state of MEF2 isoforms over the torpor-arousal cycle [Cox et al, 2003; Yoon et $a l, 2005]$. The amount of p-MEF2A protein increased during ENT ( 2 fold higher than $\mathrm{ACR}, \mathrm{p}<0.05)$, stayed elevated in EHIB (1.4-fold higher than ACR, $\mathrm{p}<0.05$ ), and peaked during LHIB (2.5-fold higher than ACR, p<0.05) (Fig. 4.1b). Subsequently, p-MEF2A Thr312 levels returned to control values when animals aroused from torpor. Phosphorylation of MEF2C showed the same pattern, although less pronounced, with significant increases in p-MEF2C Ser387 content during ENT, EHIB and LHIB (1.4, 1.7 and 1.5 fold higher than ACR, $\mathrm{p}<0.05)$. Again, levels returned to control values during arousal (Fig. 4.1b).

MEF2 must be active in the nucleus in order to modify gene transcription levels and so I also evaluated the distribution of MEF2 and p-MEF2 isoforms between cytoplasmic and nuclear fractions of ground squirrel heart (Fig. 4.2). MEF2A total protein levels increased significantly in both cell fractions when ACR controls were compared with the LHIB group; levels rose by 1.5 fold in the cytoplasmic fraction and by 1.6 fold in the nuclear fraction, as compared with the corresponding ACR values for these fractions ( $\mathrm{p}<0.05$ ) (Fig. 4.2a). The amount of MEF2C in each cell fraction did not change significantly between the ACR and LHIB conditions but phosphorylated MEF2C increased in both fractions during torpor (by 1.4 and 1.2 fold compared with cytoplasmic and nuclear ACR values, respectively, p<0.05) (Fig. 4.2b). Phosphorylated MEF2A also 
increased strongly (by 1.4 fold, $\mathrm{p}<0.05$ ) in the nuclear fraction of torpid animals) (Fig. 4.2b).

\section{Analysis of GLUT4 and MyoD protein levels}

Two of the important downstream genes under MEF2 control are GLUT4 and MyoD and, hence, I chose to monitore changes in their protein levels over the torporarousal cycle in ground squirrel heart (Fig. 4.3a \& Fig. 4.4a). Antibodies for GLUT4 and MyoD cross-reacted with single bands on immunoblots at the expected molecular masses of the mammalian proteins of 50 and $45 \mathrm{kDa}$, respectively. GLUT4 relative protein levels increased significantly during ENT (1.4 fold higher than ACR, p<0.05) and remained high over all subsequent sampling times (Fig. 4.3a). GLUT4 levels were 1.6 and 1.4 fold higher than ACR during EHIB and LHIB, respectively $(\mathrm{p}<0.05)$, and rose higher during arousal to 1.8 fold and 2.2 fold higher than ACR values in EAR and LAR, respectively $(\mathrm{p}<0.05)$. MyoD relative protein levels were stable from ACR to EAR but increased sharply during the late arousal period (4.7 fold higher than EAR, p<0.05) (Fig. 4.4a).

Analysis of Mef2, Glut4 and MyoD transcript levels

Primers designed to amplify $M e f 2 a, M e f 2 c, G l u t 4$, and $M y o D$ were first used to amplify these genes from ground squirrel skeletal muscle (Chapter 3) and were confirmed as also amplifying the cardiac genes. RT-PCR was used to evaluate relative mRNA transcript levels in heart over the torpor-arousal cycle. Neither Mef $2 a$ nor Mef $2 c$ transcript levels increased during entry into torpor but both were elevated over the remainder of the torpor-arousal course (Fig. 4.5). As compared with ACR values, Mef $2 a$ 
expression levels were elevated in EHIB (1.4 fold higher, $\mathrm{p}<0.05$ ) and remained significantly higher ( $\mathrm{p}<0.05)$ in LHIB (1.26 fold), EAR (1.4 fold) and LAR (1.5 fold). Mef $2 c$ transcript levels were 1.3, 1.26, 1.4 and 1.35 fold higher than ACR values $(\mathrm{p}<0.05)$ in EHIB, LHIB, EAR, LAR, respectively. Figure 4.3b shows Glut4 transcript levels were also elevated during LHIB (1.4 fold higher than ACR, $\mathrm{p}<0.05)$ and LAR (1.5 fold) but not at other points in the torpor-arousal cycle. Figure $4.4 \mathrm{~b}$ depicts expression levels of $M y o D$ transcripts which showed an interesting pattern. Transcript levels fell as animals entered hibernation to $47 \%$ in EHIB as compared to ACR $(\mathrm{p}<0.05)$. However, levels rose again during LHIB (to 2.6 fold higher than in EHIB, $\mathrm{p}<0.05$ ) and then fell as animals aroused from torpor with levels in LAR that were just $41 \%$ of the LHIB values $(p<0.05)$. Analysis of $M E F 2$ relative DNA binding

Relative MEF2 binding to DNA in nuclear extracts of cardiac muscle was measured by an enzyme-linked immunosorbent assay comparing hearts from animals that had not entered cold torpor with those from four time points on the torpor-arousal cycle: ENT, EHIB, LHIB, EAR (Fig. 4.6a,b). The probes were designed based on the specific DNA binding element of MEF2 and the mammalian MEF2A and MEF2C primary antibodies were the same as those used for immunoblotting. As compared with ACR controls, MEF2A total protein binding rose during entry into torpor (by 1.9 -fold, $\mathrm{p}<0.05$ ) and remained high during EHIB, LHIB and $\operatorname{EAR}(2.1,2.1$, and 2.8 fold higher than ACR, respectively, p<0.05) (Fig. 4.6a). MEF2C total protein binding increased in ENT (by 1.9fold compared with $\mathrm{ACR}, \mathrm{p}<0.05$ ) but decreased again to levels not significantly different from ACR during EHIB, LHIB, and EAR (Fig. 4.6b). 

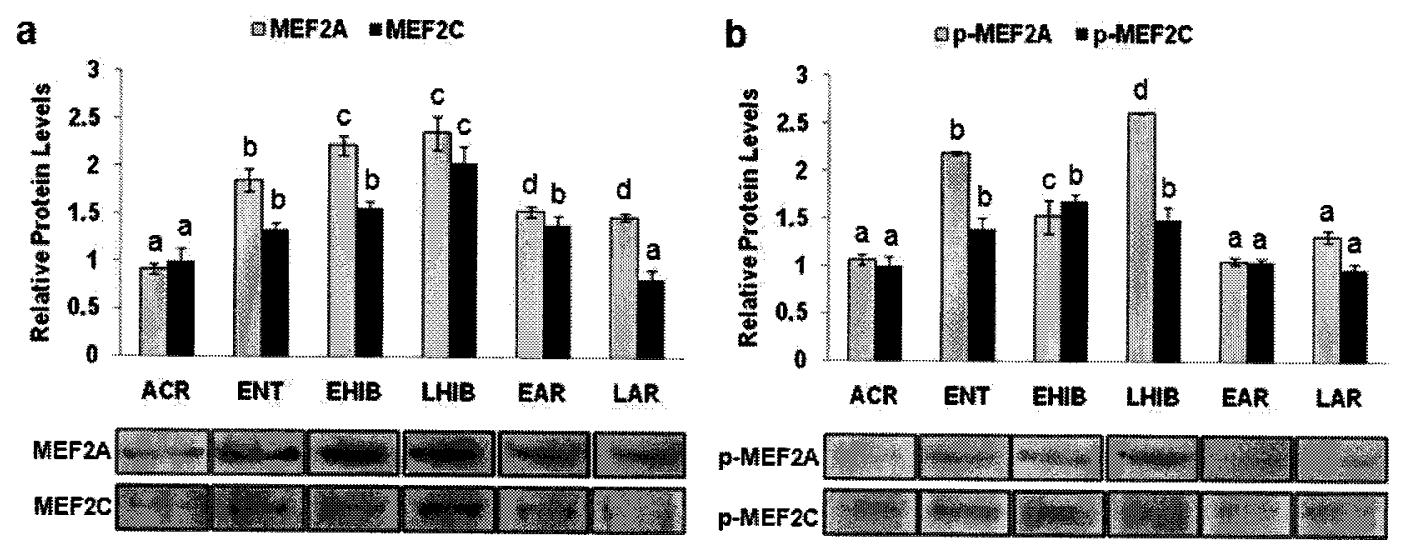

Fig. 4.1. Changes in the protein levels of MEF2 Tfs over the course of the torpor-arousal cycle in cardiac muscle of $S$. tridecemlineatus. Sampling points were: active in the cold room (ACR), entrance into torpor (ENT), early hibernation (EHIB), late hibernation (LHIB), early arousal (EAR) and late arousal (LAR). See the Materials and Methods for more extensive definitions. (a) MEF2A and MEF2C total protein expression at six sampling points. (b) Levels of phosphorylated MEF2A (Thr312) and MEF2C (Ser387). Representative Western blots are shown along with histograms showing mean normalized band densities ( \pm S.E.M., $n=4$ independent trials on tissue from different animals). Data were analyzed using analysis of variance with a post hoc Student-Newman-Keuls test; different letters denote values are significantly different from each other, $\mathrm{P}<0.05$. 

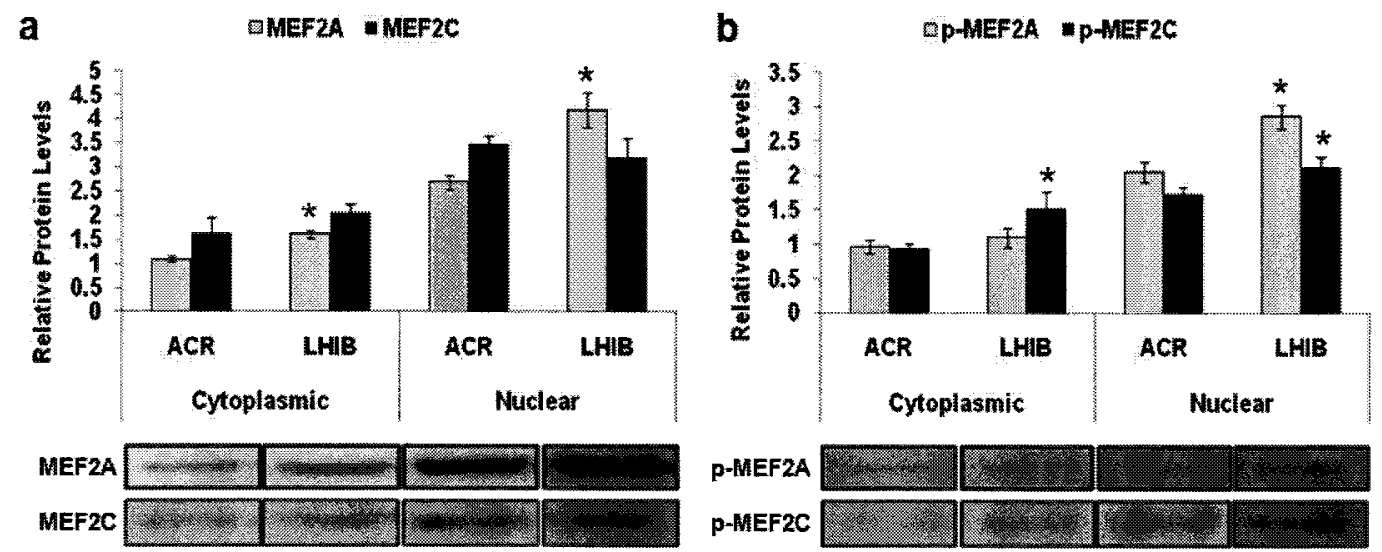

Fig. 4.2. Changes in the distribution of total MEF2 protein and phosphorylated MEF2 content in nuclear and cytoplasmic fractions over the course of a torpor-arousal cycle in cardiac muscle of S. tridecemlineatus. Representative Western blots show the distribution of (a) MEF2A and MEF2C between cytoplasm and nucleus, and (b) p-MEF2A (Thr 312) and p-MEF2C (Ser 387) between cytoplasm and nucleus between control (ACR) and long-term torpor (LHIB) conditions. Histograms show mean normalized band densities ( \pm S.E.M., $n=4$ independent trials on tissue from different animals). * - Significantly different from the corresponding ACR value for the same cell fraction using the Student's t-test, $\mathrm{P}<0.01$. 

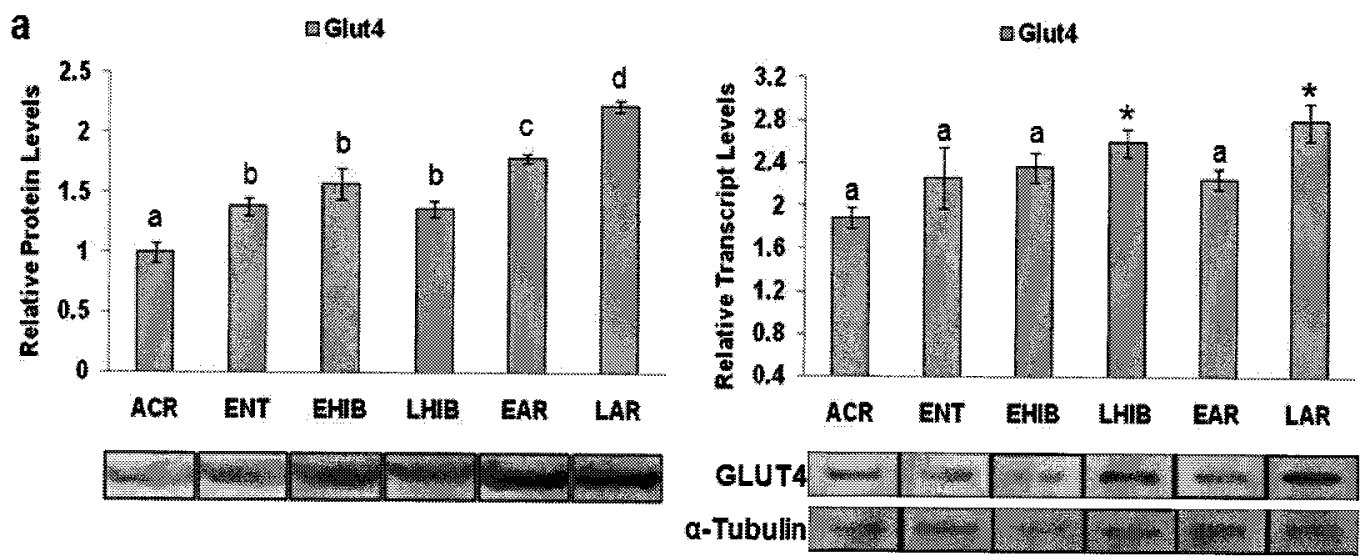

Fig. 4.3. Changes in glucose transporter isoform 4 protein and mRNA transcript levels in cardiac muscle of $S$. tridecemlineatus over the torpor-arousal cycle. (a) Representative Western blots and histogram showing mean GLUT4 protein levels. (b) Representative transcript bands on agarose gels and histogram showing mean normalized glut4 transcript levels. Glut4 bands were normalized against tubulin bands amplified from the same sample. Data are means ( \pm S.E.M., $n=4$ samples from different animals). Other information as in Fig. 4.1. 

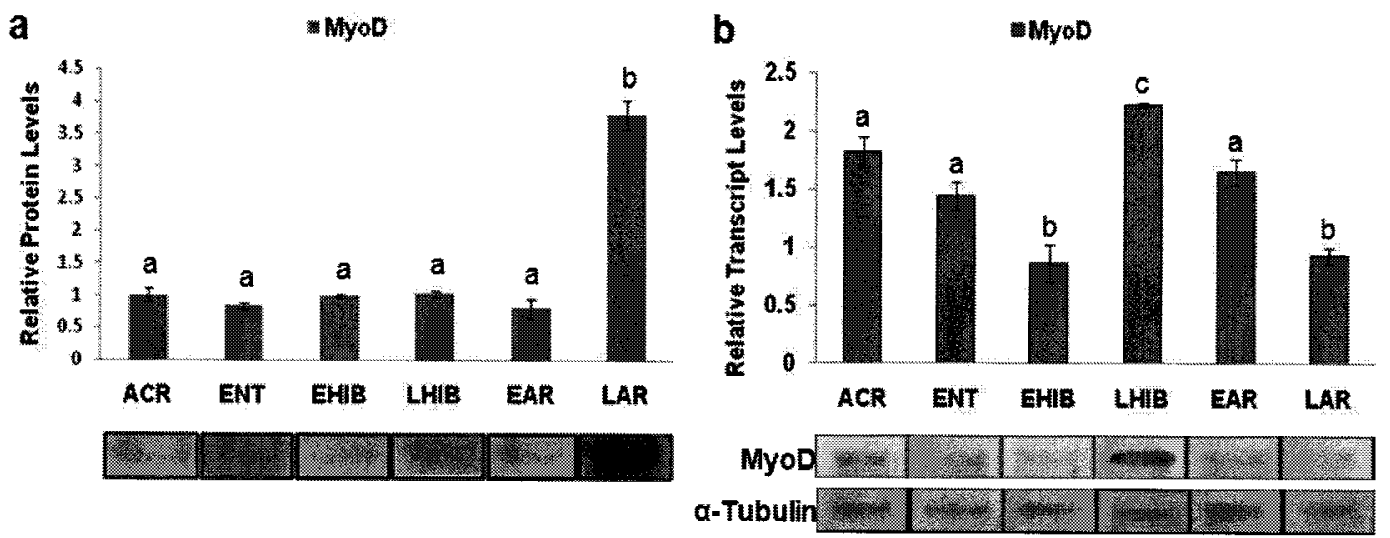

Fig. 4.4. Changes in myogenic differentiation protein and mRNA transcript levels in cardiac muscle of $S$. tridecemlineatus over the torpor-arousal cycle. (a) Representative Western blots and histogram showing mean MyoD protein levels. (b) Representative transcript bands on agarose gels and histogram showing mean normalized $M y o D$ transcript levels. MyoD bands were normalized against tubulin bands amplified from the same sample. Data are means ( \pm S.E.M., $n=4$ samples from different animals). Other information as in Fig. 4.3. 


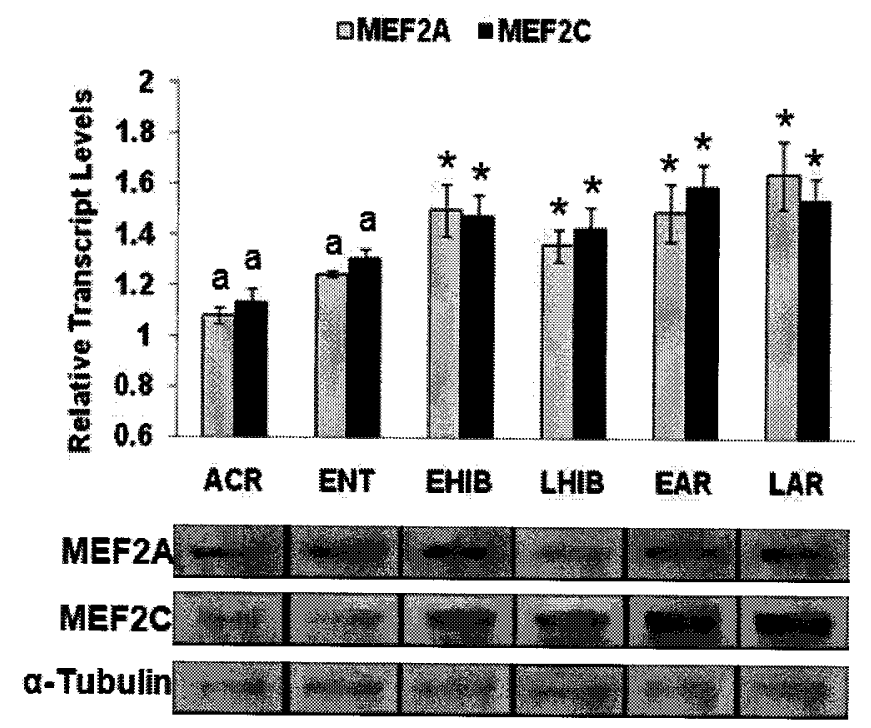

Fig. 4.5. Changes in the levels of Mef2a and Mef2c mRNA transcript levels in cardiac muscle of $S$. tridecemlineatus over the torpor-arousal cycle. Shown are representative bands on agarose gels (and bands for $\alpha$-tubulin that was used for normalization) and histograms of means ( \pm S.E.M., $n=4$ independent trials on separate RNA isolations from different animals) for six sampling points. Other information as in Fig. 4.1. 

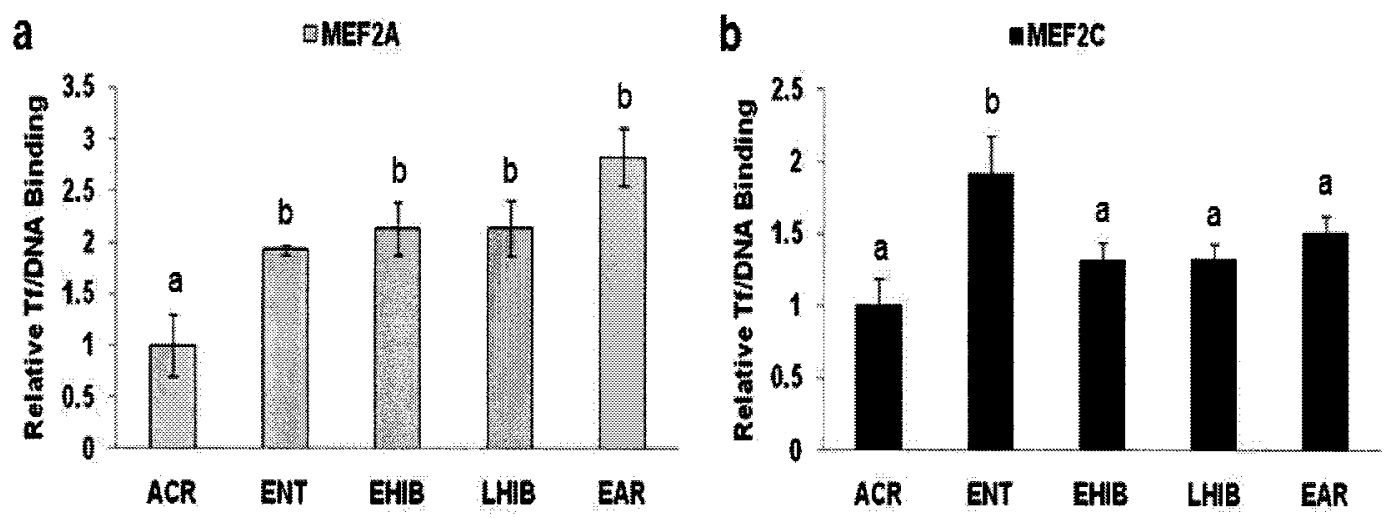

Fig. 4.6. Changes in the DNA binding of MEF2 Tfs over the course of a torpor-arousal cycle in cardiac muscle of $S$. tridecemlineatus. Sampling points are: active in the cold room (ACR), entrance into torpor (ENT), early hibernation (EHIB), late hibernation (LHIB), and early arousal (EAR). (a) MEF2A relative DNA binding at five sampling points. (b) MEF2C relative DNA binding at five sampling points. Other information as in Fig. 4.1. 


\section{Discussion}

The present study aimed at deepening our understanding of the molecular regulation of cardiomyocytes during hibernation in the thirteen-lined ground squirrel. The ground squirrel represents a natural model system where euthermic cardiac function can be compared to processes which maintain cardiomyocyte viability under cold exposure and reversible cardiac hypertrophy. Whereas hypertrophy of the human heart is also a natural phenomenon for humans in the first few weeks of life, after the terminal differentiation of cardiomyocytes, prolonged hypertrophy is detrimental to the normal function of the cardiac muscle [Czubryt \& Olson, 2004]. In addition, cellular mechanisms which counter the effects of low body temperatures can help design new preservation techniques for extant organs for transplant. Therefore, it is of great interest to highlight the elicited responses of transcription factors in order to expose the biochemical pathways that regulate cardiac muscle plasticity during hibernation.

The present chapter evaluated two MEF2 transcription factors, MEF2A and MEF2C, using a multidimensional approach that assessed relative transcript levels, protein expression and DNA binding over the torpor-arousal cycle in ground squirrel heart. Furthermore, two downstream genes under MEF2 regulatory control, MyoD and GLUT4, were evaluated because of their potential importance to cardiac metabolism during hibernation. MEF2 transcription factors are vital MyoD regulators [Leibham et al, 1994] and MEF2 and MyoD have been shown to act synergistically to activate muscle specific genes [Yu et al, 1992; Ornatsky et al, 1997]. Glucose transporters are membrane proteins that in most cases mediate glucose uptake into cells, except for the bifunctional GLUT2 of liver that conducts both uptake and release of glucose [Patterson et al, 2009]. 
In humans, accumulating evidence suggests that impaired myocardial glucose uptake may contribute to the pathogenesis of cardiomyocyte hypertrophy [Patterson et al, 2009; Domenighetti et al, 2010]. In a recent study, researchers linked GLUT4 deficiency with profound alterations in cardiomyocyte $\mathrm{Ca}^{2+}$ and $\mathrm{pH}$ homeostasis [Domenighetti et al, 2010]. Since GLUT4 is under MEF2 control it is of interest to determine its role during hibernation when, notably, ground squirrels rely primarily on the liberation and mobilization of fatty acid stores from white adipose tissue for their fuel needs [Andrews et al, 2009; Storey \& Storey, 2010].

The responses of total MEF2A and $2 \mathrm{C}$ protein and the phosphorylated forms, $\mathrm{p}$ MEF2A Thr312 and p-MEF2C Ser387, were evaluated over the torpor-arousal cycle in ground squirrel heart and the results demonstrate that MEF2 transcription factors are positively regulated during hibernation (Fig. 4.1a,b). MEF2A relative protein levels increased significantly during ENT and remained high throughout the cold torpor periods before returning to control levels in the fully aroused animal. The amount of phosphorylated MEF2A was similarly elevated (by 1.4-2.5 fold) during ENT and throughout torpor. Similarly, MEF2C total protein levels and phosphorylation state increased during ENT, EHIB, LHIB and fell again during arousal. Phosphorylation of MEF2A at Thr312 and MEF2C at Ser387 are both known to enhance transcriptional capacity of these MEF2 isoforms [Cox et al, 2003; Yoon et al, 2005] and therefore the data suggest downstream genes under MEF2 control would be up-regulated during torpor. In addition, both total MEF2A and the amount of p-MEF2A increased in the nucleus during torpor and p-MEF2C content also increased in the nucleus during LHIB (Fig. 4.2a, b). Nuclear translocation is an essential prerequisite for enhanced transcription 
and, hence, these data provide further evidence that MEF2 mediated gene transcription is up-regulated in heart when ground squirrels enter torpor. Finally, binding of MEF2 isoforms to DNA was also enhanced over the torpor-arousal cycle; for MEF2C, DNA binding was highest during ENT (Fig. 4.6b) whereas DNA binding capacity of MEF2A remained elevated (at about 2 fold higher than the ACR value) from ENT through to EAR (Fig. 4.6a). Overall, these data provide strong evidence for an important role of MEF2 transcription factors in the selective expression of genes that aid heart function under cold torpor conditions in the hibernating ground squirrel.

Curiously, phospho-MEF2C levels remain elevated throughout EHIB (1.7-fold higher than ACR, p<0.05) and LHIB (1.5 fold higher than ACR, p<0.05) (Fig. 4.1b); however, post-translational states which are characterized with enhanced transcriptional capacity did not demonstrate higher DNA binding under the same experimental conditions. While further studies are required to elucidate the relevance of this data, it could indicate that MEF2C effects on gene expression might be most potent, localized and/or important during ENT. Furthermore, MEF2A DNA binding remained significantly higher than ACR throughout the entire torpor-arousal cycle (Fig. 4.6a). Notably, DNA binding peaked during EAR (2.8 fold higher than ACR, $\mathrm{p}<0.05)$ when $\mathrm{p}-\mathrm{MEF} 2 \mathrm{~A}$ levels had returned to euthermic levels. It is possible that other post-translational modifications are also important in increasing DNA binding [Wei et al, 2008; Riquelme et al, 2006] and perhaps play a vital role during arousal of the ground squirrel. The data suggests that genes that are $\mathrm{MEF} 2 \mathrm{C}$ regulated are more likely to be up-regulated in ENT whereas MEF2A might support genes that are more generally elevated throughout torpor.

The enhanced protein expression and transcriptional capacity of MEF2 in heart 
during torpor potentially represents important adaptive changes in gene expression for ground squirrels that activate key gene loci when the animals enter into hypometabolism. Downstream genes under MEF2 regulation indicate that MEF2 enhanced transcriptional capacity is synchronized with the expression of target genes in cardiomyocytes during hibernation. During LHIB, when both p-MEF2 and DNA/protein binding were elevated, MyoD transcript levels increased significantly by 2.6 fold compared with EHIB (Fig. 4.4b). Subsequently, MyoD relative protein levels increased during LAR to levels 3.8 fold higher than in ACR (Fig. 4.4a). Conversely, the pattern of GLUT4 expression showed elevated protein levels in the early stages of hibernation that persisted throughout torpor and actually increased further during LAR (Fig. 4.3a). Peculiarly, GLUT4 transcript levels showed a much later response and were significantly elevated during LHIB and LAR (Fig. 4.3b). This incongruence was also demonstrated by the mRNA versus protein changes observed with MEF2A and MEF2C (Fig 4.1a and 4.5). Transcript levels for MEF2 transcription factors increased during EHIB whereas protein expression increased during ENT. Hibernation represents a cyclical phenomenon where successive rounds of deep torpor and arousal are closely regulated. Therefore, increases in transcript levels during later phases of hibernation may prepare cardiac cells for the next hibernation cycle.

In summary, the present study provides a dynamic view of the regulation of MEF2 transcription factors and their downstream genes in cardiac muscle of the thirteenlined ground squirrel over the course of a torpor-arousal cycle. MEF2 transcription factors are regulated at multiple checkpoints including transcription, translation, and posttranslationally in order to elicit downstream responses that include enhanced expression 
of MyoD and GLUT4 proteins. These changes occur, in part, to aid cardiac muscle in maintaining function in the face of the physiological challenges associated with torpor that include low $\mathrm{Tb}$ values near to $0^{\circ} \mathrm{C}$, increased blood viscosity, and low rates of blood flow that would be considered ischemic during euthermia. This display of cardiac muscle plasticity, makes the thirteen-lined ground squirrel an excellent model for the study of various cardiomyopathies. 


\section{Chapter 5}

Molecular adaptations of structural proteins in striated muscle of the thirteen-lined ground squirrel during hibernation 


\section{Introduction}

In order to further explore the extent and nature of muscle remodeling under strong environmental pressures, five proteins related to the structural apparatus of striated muscle (troponin, tropomyosin, myomesin, desmin, vimentin) were evaluated using immunoblot techniques over a time course of torpor and arousal in hibernating 13-lined ground squirrels. Troponin and tropomyosin play an integral role in skeletal and cardiac muscle contraction. Initiated by action potentials, calcium is released from the sarcoplamic reticulum, binds to troponin $\mathrm{C}$ which releases troponin I, and subsequently, tropomyosin from actin sites for the binding of myosin cross-bridges [Watkins et al, 1995; Kostin et al, 2000; Chang et al, 2008]. Myomesin is an end line protein, attaching myosin thick filaments to the $\mathrm{M}$ line and maintaining the thick filament lattice [Agarkiva \& Perriard, 2005]. Myomesin has a complex elastic structure which allows it to adapt to the thick filament lattice during contraction [Agarkiva \& Perriard, 2005]. Intermediate filaments (IFs) interconnect myofibrils through the Z-disk and link the contractile apparatus to the sarcolemma as well as to the nucleus, thereby playing a role in cellular integrity, force transmission, and integration of organelle structure [Capetanaki et al, 2007]. Moreover, IFs also participate in signaling cascades that are linked to both integrin and dystroglycan complex (DGC) signaling [Chockalingam et al, 2002; Capetanaki et al, 2007]. Desmin, a Z-disk protein, is the dominant muscle specific type III IF and is essential for the proper development of both cardiac and skeletal muscle [Goldfarb \& Dalakas, 2009]. Vimentin is another type III intermediate filament which is responsible for the organization of proteins involved in adhesion, migration, and cell signaling [Ivaska et al, 2007]. Vimentin filaments are connected to integrins via connector proteins 
and may play a role in integrin signaling [Ivaska et al, 2007]. Additionally, many studies have linked vimentin to signal transduction pathways such as Erk signaling [Ivaska et al, 2007]. The present chapter explores the changes in expression of these five structural proteins in both cardiac and skeletal muscles over the course of torpor and arousal in hibernating 13-lined ground squirrels.

\section{Materials \& Methods}

Animals.

All animals were captured and treated, and organs were harvested following the same protocol as previously described in Chapter 2 . The skeletal muscle used was a mixture of several hind limb muscles while the cardiac muscle used was a mixture of atrial and ventricular tissue.

Total protein extraction.

Samples of frozen hind leg skeletal muscle $(\sim 500 \mathrm{mg})$ and cardiac muscle $(\sim 500$ $\mathrm{mg}$ ) were homogenized as previously described.

\section{Western Blotting.}

Western blotting was performed as described in Chapter 2. Equal amounts of protein from each sample $(10-25 \mu \mathrm{g})$ were loaded onto $8-12 \%$ polyacrylamide gels and run at $180 \mathrm{~V}$ for 45-60 minutes. To evaluate relative protein levels of troponin and tropomyosin a $12 \%$ polyacrylamide gel was run for 60 minutes, $20 \mu \mathrm{g}$ protein/well; for desmin and vimentin a $10 \%$ gel for 45 minutes, $10 \mu \mathrm{g}$ protein/well; for myomesin a $8 \%$ gel for 60 minutes, $25 \mu \mathrm{g}$ protein/well. PVDF membranes to be probed with antibodies specific for troponin, tropomyosin and myomesin were not blocked, while membranes to 
be probed with desmin and vimentin were blocked with $30-70 \mathrm{kDa}$ PVA $[1 \mu \mathrm{g} / \mu \mathrm{l} / \mathrm{v}$ in TBST (0.05\% Tween-20)] for 45 seconds.

Antibodies specific for mammalian desmin, myomesin, tropomyosin, troponin, and vimentin were purchased from Developmental Studies Hybridoma Bank (University of Iowa). All primary antibodies were used at 1:500 v/v dilution in TBST $(0.05 \% \mathrm{v} / \mathrm{v}$ Tween-20) and were probed for 24 hours at $4^{\circ} \mathrm{C}$. All antibodies were detected with HRPlinked anti-mouse IgG secondary antibody (1:2000 v:v dilution). All membranes were washed three times between incubation periods in $1 \mathrm{X}$ TBST $(0.05 \%$ Tween-20) for approximately 5 minutes/wash. Desmin and vimentin required more washes after probing with secondary antibody ranging from $\sim 40$ minutes to 2 hours. Signal detection and quantification were as described in Chapter 2.

Quantification and statistics.

Band densities on chemiluminescent immunoblots were visualized and quantified as described in Chapter 2. Data are expressed as means $\pm \mathrm{SEM}, \mathrm{n}=4$ independent samples.

\section{Results}

Troponin I, $\alpha / \beta$-tropomyosin, and myomesin in skeletal muscle

Troponin I, $\alpha / \beta$-tropomyosin, and myomesin protein levels in skeletal muscle were measured by immunoblotting comparing the control condition (ACR) to five other experimental conditions; ENT, EHIB, LHIB, EAR, LAR (Fig.5.1 a-c). The antibodies used each cross-reacted with single bands on the immunoblots at the expected molecular 
masses for troponin I, $\alpha / \beta$-tropomyosin and myomesin of $28 \mathrm{kDa}, 36 \mathrm{kDa}$, and $185 \mathrm{kDa}$, respectively. Troponin I total protein levels did not change significantly over the torporarousal cycle when compared to ACR controls (Fig. 5.1a). However, significant changes were observed when EHIB/LHIB values were compared with values in EAR/LAR; troponin I protein levels in EAR were 1.5 and 1.46 fold higher than in EHIB and LHIB, respectively ( $\mathrm{p}<0.05$ ). $\alpha / \beta$-Tropomyosin protein levels remained constant in the early stages of the torpor-arousal cycle, but rose significantly during LHIB (1.54 fold compared with ACR; 1.8 fold compared with ENT, p<0.05), and returned to control conditions in EAR and LAR. Myomesin total protein levels remained fairly stable from ACR to LHIB before increasing during arousal. Myomesin was significantly higher during LAR as compared with ACR (by 1.6 fold, p<0.05) and values in EAR and LAR were significantly higher when directly compared with ENT (by 2 and 2.3 fold, $p<0.05$ ).

\section{Desmin and vimentin in skeletal muscle}

Fig. 5.2 shows the changes in desmin and vimentin protein levels in skeletal muscle over the torpor-arousal course. The antibodies used cross-reacted with single bands on the immunoblots at the expected molecular masses for desmin and vimentin of 52 and $55 \mathrm{kDa}$, respectively. Desmin total protein levels increased significantly in EHIB (2.0 fold higher than ACR, $\mathrm{p}<0.05$ ) but were similar to ACR values at all other sampling times. Vimentin total protein levels were unchanged throughout the ENT, EHIB and LHIB periods but increased significantly by 2.7 and 3.1 fold in EAR and LAR, respectively (as compared to $\mathrm{ACR}, \mathrm{p}<0.05$ ). 
Troponin I, $\alpha / \beta$-tropomyosin, and myomesin in cardiac muscle

Troponin I, $\alpha / \beta$-tropomyosin, and myomesin protein levels were also assessed in ground squirrel heart over the course of torpor and arousal (Fig. 5.3). Troponin I total protein levels changed dramatically over time; spiking during ENT ( 2.3 fold higher than $\mathrm{ACR}, \mathrm{p}<0.05)$, returning to near-ACR levels during early and late torpor periods, and finally decreasing strongly as animals moved into the arousal phase. Levels during EAR and LAR were just 10 and $11 \%$, respectively, of the maximum levels measured during ENT $(p<0.05)$. Similarly, $\alpha / \beta$-tropomyosin total protein levels increased significantly during ENT (by 1.8 fold higher than ACR, $\mathrm{p}<0.05$ ), but, returned to levels comparable to ACR for the rest of the torpor-arousal cycle. Myomesin total protein also increased during ENT ( 2.3 fold higher than $\mathrm{ACR}, \mathrm{p}<0.05$ ), and remained high throughout the torpor period; values during EHIB and LHIB were 2.0 and 1.8 fold higher than ACR, respectively $(\mathrm{p}<0.05)$. Myomesin protein levels during EAR and LAR were not significantly different from ACR.

Desmin and vimentin in cardiac muscle

Desmin and vimentin protein levels in cardiac muscle are shown in Fig. 5.4. Desmin total protein levels increased strongly during entry into torpor ( 2.3 fold higher than ACR, $\mathrm{p}<0.05$ ) but then fell back to a constant level over the remainder of the torporarousal cycle. Vimentin total protein levels also increased during ENT (by 2.5 fold higher than ACR, $\mathrm{p}<0.05$ ), but were reduced again during EHIB and LHIB. Levels rebounded again during arousal with values in EAR being 4.0 fold higher than in ACR $(\mathrm{p}<0.05)$, before dropping again to basal levels during LAR. 

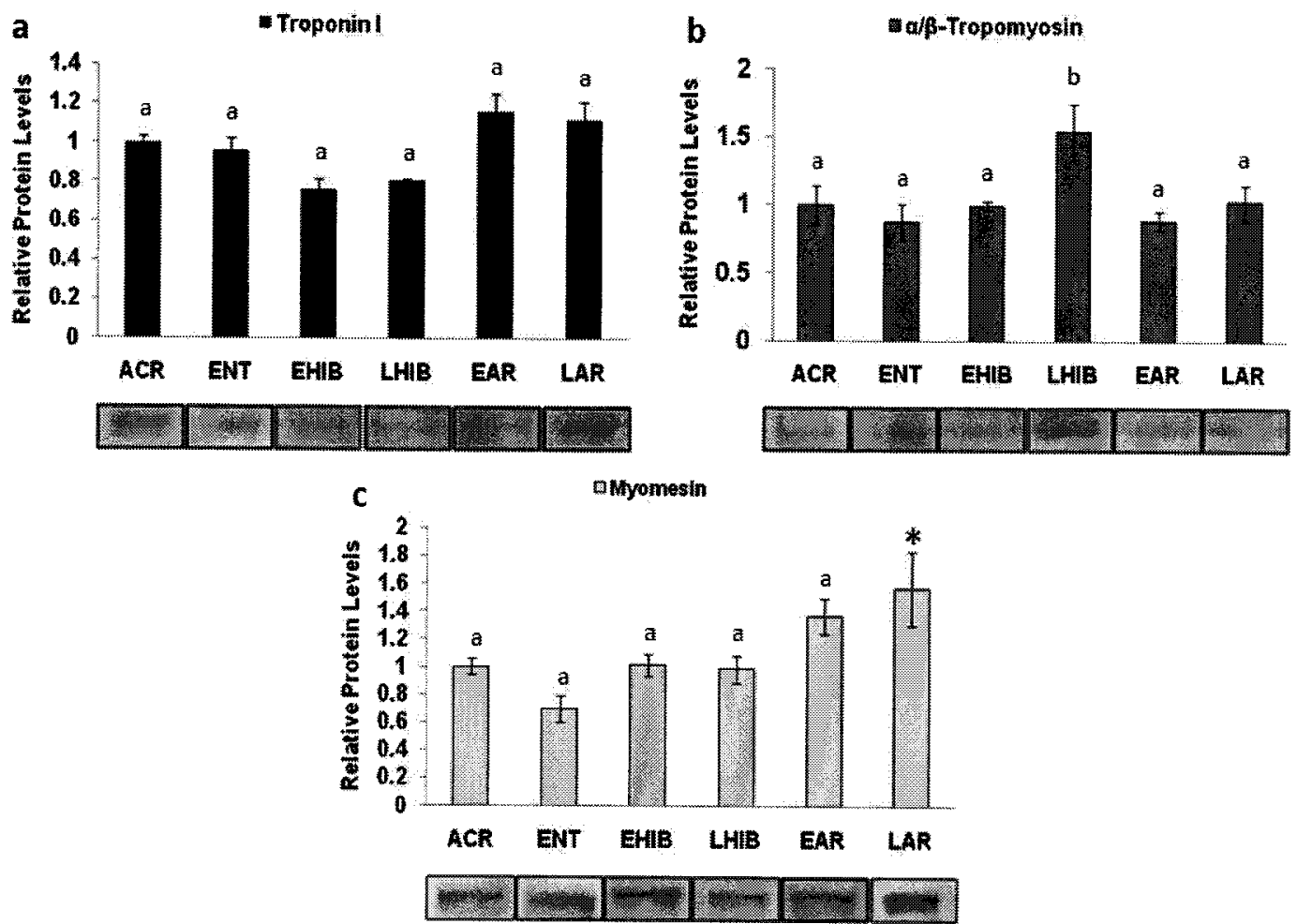

Fig. 5.1. Changes in the protein levels of troponin $I, \alpha / \beta$-tropomyosin, and myomesin over the course of a torpor-arousal cycle in skeletal muscle of $S$. tridecemlineatus. Sampling points are: active in the cold room (ACR), entrance into torpor (ENT), early hibernation (EHIB), late hibernation (LHIB), early arousal (EAR) and late arousal (LAR). See the Materials and Methods for more extensive definitions. Panels show protein expression levels at six sampling points for (a) troponin $I$, (b) $\alpha / \beta$-tropomyosin, and (c) myomesin. Representative Western blots accompany histograms showing mean normalized band densities ( \pm S.E.M., $n=4$ independent trials on tissue from different animals). Data were analyzed using analysis of variance with a post hoc StudentNewman-Keuls test; different letters denote values that are significantly different from each other, $\mathrm{P}<0.05$. * values are significantly different from the corresponding ACR value using the Student's t-test, $\mathrm{P}<0.05$. 

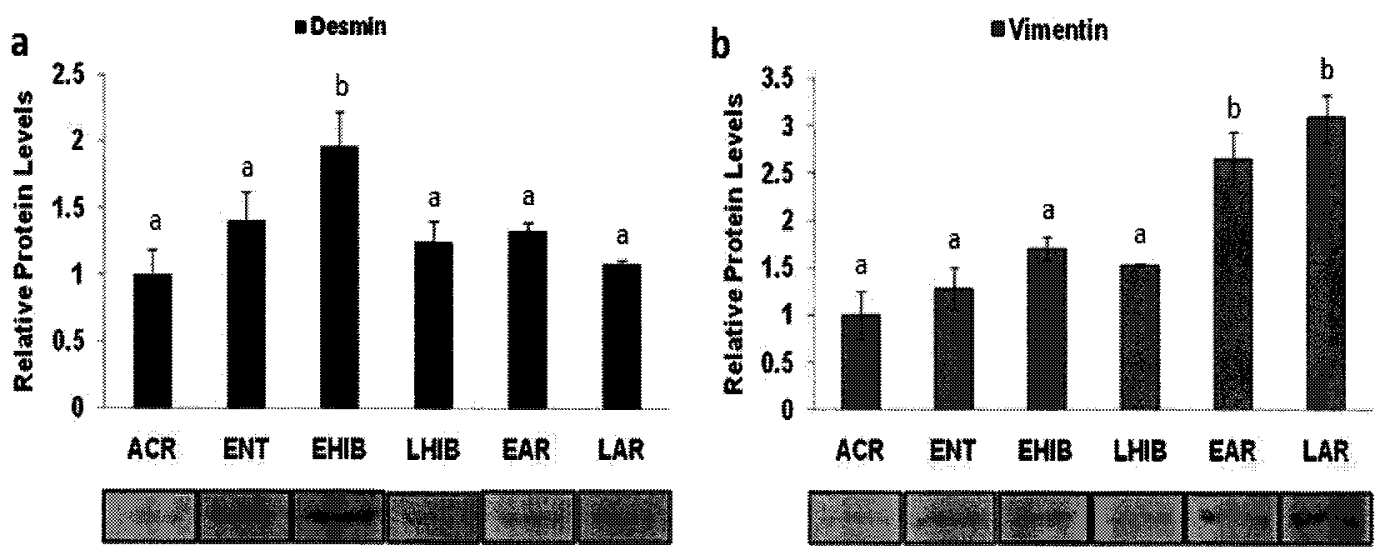

Fig. 5.2. Changes in the protein levels of desmin and vimentin in skeletal muscle of $S$. tridecemlineatus over the torpor-arousal cycle. Western blots and histograms show relative protein levels of (a) desmin, and (b) vimentin at six sampling points. Other information as in Fig. 5.1. 

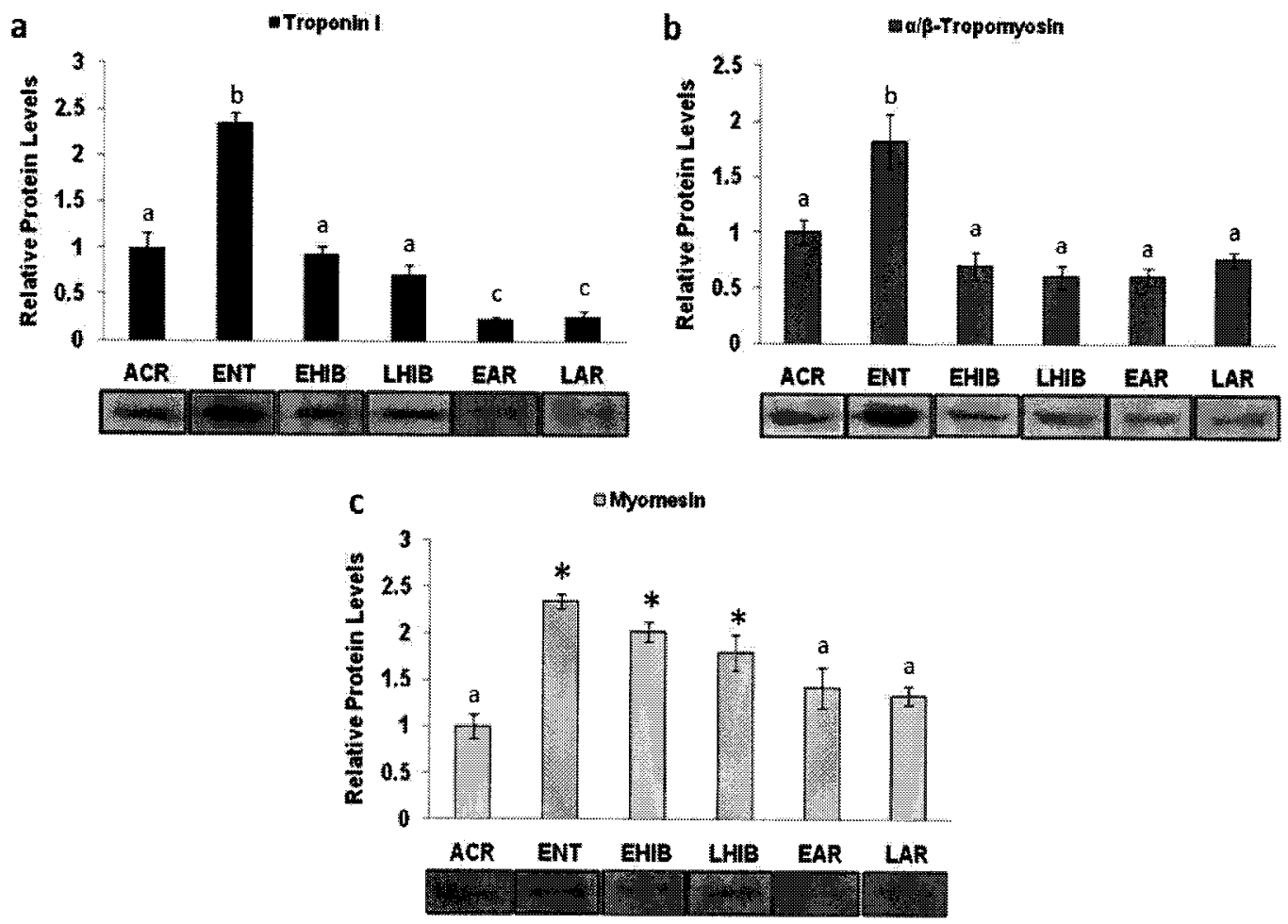

Fig. 5.3. Changes in the protein levels of troponin I, $\alpha / \beta$-tropomyosin, and myomesin in cardiac muscle of S. tridecemlineatus over the torpor-arousal cycle. Western blots and histograms show relative protein levels of (a) troponin I, (b) $\alpha / \beta$-tropomyosin, and (c) myomesin at six sampling points. Other information as in Fig. 5.1. 

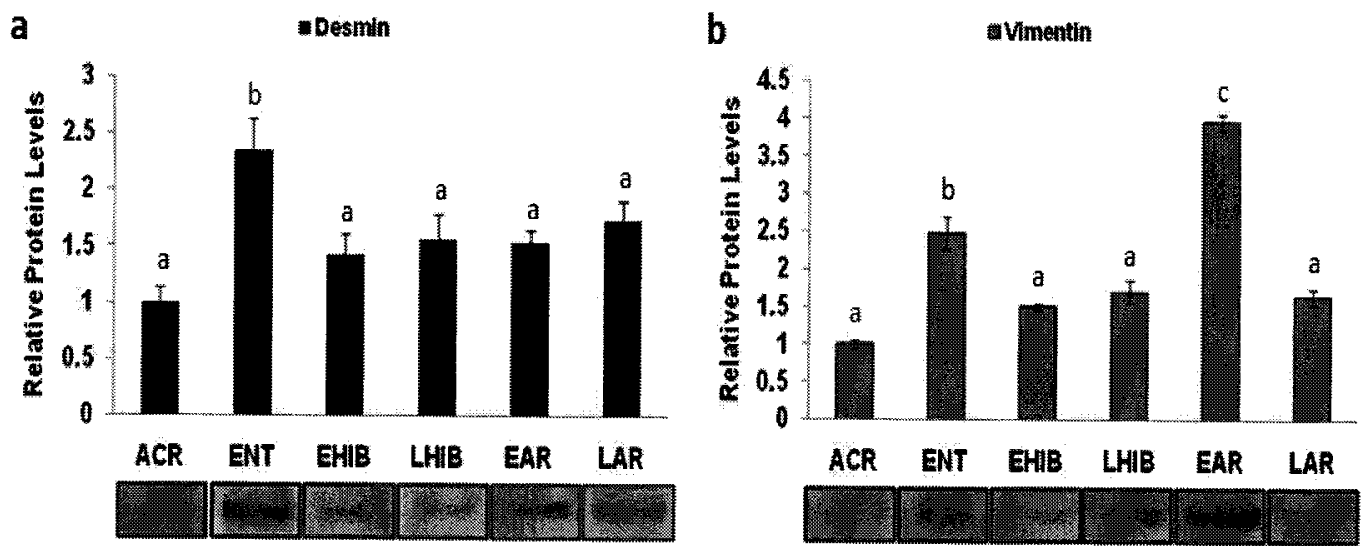

Fig. 5.4. Changes in the protein levels of desmin and vimentin in cardiac muscle of $S$. tridecemlineatus over the torpor-arousal cycle. Western blots and histograms show relative protein levels of (a) desmin, and (b) vimentin at six sampling points. Other information as in Fig. 5.1. 


\section{Discussion}

In the present chapter, the responses of five structural proteins were examined in ground squirrel skeletal and cardiac muscle over the torpor-arousal cycle. Troponin I total protein levels did not change substantially in skeletal muscle during hibernation; only a small increase was seen when arousal conditions were compared with torpor (Fig. 5.1a). This might be interpreted as a recovery during arousal to reset troponin to baseline euthermic levels after a downward reduction in the protein during torpor. By contrast, $\alpha / \beta$-tropomyosin protein levels were elevated during LHIB by 1.8 -fold, as compared to ENT (Fig. 5.1b). In nonhibernating mammals, muscle wasting due to disuse or denervation is largely attributable to increases in protein degradation which target components of the myofibrillar apparatus and result in a decrease in force production [Cohen et al, 2009]. Components of the myofiber, including troponin I, are targets of the ubiquitin-proteosome pathway [Solomon \& Goldberg, 1996] and two muscle specific ubiquitin ligases, atrogin-1/MAFbx and muscle RING-finger 1 (MuRF1), are both significantly induced upon disuse [Cohen et al, 2009]. Studies in our lab found an 20\% decrease in atrogin-1/MAFbx ubiquitin ligase protein levels in the ground squirrel skeletal muscle during torpor, which suggests that one possible mechanism that could be involved in resisting muscle atrophy in the hibernator may involve regulation of the amount or activity of this enzyme [Mamady, 2006]. However, other evidence has indicated that additional factors must also be involved as Rourke et al (2004) noted no changes in MAFbx mRNA in the soleus muscle in ground squirrel during torpor and Stitt et al (2004) demonstrated that overexpression of MAFbx/atrogin-1 alone does not cause muscle atrophy. Regardless, the present study suggests that simply maintaining troponin 
at levels similar to euthermic values under the inactivity conditions of torpor may represent a significant change to the standard pattern of mammalian skeletal muscle response to disuse. Furthermore, stabilizing troponin levels during torpor may in fact require molecular readjustments and the concerted efforts of various upstream signals including Akt and FOXO transcription factors that regulate the expression of ubiquitinproteosomal machinery [Mamady, 2006]. The small increases in both troponin and $\alpha / \beta$ tropomyosin late in the hibernation cycle, EAR and LHIB respectively, may reflect anticipatory changes for the high metabolic demands of shivering thermogenesis, whereby muscle cells create warmth by expending energy.

Myomesin total protein levels showed a similar pattern to that seen for troponin (and also vimentin), remaining virtually stable in skeletal muscle until EAR and LAR where levels increased by 2- and 2.3-fold, respectively, as compared to ENT (Fig. 5.1c). During muscle wasting, skeletal muscle disassembles from the $\mathrm{M}$ line to the Z-disk [Peng et al, 2006]. Contained within the $\mathrm{M}$ line are important proteins responsible for providing an anchor for myosin thick filaments including the $185 \mathrm{kDa}$ myomesin protein [Peng et $a l, 2006]$. Therefore, reduced stability of the $\mathrm{M}$ line during atrophy is directly related to the loss of myomesin which may become aggravated by strain [Peng et al, 2006]. In addition, $\mathbf{M}$ line myomesin is almost exclusively expressed in Type I muscle fibers [Peng et $a l, 2006]$ and may give additional support to the hypothesis for a preference for Type I muscle fibers, increasing oxidative capacity during hibernation. Alternatively, myomesin may simply be important for additional structural support when dramatic changes in body temperatures within a few short hours accompany the arousal phase.

In cardiac muscle, troponin I and $\alpha / \beta$-tropomyosin showed similar trends in 
relative expression levels over the torpor-arousal cycle. Both peaked during ENT, increasing by 2.3- and 1.8-fold respectively, as compared to ACR controls, and then declined gradually to levels at or below ACR during the arousal (Fig. 5.3). During hibernation, cardiac contraction, while slower in frequency, must generate more force in order to deal with cold body temperatures [Dawe \& Morrison, 1955]. Elevation of troponin I and $\alpha / \beta$-tropomyosin may reflect a potential compensation tool, providing the ground squirrel with the necessary changes to contractile protein composition that are needed to maintain strong cardiac contractions throughout the period of cold torpor when $\mathrm{Tb}$ is only $5-7^{\circ} \mathrm{C}$. In accordance with these data, previous research has shown that hibernators show a unique ability to enhance intracellular calcium stores in the torpid state [Wang et al, 2002], perhaps providing the necessary cellular signaling to support strong and consistent contractions of the heart during torpor. Furthermore, various cardiac myopathies that lead to hypertrophy in humans involve mutations in contractile proteins such as troponin and tropomyosin [Watkins et al, 1995]. These mutations correlate strongly with alterations in calcium sensitivity and force production in cardiac muscle [Chang et al, 2008; Ohtsuki \& Morimoto, 2008]. It is hypothesized that shifts in intracellular calcium levels reflect changes in contractile proteins which play a role in remodeling cardiac muscle in an attempt to deal with stress [Chang et al, 2008; Ohtsuki \& Morimoto, 2008]. Therefore, changes in both troponin I and $\alpha / \beta$-tropomyosin over torpor-arousal cycles may represent important molecular adaptations to the altered metabolic/physiological conditions encountered by heart during cold torpor. Myomesin protein levels in cardiac muscle also rose strongly during ENT but remained high throughout the torpor period (Fig. 5.3c). Similar to its function in skeletal muscle, 
myomesin maintains stability of the sacromere at the $\mathbf{M}$ line. Interestingly, studies using confocal microscopy and antibodies against myomesin, discovered that this protein was largely missing, perhaps degraded, in myocytes from failing hearts [Kostin et al, 2000]. Therefore, it is possible that enhanced myomesin content helps to provide the necessary framework for the increased strength of muscle contractions during cold torpor.

Desmin protein levels also responded strongly to torpor in both muscle types, doubling in ground squirrel skeletal muscle during EHIB (Fig. 5.2a) and rising about 2.4fold in cardiac muscle during ENT (Fig. 5.4a). Interestingly, misfolded desmin, caused by genetic mutations in skeletal and cardiac muscle in humans, results in severe muscle wasting characterized by myofibril dissolution and aggregations of degraded proteins [Bar et al, 2005; Goldfarb \& Dalakas, 2009]. The primary components of these aggregates are desmin, its molecular chaperone $\alpha \beta$-crystallin, and dystrophin, myotilin, and ubiquitin [Bar et al, 2005]. Indeed, several desminopathies have been characterized in humans [Goebel, 1995] and show a critical role for desmins in the normal development and maintenance of the highly organized sarcomere. The current data indicate another potential facet of muscle remodeling for cold torpor potentially contributing to minimizing disuse atrophy by skeletal muscle and to the enhanced strength required for increased cardiac output at cold $\mathrm{T}_{\mathrm{b}}$. This evidence is further substantiated by the responses of upstream effectors that exert control on desmin expression levels (Chapter 3). Myocyte enhancer factor-2 (MEF2) transcription factors regulate the expression of desmin [Black \& Olson, 1998] and increase their transcriptional capacitance in both skeletal and cardiac muscle during hibernation (Chapter 3). The earlier rise of desmin expression levels in cardiac versus skeletal muscle may reflect the heart's need to quickly 
resculpt itself to support the changing demands on heart as the animal enters cold torpor.

Vimentin protein levels in skeletal muscle responded differently, rising during EAR and LAR by 2.7 and 3.1 fold compared with ACR (Fig. 5.2b). This may touch on the hypothesis that desmin and vimentin have overlapping functions [Capetanaki et al, 1997; Colucci-Guyon et al, 1994], yet perhaps also distinct actions. Desmin and vimentin show considerable overlap in function, as illustrated from studies with knock-out mice [Capetanaki et al, 1997; Colucci-Guyon et al, 1994]. Surprisingly, both desmin and vimentin null mice were viable, despite the importance of these IFs for cellular organization, but it has been hypothesized that these proteins (along with other IFs such as nestin and synemin) can compensate for one another to produce normal phenotypies [Capetanaki et al, 1997; Colucci-Guyon et al, 1994]. Interestingly, desmin levels were enhanced during the stage of declining $\mathrm{Tb}$ whereas vimentin levels rose strongly when $\mathrm{Tb}$ was rising. Temporally separating their expression profiles may ensure that the muscle cell has ample cytoskeleton support over the whole torpor-arousal course. In heart, vimentin levels peaked twice, once during ENT (2.5 fold higher than ACR) and again during EAR (4-fold higher than ACR) (Fig. 5.4b). This suggests a role for cardiac vimentin in transitional times to/from the torpid state. Perhaps the large temperature changes that accompany entrance/arousal require selective cytoskeleton reorganization in order to support functionality of myocytes. Regardless, as evidenced from these results, modification of desmin and vimentin levels is clearly an integral response of skeletal and cardiac muscle to changing physiological demands over the torpor-arousal cycle.

In summary, the present data elucidate important muscle protein expression profiles that are altered during hibernation, potentially contributing to the optimal 
remodeling of heart and skeletal muscle for function in torpor. Modulation of components of the contractile apparatus (e.g. troponin I, tropomyosin), of the sarcomere (e.g. myomesin), and of the cytoskeleton (e.g. desmin, vimentin), may play a coordinated role in minimizing the strain placed on striated muscle during cold torpor. This study highlights excellent candidates for further research on the cell signaling events which underlie these remodeling processes. Obtaining a more in depth view of myocytes at the molecular and biochemical level will bring progress in understanding myocyte atrophy and hypertrophy. 
Chapter 6

\section{General Discussion}


The study of hibernating mammals is a powerful instrument for untangling the molecular and biochemical mechanisms, existing in lineages quite close to man, for coping with environmental conditions that are known to be harmful or lethal for nonhibernating mammals (such as $\mathrm{T}_{\mathrm{b}}$ lower than $5^{\circ} \mathrm{C}$ ). A variety of gene adaptations have been identified in ground squirrels which ensure survival during these adverse conditions including; enhanced antioxidant defenses and cellular preservation strategies, inhibition of ubiquitin-proteosomal pathways, improved mechanisms to deal with protein misfolding, the storage of transcripts in stress granules and microRNA regulation, as well as modification of chromatin structure [Storey \& Storey, 2010; Storey, 2010]. In particular, a number of studies have demonstrated the usefulness of the ground squirrel model in the field of skeletal and cardiac myopathies [Fahlman et al, 2000; Rourke et al, 2004; Zuikova et al, 2005; Eddy \& Storey, 2007; Malatesta et al, 2009; Lee et al, 2010]. The thirteen-lined ground squirrel exemplifies a level of muscle plasticity far in excess of that known for humans; drastically modifying physiological parameters based on extrinsic demands. By understanding how ground squirrel muscle adjusts its cellular environment to maintain function at high versus low temperatures, respond to different work load demands in euthermia versus torpor (e.g. prolonged inactivity by skeletal muscle, greater contractive force needed to pump cold viscous blood at slow heart beat rates) and optimize shivering thermogenesis, we can gain increased understanding of the mechanisms of adaptation and compensation that are available to mammalian muscle.

The work presented in this thesis highlights two themes in hibernation biochemistry: 1) adaptations of transcription factor regulation, and 2) muscle remodeling through alterations of structural proteins in skeletal and cardiac muscle. Conserving 
metabolic energy in all tissues during torpor relies on turning down or turning off the majority of metabolic functions which are not needed in the torpid state. However, as evidenced in this thesis, a subset of metabolic functions must be activated in order to ensure that transitions into and out of torpor, as well as extended periods in deep torpor, do not result in cellular damage. Incidentally, transcription factors and structural proteins in both skeletal and cardiac muscle work in tandem to reduce the negative effects of low body temperature and depressed metabolic rate during hibernation. Nevertheless, the temporal expression of proteins illustrates discrete differences between skeletal and cardiac muscle during hibernation and these divergent responses may reflect the different challenges faced by each tissue. The typical response associated with unloaded skeletal muscle is the activation of catabolic pathways, such as proteosomal networks, and the inactivation of anabolic pathways, such as the insulin-mTOR pathway [Glass, 2010]. Therefore, ground squirrel skeletal muscle must possess enhanced regulatory pathways which serve to both suppress the degradation of myofibrilar proteins while simultaneously directing transcription to enhance the expression of proteins critical for the minimization of muscle atrophy. Conversely, cardiac muscle hypertrophy is characterized by enhanced protein synthesis, changes in the structural proteins of the sarcomere and changes in gene transcription [Frey et al, 2004]. In humans, these changes may at first be beneficial, however, over time they lead to impaired cardiac function and heart failure [Frey et al, 2004]. This suggests that the hibernator heart possesses an unusual pattern of response, which may include differential transcription factor regulation and muscle remodeling, as a critical cell preservation strategy. 


\section{Adaptations of transcription factor regulation in skeletal muscle}

This thesis has identified roles of MEF2 transcription factor regulation in skeletal muscle highlighting its importance in hibernation success. MEF2 relative protein levels were significantly upregulated during deep torpor and levels of the activated (phosphorylated) MEF2 were also enhanced. This expression pattern indicates that MEF2 Tfs are positively regulating skeletal muscle gene transcription and, therefore, do not play an inhibitory role during hibernation. The upregulation of downstream genes under MEF2 control further corroborates the significant role of MEF2 during hibernation. MyoD is another Tf which plays a critical role in muscle metabolism and Chapter 3 highlights a potential tissue specific synergy between MEF2 and MyoD during hibernation. In addition, GLUT4 levels rise during hibernation and may be important in optimizing the aerobic capacity of cells for function in cold torpor. Notably, skeletal muscle plays a key role in the process of shivering thermogenesis during arousal, contributing to the rapid rise in body temperature to euthermic levels. Therefore, proteins which are elevated during arousal in skeletal muscle, such as MyoD and GLUT4, may be important for this response.

The typical response associated with endurance training is the differentiation of myocytes towards a phenotype associated with high mitochondrial density, increase in capillary density, and a shift in sarcomeric components toward slow-type muscle fibers [Fluck, 2006]. Glucose transporter 4 is tightly correlated with this response in humans, whereby molecular expression levels of GLUT4 (through MEF2 regulation) increase significantly following a single bout of aerobic exercise [McGee \& Hargreaves, 2006]. During development, the re-entrance of mitotically quiescent muscle cells to the cell 
cycle is dependent on MyoD expression [Sabourin \& Rudnicki, 2000]. Following multiple rounds of division these cells fuse with existing myofibers and promote muscle growth [Sabourin \& Rudnicki, 2000]. Additionally, MyoD expression is enhanced in skeletal muscle following a single bout of aerobic exercise [Sabourin \& Rudnicki, 2000]. Therefore, evidence from this thesis suggests two central adaptations of transcription factor regulation in the skeletal muscle of ground squirrel; 1) pathways which mediate the changes associated with endurance training and aerobic exercise are mimicked in hibernation and represent an important defense mechanism against disuse, and 2) developmental pathways, whereby increases in cell size and growth are most profound, may be activated during hibernation in order to compensate for the effects of disuse.

Curiously, the transcript and protein levels of MEF2 analyzed in skeletal muscle show protein levels increasing prior to transcript levels. While the torpor-arousal cycle is a cyclical phenomenon and increases in transcripts during arousal may actually be preparing tissue for the next bout of deep torpor, alternative reasons for this response may be proposed. The process of transferring information from DNA to amino acid polypeptides via mRNA is fundamental to our understanding of all cellular processes, however, an overwhelming body of evidence suggests that this classical model is far more complex than previously thought [Maier et al, 2009; Le Quesne et al, 2010]. For example, stress granules form when translation initiation is impaired, such as during global suppression of translation, resulting in the accumulation and repression of mRNA transcripts [Buchan \& Parker, 2009]. Therefore, it is possible that stress granules are important post-transcriptional regulators during hibernation where strong suppression of translation has been demonstrated [Storey \& Storey, 2004]. Stress granules, therefore, 
have the potential to alter translation and degradation of mRNA and could be responsible for the incongruent transcript and protein data observed in the present study.

Studies which unravel the complex molecular mechanisms responsible for shaping healthy skeletal muscle cells, under conditions which would be unfavorable to non-hibernators, could have far-reaching benefits. For example, a multitude of neuromuscular diseases, including all forms of muscular dystrophies, are tightly associated with muscle weakness, degeneration and muscle atrophy [Marston \& Hodgkinson, 2001]. The symptoms of muscle atrophy are due to the fact that, relative to normal living, muscles are activated less frequently and for shorter periods [Chambers et al, 2009]. Additionally, muscles are exposed to lower mechanical loads and sustain these loads for less time [Chambers et al, 2009]. Finally, muscular strength continually deteriorates and the mechanical unloading stimulates degradation pathways and downregulates those which replenish and preserve cellular function [Chambers et al, 2009]. In addition, critically ill patients confined to bed rest and astronauts exposed to the weightlessness of space flight suffer from severe consequences of skeletal muscle atrophy due to disuse. In this capacity, muscle disuse atrophy contributes significant burdens to patients with a wide range of injuries and disease pathologies. Therefore, the hibernator model provides a system which illustrates the natural defense strategies against disuse atrophy and is an excellent comparative system to use to help identify the sites that are critical to atrophy regulation in human skeletal muscle, potentially illuminating therapeutic targets. 


\section{Adaptations of transcription factor regulation cardiac muscle}

Hibernation poses a unique natural model whereby transitions into and out of cardiomyocyte hypertrophy can be compared to human cardiac muscle which experiences severe fibrosis and hypothermia under the same conditions. This thesis has elucidated the response of MEF2 in cardiac muscle during hibernation as an important promoter of cell growth and key player in the transition into and out of torpor. Importantly, entrance and arousal from torpor highlight the importance of MEF2 in the transitional phases in cardiac muscle. For example, MEF2A and MEF2C relative protein levels significantly increased earlier (ENT) and remain elevated later (EAR/LAR) in cardiac muscle as compared to skeletal muscle. Additionally, in cardiac muscle, MEF2A DNA-binding remained elevated for longer periods and all structural proteins showed significantly higher values (as compared with ACR) during entrance. This response is different than in skeletal muscle which showed that relative protein levels of MEF2 were more important during deep torpor and the associated upregulation of downstream genes during arousal was probably important for shivering thermogenesis. The downstream genes in cardiac muscle, GLUT4 and MyoD, have also been shown to be pivotal during torpor-arousal cycles. During hibernation, profound alterations in cardiomycoyte calcium regulation occur as well as changes in pH homeostasis [Wang et al, 2002; Wang \& Lee, 1996]. Importantly, GLUT4 deficiency has been linked to alterations in these two pathways and given its response in hibernators may be crucial to maintaining calcium homeostasis which is critical for hibernator survival under cold temperatures [Domenighetti et al, 2010]. Additionally, similar to the response seen in skeletal muscle, increases in MyoD may be the result of the hibernator's molecular profile mimicking an early stage of 
development when cardiac muscle is undergoing its greatest changes in cell size and growth [Rudnicki et al, 2008]. Therefore, evidence from this thesis suggests two central adaptations of transcription factor regulation in the cardiac muscle of ground squirrel during hibernation; transcription factor regulation is critical for (1) maintaining cardiac functionality during drastic changes in body temperature and, (2) to support cellular growth necessary for hypertrophy of myofibers.

Similar to the response seen in skeletal muscle, cardiac muscle transcript and proteins levels demonstrated unique patterns of expression. The weak mRNA vs protein correlations that are seen actually draw attention the idea that other regulatory mechanisms may be in play, specifically to the role of small interfering RNAs (siRNA), microRNAs (miRNA) and PIWI interacting RNAs (piRNA). These are all now believed to play key roles in global post-transcriptional regulation. Indeed, a substantial output of the cell is represented by non-protein coding RNA molecules which are responsible for orchestrating diverse cellular responses [Taft et al, 2010]. For example, microRNA-133 has been shown to play a critical role in cardiac hypertrophy [Dong et al, 2010] and the transcription factors evaluated in this study, MEF2 and MyoD, activate microRNA-1 and microRNA-133 [Liu et al, 2007; Sweetman et al, 2008]. Therefore, microRNAs represent another level of translational control that may reflect the differences in mRNA-protein expression observed in the present study.

Cardiac hypertrophy is characterized by differential gene expression and, therefore, it is reasonable to assume that transcription factors play a vital role in this process. The present thesis provides support for this hypothesis and indicates that MEF2 is a critical regulator of this response. As such, a deeper understanding of transcription 
factor regulation during hibernation and how it is divergent from the "normal" response in sustained euthermia is extremely important for our understanding of the molecular aspects of cardiac muscle health and viability. Therefore, hibernation gives us a unique opportunity to show how extracellular stimulation is first perceived and then converted into intracellular signals which program the response.

\section{Muscle remodeling}

A central part of metabolic rate depression is the suppression of the highly energy-expensive process of translation [Storey \& Storey, 2004]. Strikingly, during hibernation the skeletal and cardiac muscle contractile apparatus is remodeled in a process that involves considerable protein synthesis against a backdrop of strong global suppression of translation [Tinker et al, 1998]. This response is a departure from that seen in non-hibernating mammalian cells which, under conditions of reduced energy or amino acid availability, react with an overall suppression of protein synthesis. Therefore, hibernating mammals must have unique or unusual patterns of response as compared with the "normal" response to ATP or nutrient availability (e.g. hypoxia, starvation, muscle disuse). These changes presumably occur during hibernation in order to equip striated muscle with the optimal composition of proteins to resist dramatic changes in body temperature and physiological demands. Therefore, hibernating models suggest that striated muscle reacts to homeostatic perturbations provoked by differing physiological needs and these changes are integrated into alterations in signaling pathways which 
induce gene and protein expression which ultimately provide the signal for muscle remodeling.

Muscle cells possess a remarkable ability to modify the biochemistry of the cell in order to meet fluctuating environmental conditions [Joanisse, 2004]. Thus, muscle plasticity is extremely important for life in general, however, the homeostatic balance of the cell must always be attuned to both growth versus death signals. Muscle remodeling is a vital process for hibernators as the extreme change in physiology necessitates an altered metabolic balance and the controlled suppression versus directed upregulation of critical structural proteins and the signaling pathways which produce these changes. This thesis supports the idea that skeletal muscle requires important adaptive changes during both deep torpor and under the metabolically demanding process of shivering thermogenesis. For example, myomesin upregulation in LAR suggests the need for enhanced structural support of the sarcomere during shivering thermogenesis whereas desmin and vimentin, showing different temporal expression patterns, may reflect skeletal muscle needs for extra support during both deep torpor and arousal to euthermic levels. In cardiac muscle, all proteins were significantly upregulated during entry into torpor and vimentin was also increased during arousal. This evidence suggests that major changes in body temperature require important changes in the molecular profile of the cell to ensure signaling pathways that promote cellular death are not activated.

Changes in the structural apparatus of hibernator muscle are extremely instructive to our understanding of muscle metabolism in non-hibernating mammals, including man. While the modifications of muscle documented in the present thesis represent adaptive changes, many muscle remodeling events in humans can be maladaptive leading to 
skeletal muscle wasting and/or heart failure. For example, skeletal muscle in critically ill patients confined to bed rest may go unused for long periods and the signaling pathways which degrade structural proteins of the myofiber are attractive candidates as therapeutic targets. Therefore, how do ground squirrels alter their molecular pathways to counteract degradation pathways while also actively transcribe more signal for important structural proteins? Unraveling these mysteries will provide a wealth of information on the tools available to mammalian cells and how these pathways can be manipulated during conditions such as bed rest. Heart failure represents one of the leading causes of heart disease in the United States and often the pathology is accompanied by cardiac muscle remodeling, however, these changes ultimately result in damaged heart tissue, necrosis, and cell death [Roger, 2010]. Therefore, how does the hibernator heart alter its molecular profile in ways which are beneficial, given its change in physiology, yet ensure pathways which are deleterious to healthy cardiomyocytes remain inactivated? This thesis suggests that structural proteins of the sarcomere, contractile proteins, and intermediate filaments provide the framework for the healthy function of heart cells during extreme fluctuations of body temperature and strength of cardiac contraction. 


\section{Future directions}

Nuclear factor of activated T-cells (NFAT) are a family of transcription factors, for which there are five members NFATc1, NFATc2, NFATc4, NFAT5, which have been shown to be involved in the development of cardiac and skeletal muscle [Horsley \& Pavlath, 2002]. Of these members NFATc1 and NFATc4 are regulated by calcium signaling which must be tightly regulated to ensure skeletal and cardiac muscle homeostasis [Horsley \& Pavlath, 2002]. The general response includes the activation of the calcium-sensitive phosphatase, calcineurin which dephosphorylates NFAT and unmasks a nuclear localization signal which results in NFAT translocation [Horsley \& Pavlath, 2002]. In contrast, nuclear export is promoted by kinases in the cytoplasm and nucleus [Horsley \& Pavlath, 2002]. For example, protein kinase A (PKA) must be inactivated for NFAT nuclear retention [Horsley \& Pavlath, 2002]. Together with nuclear residents (NFATn), transcription factor-DNA binding initiates the expression of important downstream signals [Horsley \& Pavlath, 2002]. Additionally, NFAT has been shown to be coregulated by MEF2 [Putt et al, 2009], a transcription factor for which this thesis has highlighted to be important for hibernation success. Recent evidence suggests that the disregulation of NFAT holds strong links to heart failure [Rinne et al, 2010] and in atrophy associated with unloading in skeletal muscle [Al-Shanti \& Stewart, 2009]. Therefore, it would be of interest to study the thirteen-lined ground squirrels natural response to NFAT regulation during hibernation. Subsequent analysis of both upstream and downstream signals in this response would elucidate additional adaptations of skeletal and cardiac muscle during hibernation. 
GATA4 activation has been documented in cardiomyocyte hypertrophy, as

evidenced by overexpression studies in cultured cardiomyocytes [Akazawa \& Komuro, 2008], and therefore would be an interesting subject for further studies in the hibernator hypertrophic heart. GATA4 is a member of the family of zinc-finger transcription factors which bind to the promoter regions of genes which regulate myocardial differentiation and function [Okay et al, 2007]. Key downstream genes under GATA4 regulation include atrial natriuretic peptide (ANP) and B-type natriuretic peptide (BNP) [Okay et al, 2007]. ANP is a polypeptide hormone secreted by heart which causes a reduction of blood volume and reduction in cardiac output upon binding to ANP receptors [Temsah \& Nemer, 2005]. BNP is also an important polypeptide hormone secreted by ventricles of the heart in response to excessive stretching of cardiomyocytes [Temsah \& Nemer, 2005]. GATA4 is regulated by cytoplasmic-nuclear shuttling and reversible phosphorylation [Akazawa \& Komuro, 2008]. The ERK pathway, a branch of the mitogen-activated protein kinase cascades, is a key biochemical signal which mediates GATA4 regulation and the hypertrophic response [Akazawa \& Komuro, 2008]. In addition to phosphorylation, the transcriptional acitivity of GATA4 is also mediated through interactions with co-factors such as Csx/Nkx2-5, MEF2, NFAT, amongst other important Tfs [Akazawa \& Komuro, 2008]. A mutli-dimensional approach which analyzed transcription factors, co-factors, downstream and upstream signals would elucidate the role of GATA4 during hibernation.

Transcription factor regulation is fundamental to molecular regulation of genes/proteins during hibernation. Therefore, I would be interested in pursuing a more in depth look at transcription factor regulation by highlighting prominent post-translational 
modifications. Reversible phophorylation is surely an important regulator and signal transduction mechanism utilized in all aspects of metabolic regulation (Storey \& Storey, 2010). However, little is known about other post-translational modifications such as ubiquitination, sumoylation, acetylation, and methylation and the regulatory control they impose on the hibernating cell. For example, acetylation is now known to occur in more than 80 transcription factors and has been predicted by Kouzarides to "rival phosphorylation" [Yang \& Seto, 2008; Kouzarides, 2000]. Moreover, there is accumulating evidence for extensive cross-talk between different post-translational modifications and all of these signals mingle to form complex regulatory programs [Yang \& Seto, 2008]. Ubiquitination involves the attachment of the 76-residue protein ubiquitin to other proteins, often targeting the substrate for degradation by proteosomal pathways [Johnson, 2004]. However, accumulating evidence indicates that ubiquitination may also serve several other functions including development and apoptosis [Hershko \& Ciechanover, 1998]. Several small ubiquitin-like modifier proteins (SUMO) share a common chemistry with ubiquitin in that that become attached to lysine residues in substrate proteins, however, have a variety of different functions and do not directly target proteins for degradation [Johnson, 2004]. Although further evidence is required, it is generally accepted that SUMO attachment to transcription factors results in repression of gene expression [Johnson, 2004]. Moreover, methylation is another post-translational modification which has been shown to regulate transcription factors and its role has been linked with signals involved in cellular localization and compartmentalization as well as activation of transcription [Rathert et al, 2008]. Elucidating these regulatory mechanisms will provide a multi-dimensional view of transcription factor regulation during 
hibernation and highlight mechanisms which may be applicable to multiple disease states in humans.

In summary, this thesis studied the molecular response of striated muscle to decreased metabolic rate, cold body temperatures, and drastic alterations in physiology. Analysis of transcription factors, MEF2A and MEF2C and selected downstream genes (GLUT4 and MyoD), elucidate the importance of these Tfs for hibernation success and outline their possible role in typical human responses to skeletal muscle disuse atrophy, cardiomyocyte hypertrophy, and hypothermia. In addition, directed changes in the structural proteins of striated muscle (such as troponin, tropomyosin, myomesin, desmin, vimentin) provide the framework for the proper functioning of myocytes at cold body temperatures and altered physiological demands. Given the strong metabolic suppression of all energy expensive cell functions, the increased expression of the mRNA/proteins in this study highlights their importance for hibernation success. The highly regulated process of hypometabolism gives us the opportunity to take a snap shot of the interworkings of the cell and observe the complex molecular attributes which fuel our same organs and tissues. Comparing systems during hibernation provides insight into how we cope with undesirable conditions and will, in the future, help design treatment methods to oppose numerous human ailments. 


\section{Publication List}

\section{Research Articles Accepted}

Tessier SN, Storey KB (2010) Expression of myocyte enhancer factor-2 and downstream genes in ground squirrel skeletal muscle during hibernation. Mol Cell Biochem, in press. Epub July 9, 2010. DOI: 10.1007/s11010-010-0538-y

\section{Research Articles in Preparation}

Tessier SN, Storey KB (2010) Myocyte enhancer factor-2 and cardiac muscle gene expression during hibernation in thirteen-lined ground squirrels.

Tessier, SN, Storey KB (2010) Molecular adaptations of structural proteins in striated muscle of the thirteen-lined ground squirrel during hibernation.

\section{GenBank Submissions}

Spermophilus tridecemlineatus myocyte enhancer factor 2A (Mef2A) mRNA, partial cds GenBank: GU434270.1

Spermophilus tridecemlineatus myocyte enhancer factor 2C (Mef2C) mRNA, partial cds GenBank: GU434272.1

Spermophilus tridecemlineatus glucose transporter 4 (Glut4) mRNA, partial cds GenBank: GU434271.1

Spermophilus tridecemlineatus myogenic differentiation 1 (MyoD1) mRNA, partial cds GenBank: GU434273.1 


\section{Communications and Scientific Meetings}

\section{Poster Presentations}

Tessier SN, Storey KB. Pioneering muscle plasticity: molecular adaptations of structural proteins in striated muscle of the thirteen-lined ground squirrel during hibernation. $7^{\text {th }}$ annual Ottawa-Carleton Institute for Biology Symposium, Ottawa, April $14^{\text {th }}, 2010$.

Tessier SN, Storey KB. Muscle Disuse Atrophy: The expression of myocyte enhancer factor-2 in the skeletal muscle of Spermophilus tridecemlineatus during hibernation. $48^{\text {th }}$ annual Canadian Society of Zoologists, Toronto, May 12-16, 2009.

Tessier SN, Storey KB. Muscle disuse atrophy: The expression of myocyte enhancer factor-2 in the skeletal muscle of Spermophilus tridecemlineatus during hibernation. $6^{\text {th }}$ annual Ottawa-Carleton Institute for Biology Symposium, Ottawa, April $30^{\text {th }}, 2009$.

Tessier SN, Storey KB. Muscle disuse atrophy: The expression of myocyte enhancer factor-2 in the skeletal muscle of Spermophilus tridecemlineatus during hibernation. $11^{\text {th }}$ Annual Chemistry and Biochemistry Graduate Research Conference, Montreal, November 21-22, 2008.

\section{Oral Presentations}

Tessier SN. Conquering adversity: amazing tales of winter survival by hibernating mammals and the biomedical secrets they hold. Celebration of Women in Science and Engineering, hosted by Carleton University Women in Science and Engineering (CU-WISE), Ottawa, April $8^{\text {th }}, 2010$. 


\section{Appendix I}

Examples of constantly expressed proteins in our animal tissues

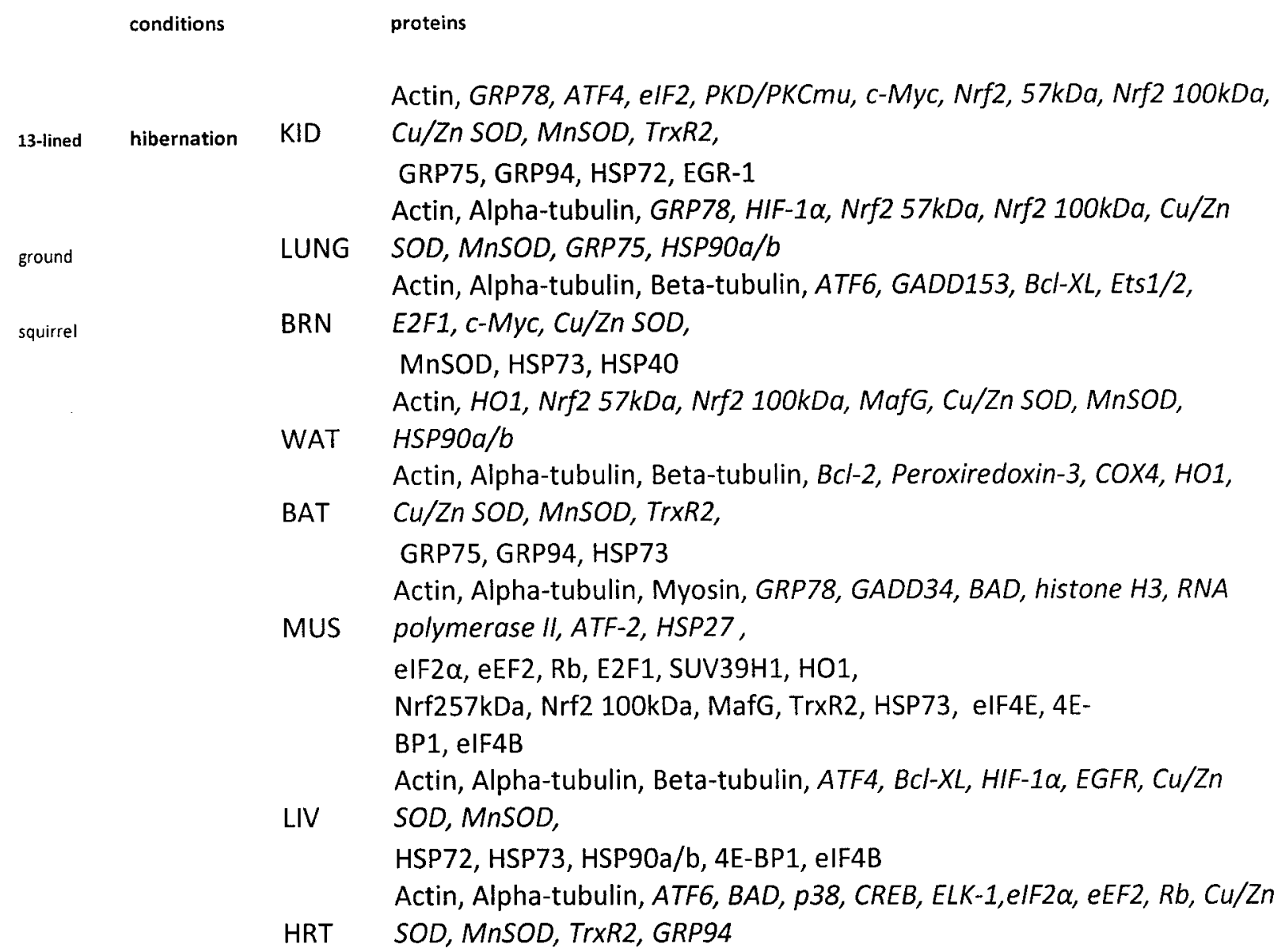

Examples of constantly expressed mRNAs from our animals

conditions

13 .

lined

ground

squirrel

\section{Genes}

KID grp78, atf4, cox-4, fasn, ho-2, grp94

LUNG grp78, hif1, nrf2, fasn, bc/2, ho-2, grp75

BRN ho-2, grp75, grp170

WAT $h$-fabp, a-fabp, ho-2

BAT atf4, hif1, nrf2, cox-4, ho-1, ho-2

grp78, atf4, foxo1a, hif1, cox-4, a-fabp, ho-1, Cu/Zn SOD, MnSOD,

MUS $\quad \operatorname{grp} 75$

LIV grp78, bcl-xl, hif1, ho-2, grp75, grp94, grp170

HRT grp78, cox-4, H-FABP, a-fabp, es1, bc/2, ho-2, grp75, grp94 


\section{References}


Agarkiva I, Perriard JC (2005) The M-band: an elastic web that crosslinks thick filaments in the center of the sarcomere. Trends Cell Biol 15(9): 477-485.

Akazawa H, Komuro I (2003) Roles of cardiac transcription factors in cardiac hypertrophy. Circ Res 92(10): 1079-1088.

Amat R, Planavila A, Chen SL, Iglesias R, Giralt M, Villarroya F (2009) SIRT1 controls the transcription of the peroxisome proliferator-activated receptor-gamma co-activator1alpha (PGC-1alpha) gene in skeletal muscle through the PGC-1alpha autoregulatory loop and interaction with MyoD. J Biol Chem 284(33): 21872-21880.

Andrews MT, Russeth KP, Drewes LR, Henry PG (2009) Adaptive mechanisms regulate preferred utilization of ketones in the heart and brain of a hibernating mammal during arousal from torpor. Am J Physiol 296(2): R383-393.

Bar H, Fischer D, Goudeau B, Kley RA, Clemen CS, Vicart P, Herrman H, Vorgerd M, Schroder R (2005) Pathogenic effects of a novel heterozygous R350P desmin mutation on the assembly of desmin intermerdiate filaments in vivo and in vitro. Hum Mol Genet 14(10): 1251-1260.

Bassel-Duby R, Olson EN (2006) Signaling pathways in skeletal muscle remodeling. Annu Rev Biochem 75:19-37.

Berkes CA, Tapscott SJ (2005) MyoD and the transcriptional control of myogenesis. Semin Cell Dev Biol 16(4-5): 585-595.

Black BL, Olson EN (1998) Transcriptional control of muscle development by myocyte enhancer factor-2 (MEF2) proteins. Annu Rev Cell Dev Biol 14:167-196.

Bratincsák A, McMullen D, Miyake S, Tóth ZE, Hallenbeck JM, Palkovits M (2007) Spatial and temporal activation of brain regions in hibernation: c-fos expression during the hibernation bout in thirteen-lined ground squirrel. J Comp Neurol 505(4): 443-458. 
Brauch KM, Dhruv ND, Hanse EA, Andrews MT (2005) Digital transcriptome analysis indicates adaptive mechanisms in the heart of a hibernating mammal. Physiol Genomics 23(2): 227-234.

Buchan, JR, Parker, R (2009) Eukaryotic stress granules: the ins and outs of translation. Mol Cell 36(6): 932-41.

Caiozzo VJ (2002) Plasticity of skeletal muscle phenotype: mechanical consequences. Muscle Nerve 26(6): 740-768.

Capetanaki Y, Bloch RJ, Kouloumenta A, Mavroidis M, Psarras S (2007) Muscle intermediate filaments and their links to membranes and membranous organelles. Exp Cell Res 313(10): 2063-2076.

Capetanaki Y, Milner DJ, Weitzer G (1997) Desmin in muscle formation and maintenance: knockouts and consequences. Cell Struct Funct 22(1): 103-116.

Carey HV, Andrews MT, Martin SL (2003) Mammalian hibernation: cellular and molecular responses to depressed metabolism and low temperatures. Physiol Rev 83(4): 1153-1181.

Chambers MA, Moylan JS, Reid MB (2009) Physical inactivity and muscle weakness in the critically ill. Crit Care Med 37(10 Suppl): S337-346.

Chandran R, Knobloch TJ, Anghelina M, Agarwal S (2007) Biomechanical signals upregulate myogenic gene induction in the presence or absence of inflammation. Am J Physiol Cell Physiol 293(1):C267-276.

Chang AN, Parvatiyar MS, Potter JD (2008) Troponin and cardiomyopathy. Biochem Biophys Res Commun 369(1): 74-81.

Chockalingam SP, Cholera R, Oak SA, Zheng Y, Jarrett HW, Thomason DB (2002) Dystrophinglycoprotein complex and Ras and Rho GTPase signaling are altered in muscle atrophy. Am J Physiol 283: C500-C511. 
Choi H, Selpides PJ, Nowell MM, Rourke BC (2009) Functional overload in ground squirrels plantaris muscle fails to induce myosin isoform shifts. Am J Physiol Regul Integr Comp Physiol 297(3): R578-R586.

Cohen S, Brault JJ, Gygi SP, Glass DJ, Valenzuela DM, Gartner C, Latres E, Goldberg AL (2009) During muscle atrophy, thick, but not thin, filament components are degraded by MuRF1-dependent ubiquitylation. J Cell Biol 185(6): 1083-1095.

Colucci-Guyon E, Portier MM, Dunia I, Paulin D, Pournin S, Babinet C. (1994) Mice lacking vimentin develop and reproduce without an obvious phenotype. Cell 79: 679-79694.

Cotton CJ, Harlow HJ (2010) Avoidance of skeletal muscle atrophy in spontaneous and facultative hibernators. Physiol Biochem Zool 83(3): 551-560.

Cox DM, Du M, Marback M, Yang EC, Chan J, Siu KW, McDermott JC (2003) Phosphorylation motifs regulating the stability and function of myocyte enhancer factor $2 \mathrm{~A}$. J Biol Chem 278(17): 15297-15303.

Czubryt MP, Olson EN (2004) Balancing contractility and energy production: the role of myocyte enhancer factor 2 (MEF2) in cardiac hypertrophy. Recent Prog Horm Res 59: 105-124.

Dawe AR, Morrison PR (1955) Characteristics of the hibernating heart. Am Heart J 49: 367-384.

De Falco G, Comes F, Simone C (2006) pRb: master of differentiation. Coupling irreversible cell cycle withdrawal with induction of muscle-specific transcription. Oncogene 25(38): $5244-5249$.

Dechesne CA, Wei Q, Eldridge J, Gannoun-Zaki L, Millasseau P, Bougueleret L, Caterina D, Paterson BM (1994) E-box-and MEF-2-independent muscle-specific expression, positive autoregulation, and cross-activation of the chicken MyoD (CMD1) promoter reveal an indirect regulatory pathway. Mol Cell Biol 14(8): 5474-5486.

Dignam JD, Lebovitz RM, Roeder RG (1983) Accurate transcription initiation by RNA polymerase II in a soluble extract from isolated mammalian nuclei. Nuc Acids Res 11(5): $1475-1489$. 
Domenighetti AA, Danes VR, Curl CL, Favaloro JM, Proietto J, Delbridge LM (2010) Targeted GLUT-4 deficiency in the heart induces cardiomyocyte hypertrophy and impaired contractility linked with $\mathrm{Ca}^{2+}$ and proton flux dysregulation. J Mol Cell Cardiol 48(4): 663-672.

Eddy SF, Morin PJ, Storey KB (2005) Cloning and expression of PPAR $\gamma$ and PGC-1 $\alpha$ from the hibernating ground squirrel, Spermophilus tridecemlineatus. Mol Cell Biochem 269(1-2): $175-182$.

Eddy SF, Storey KB (2007) p38 MAPK regulation of transcription factor targets in muscle and heart of the hibernating bat, Myotis lucifugus. Cell Biochem Funct 25(6): 759-765.

El Kebbaj Z, Andreoletti P, Mountassif D, Kabine M, Schohn H, Dauca M, Latruffe N, El Kebbaj MS, Cherkaoui-Malki M. (2009) Differential regulation of peroxisome proliferatoractivated receptor (PPAR)-alpha1 and truncated PPARalpha2 as an adaptive response to fasting in the control of hepatic peroxisomal fatty acid beta-oxidation in the hibernating mammal. Endocrinology 150(3): 1192-1201.

Fahlman A, Storey JM, Storey KB (2000) Gene up-regulation in heart during mammalian hibernation. Cryobiology 40(4): 332-342.

Frerichs KU, Hallenbeck JM (1998) Hibernation in ground squirrels induces state and speciesspecific tolerance to hypoxia and aglycemia: an in vitro study in hippocampal slices. $J$ Cereb Blood Flow Metab 18(2): 168-175.

Frerichs KU, Kennedy C, Sokoloff L, Hallenbeck JM (1994) Local cerebral blood flow during hibernation, a model of natural tolerance to "cerebral ischemia". J Cereb Blood Flow Metab 14(2): 193-205.

Frey N, Katus HA, Olson EN, Hill JA (2004) Hypertrophy of the heart: a new therapeutic target? Circulation 109(13): 1580-1589.

Geiser F (2004) Metabolic rate and body temperature reduction during hibernation and daily torpor. Annu Rev Physiol 66: 239-274. 
Goebel HH (1995) Desmin-related neuromuscular disorders. Muscle Nerve 18(11): 1306-1320.

Goldfarb LG, Dalakas MC (2009) Tragedy in a heartbeat: malfunctioning desmin causes skeletal and cardiac muscle disease. J Clin Invest 119(7): 1806-1813.

Glass DJ (2010) PI3 Kinase Regulation of Skeletal Muscle Hypertrophy and Atrophy. Curr Top Microbiol Immunol [Epub ahead of print]

Graham TE, Kahn BB (2007) Tissue-specific alterations of glucose transport and molecular mechanisms of intertissue communication in obesity and type 2 diabetes. Horm Metab Res 39(10): 717-721.

Harlow HJ, Lohuis T, Beck TD, Iaizzo PA (2001) Muscle strength in overwintering bears. Nature 409(6823): 997.

Hershko A, Ciechanover A (1998) The ubiquitin system. Annu Rev Biochem 67:425-79.

Holloszy JO (2008) Regulation by exercise of skeletal muscle content of mitochondria and GLUT4. J Physiol Pharmacol 59(Suppl 7): 5-18.

Horsley V, Pavlath GK (2002) NFAT: ubiquitous regulator of cell differentiation and adaptation. J Cell Biol 156(5):771-4.

Ishikawa F, Miyoshi H, Nose K, Shibanuma M (2010) Transcriptional induction of MMP-10 by TGF-beta, mediated by activation of MEF2A and downregulation of class IIa HDACs. Oncogene 29(6): 909-919.

Ivaska J, Pallari HM, Nevo J, Eriksson JE (2007) Novel functions of vimentin in cell adhesion, migration, and signaling. Exp Cell Res 313(10): 2050-2062.

Joanisse DR (2004) Skeletal muscle metabolism and plasticity. Functional Metabolism: Regulation and Adaptation, Copyright \# 2004 John Wiley \& Sons, Inc.

Johnson ES (2004) Protein modification by SUMO. Annu Rev Biochem 73:355-82.

Kang J, Gocke CB, Yu H (2006) Phosphorylation-facilitated sumoylation of MEF2C negatively regulates its transcriptional activity. BMC Biochem 7(5): 1-14. 
Karamboulas C, Dakubo GD, Liu J, De Repentigny Y, Yutzey K, Wallace VA, Kothary R, Skerjanc IS (2006) Disruption of MEF2 activity in cardiomyoblasts inhibits cardiomyogenesis. J Cell Sci 119(Pt 20): 4315-4321.

Kato Y, Kravchenko VV, Tapping RI, Han J, Ulevitch RJ, Lee JD (1997) BMK1/ERK5 regulates serum-induced early gene expression through transcription factor MEF2C. EMBO J 16(23): 7054-7066.

Kato Y, Zhao M, Morikawa A, Sugiyama T, Chakravortty D, Koide N, Yoshida T, Tapping RI, Yang Y, Yokochi T, Lee JD (2000) Big mitogen-activated kinase regulates multiple members of the MEF2 protein family. J Biol Chem 275(24): 18534-18540.

Kim MS, Fielitz J, McAnnally J, Shelton JM, Lemon DD, McKinsey TA, Richardson JA, BasselDuby R, Olson EN (2008) Protein kinase D1 stimulates MEF2 activity in skeletal muscle and enhances muscle performance. Mol Cell Biol 28(11): 3600-3609.

Kondo N, Sekijima T, Kondo J, Takamatsu N, Tohya K, Ohtsu T (2006) Circannual control of hibernation by HP complex in the brain. Cell 125(1): 161-172.

Kostin S, Hein S, Arnon A, Scholz D, Schaper J (2000) The cytoskeleton and related proteins in the human failing heart. Heart Failure Rev 5(3): 271-280.

Kouzarides T (2000) Acetylation: a regulatory modification to rival phosphorylation? EMBO J $19(6): 1176-9$.

Kuzman JA, Thomas TA, Vogelsang KA, Said S, Anderson BE, Gerdes AM (2005) Effects of induced hyperthyroidism in normal and cardiomyopathic hamsters. J Appl Physiol 99(4): 1428-1433. 
Lee K, Park JY, Yoo W, Gwag T, Lee JW, Byun MW, Choi I (2008) Overcoming muscle atrophy in a hibernating mammal despite prolonged disuse in dormancy: proteomic and molecular assessment. J Cell Biochem 104(2): 642-656.

Lee K, So H, Gwag T, Ju H, Lee JW, Yamashita M, Choi I (2010) Molecular mechanism underlying muscle mass retention in hibernating bats: role of periodic arousal. J Cell Physiol 222(2): 313-319.

Legerlotz K, Smith HK (2008) Role of MyoD in denervated, disused, and exercised muscle. Muscle Nerve 38(3): 1087-1100.

Leibham D, Wong MW, Cheng TC, Schroeder S, Weil PA, Olson EN, Perry M (1994) Binding of TFIID and MEF2 to the TATA element activates transcription of the Xenopus MyoDa promoter. Mol Cell Biol 14(1): 686-699.

Le Quesne, PC, Spriggs, KA, Bushell, M \& Willis, AE. (2010) Dysregulation of protein synthesis and disease. J Pathol 220(2): 140-151.

Lin J, Wu H, Tarr PT, Zhang CY, Wu Z, Boss O, Michael LF, Puiqserver P, Isotani E, Olson EN, Lowell BB, Bassel-Duby R, Spiegelman BM (2002) Transcriptional co-activator PCG-1 alpha drives the formation of slow-twitch muscle fibers. Nature 418(6899): 797-801.

Lin Q, Schwarz J, Bucana C, Olson EN (1997) Control of mouse cardiac morphogenesis and myogenesis by transcription factor MEF2C. Science 276(5317): 1404-1407.

Liu B, Wang LC, Belke DD (1993) Effects of temperature and $\mathrm{pH}$ on cardiac myofilament $\mathrm{Ca}^{2+}$ sensitivity in rat and ground squirrel. Am J Physiol 264(1 Pt 2): R104-108.

Lynch J, Guo L, Gelebart P, Chilibeck K, Xu J, Molkentin JD, Agellon LB, Michalak M (2005) Calreticulin signals upstream of calcineurin and MEF2C in a critical $\mathrm{Ca}^{2+}$-dependent signaling cascade. J Cell Biol 170(1): 37-47.

Ma K, Chan JK, Zhu G, Wu Z (2005) Myocyte enhancer factor 2 acetylation by p300 enhances its DNA binding activity, transcriptional activity, and myogenic differentiation. Mol Cell Biol 25(9): 3575-3582. 
Maeda T, Gupta MP, Stewart AF (2002) TEF-1 and MEF2 transcription factors interact to regulate muscle-specific promoters. Biochem Biophys Res Commun 294(4): 791-797.

MacDonald JA, Storey KB (2005) Mitogen-activated protein kinases and selected downstream targets display organ-specific responses in the hibernating ground squirrel. Int J Biochem Cell Biol 37(3): 679-691.

MacDonald JA, Storey KB (2007) The effect of hibernation on protein phosphatases from ground squirrel organs. Arch Biochem Biophys 468(2): 234-243.

Maier T, Güell M, Serrano L. (2009) Correlation of mRNA and protein in complex biological samples. FEBS Lett 583(24):3966-73.

Malatesta M, Perdoni F, Battistelli S, Muller S, Zancanaro C (2009) The cell nuclei of skeletal muscle cells are transcriptionally active in hibernating edible dormice. MBC Cell Biol 10:19.

Mamady H (2006) Muscle disuse atrophy: profile and assessment of FoxO1a activation, MAFbx/atrogin-1, Bcl-3 and NFאB p50 in skeletal muscle and heart during hibernation. $\mathrm{PhD}$ thesis, Chapter 4; Department of Biology, Carleton University.

Mamady H, Storey KB (2006) Up-regulation of the endoplasmic reticulum molecular chaperone GRP78 during hibernation in thirteen-lined ground squirrels. Mol Cell Biochem 292(12): 89-98.

Mamady H, Storey KB (2008) Coping with stress: expression of ATF4, ATF6 and downstream targets in organs of hibernating ground squirrels. Arch Biochem Biophys 477(1): 77-85.

Marston SB, Hodgkinson JL (2001) Cardiac and skeletal myopathies: can genotype explain phenotype? J Muscle Res Cell Motil 22(1):1-4.

McGee SL, Hargreaves M (2006) Exercise and skeletal muscle glucose transporter 4 expression: molecular mechanisms. Clin Exp Pharmacol Physiol 33(4): 395-399. 
McKinsey TA, Zhang CL, Olson EN (2000) Activation of the myocyte enhancer factor-2 transcription factor by calcium/calmodulin-dependent protein kinase-stimulated binding of 14-3-3 to histone deacetylase 5. Proc Natl Acad Sci USA 97(26): 14400-14405.

McKinsey TA, Zhang CL, Olson EN (2002) Signaling chromatin to make muscle. Curr Opin Cell Biol 14(6): 763-772.

McMullen DC, Hallenbeck, JM (2010) Regulation of Akt during torpor in the hibernating ground squirrel, Ictidomys tridecemlineatus. J Comp Physiol B [Epub ahead of print].

Molkentin JD, Firulli AB, Black BL, Martin JF, Hustad CM, Copeland N, Jenkins N, Lyons G, Olson EN (1996) MEF2B is a potent transactivator expressed in early myogenic lineages. Mol Cell Biol 16(7): 3814-3824.

Molkentin JD, Lu JR, Antos CL, Markham B, Richardson J, Robbins J, Grant SR, Olson EN (1998) A calcineurin-dependent transcriptional pathway for cardiac hypertrophy. Cell 93(2): 215-228.

Molkentin JD, Markham BE (1993) Myocyte-specific enhancer-binding factor (MEF-2) regulates alpha-cardiac myosin heavy chain gene expression in vitro and in vivo. $\mathrm{J}$ Biol Chem 268(26): 19512-19520.

Morano I, Adler K, Agostini, B, Hasselbach W (1992) Expression of myosin heavy and light chains and phosphorylation of the phosphorylatable myosin light chain in the heart ventricle of the European hamster during hibernation and in summer. J Muscle Res Cell Motil 13(1): 64-70.

Morin PJ, Dubuc A, Storey KB (2008) Differential expression of microRNA species in organs of hibernating ground squirrels: a role in translational suppression during torpor. Biochim Biophys Acta 1779(10): 628-633.

Morin PJ, Ni Z, McMullen DC, Storey KB (2008) Expression of Nrf2 and its downstream gene targets in hibernating 13-lined ground squirrels, Spermophilus tridecemlineatus. Mol Cell Biochem 312(1-2): 121-129. 
Morin PJ, Storey KB (2006) Evidence of a reduced transcriptional state during hibernation in ground squirrels. Cryobiology 53(3): 310-318.

Morin PJ, Storey KB (2007) Antioxidant defense in hibernation: cloning and expression of peroxiredoxins from hibernating ground squirrels, Spermophilus tridecemlineatus. Arch Biochem Biophys 461(1): 59-65.

Morin PJ, Storey KB (2009) Mammalian hibernation: differential gene expression and novel application of epigenetic controls. Int J Dev Biol 53(2-3): 433-442.

Muñoz JP, Collao A, Chiong M, Maldonado C, Adasme T, Carrasco L, Ocaranza P, Bravo R, Gonzalez L, Díaz-Araya G, Hidalgo C, Lavandero S (2009) The transcription factor MEF2C mediates cardiomyocyte hypertrophy induced by IGF-1 signaling. Biochem Biophys Res Commun 388(1):155-160.

Musacchia XJ, Steffen JM, Steffen MC, Geoghegan TE, Dombrowski JM, Milsom WK, Burlington RF (1989) Morphometric and biochemical adaptations of skeletal muscle in hibernating and non-hibernating ground squirrels, S. lateralis. In: Living in the Cold, edited by A. Malan and B. Canguilhem. Paris: INSERM, 1989, p. 217-224.

Naya FJ, Black BL, Wu H, Bassel-Duby R, Richardson JA, Hill JA, Olson EN (2002) Mitochondrial deficiency and cardiac sudden death in mice lacking the MEF2A transcription factor. Nat Med 8(11):1303-1309.

Naya FJ, Olson E (1999) MEF2: a transcriptional target for signaling pathways controlling skeletal muscle growth and differentiation. Curr Opin Cell Biol 11(6): 683-688.

Nelson CJ, Otis JP, Martin SL, Carey HV (2009) Analysis of the hibernation cycle using LC-MS based metabolomics in ground squirrel liver. Physiol Genomics 37(1): 43-51.

Ni Z, Storey KB (2010) Heme oxygenase expression and Nrf2 signaling during hibernation in ground squirrels. Can J Physiol Pharmacol 88(3): 379-387.

Ohtsuki I, Morimoto S (2008) Troponin: regulatory function and disorders. Biochem Biophys Res Commun 369(1): 62-73. 
Oka T, Xu J, Molkentin JD (2007) Re-employment of developmental transcription factors in adult heart disease. Semin Cell Dev Biol 18(1):117-31.

Olson EN (2004) Undermining the endothelium by ablation of MAPK-MEF2 signaling. J Clin Invest 113(8):1110-1112.

Ornatsky OI, Andreucci JJ, McDermott JC (1997) A dominant-negative form of transcription factor MEF2 inhibits myogenesis. J Biol Chem 272(52): 33271-33278.

Ornatsky OI, Cox DM, Tangirala P, Andreucci JJ, Quinn ZA, Wrana JL, Prywes R, Yu YT, McDermott JC (1999) Post-translational control of the MEF2A transcriptional regulatory protein. Nucleic Acids Res 27(13): 2646-2654.

Patterson B, Fields AV, Shannon RP (2009) New insights into myocardial glucose metabolism: surviving under stress. Curr Opin Clin Nutr Metab Care 12(4): 424-430.

Peng J, Raddatz K, Labeit S, Granzier H, Gotthardt M (2006) Muscle atrophy in titin M-line deficient mice. J Muscle Res Cell Motil 26(6-8): 381-388.

Postnikova GB, Tselikova SV, Kolaeva SG, Solomonov NG (1999) Myoglobin content in skeletal muscles of hibernating ground squirrels rises in autumn and winter. Comp Biochem Physiol A 124(1): 35-37.

Potthoff MJ, Olson EN (2007) MEF2: a central regulator of diverse developmental programs. Development 134(23): 4131-4140.

Rampalli S, Li L, Mak E, Ge K, Brand M, Tapscott SJ, Dilworth FJ (2007) p38 MAPK signaling regulates recruitment of Ash2L-containing methyltransferase complexes to specific genes during differentiation. Nat Struct Mol Biol 14(12): 1150-1156.

Rathert P, Dhayalan A, Ma H, Jeltsch A (2008) Specificity of protein lysine methyltransferases and methods for detection of lysine methylation of non-histone proteins. Mol Biosyst 4(12):1186-90. 
Riquelme C, Barthel KK, Liu X (2006) SUMO-1 modification of MEF2A regulates its transcriptional activity. J Cell Mol Med 10(1): 132-144.

Roger VL (2010) The heart failure epidemic. Int J Environ Res Public Health 7(4):1807-30.

Rourke BC, Cotton CJ, Harlow HJ, Caiozzo VJ (2006) Maintenance of slow type I myosin protein and mRNA expression in overwintering prairie dogs and black bears. J Comp Physiol B 176(7): 709-720.

Rourke BC, Yokoyama Y, Milsom WK, Caiozzo VJ (2004) Myosin isoform expression and MAFbx mRNA levels in hibernating golden mantled ground squirrels (Spermophilus lateralis). Physiol Biochem Zool 77(4): 582-593.

Sabourin LA, Rudnicki MA (2000) The molecular regulation of myogenesis. Clin Genet $57(1): 16-25$.

Shavlakadze T, Grounds M (2006) Of bears, frogs, meat, mice and men: complexity of factors affecting skeletal muscle mass and fat. Bioessays 28(10): 994-1009.

Staples JF, Brown JC (2008) Mitochondrial metabolism in hibernation and daily torpor: a review. J Comp Physiol B 178(7): 811-827.

Smith JA, Kohn TA, Chetty AK, Ojuka EO (2008) CaMK activation during exercise is required for histone hyperacetylation and MEF2A binding at the MEF2 site on the Glut4 gene. Am J Physiol 295(3): E698-E704.

Solomon V, Goldberg AL (1996) Importance of the ATP-ubiquitin-proteosome pathway in the degradation of soluble and myofribrillar protein in rabbit muscle extracts. J Biol Chem 271(43): $26690-26697$. 
Stitt TN, Drujan D, Clarke BA, Panaro FJ, Timofeyva Y, Kline WO, Gonzalez M, Yancopoulos GD, Glass DJ (2004) The IGF-1/PI3K/Akt pathway prevents expression of muscle atrophy-induced ubiquitin ligases by inhibiting FOXO transcription factors. Mol Cell 14(3): 395-403.

Storey KB (2010) Out cold: biochemical regulation of mammalian hibernation - a mini-review. Gerontology 56(2): 220-230.

Storey KB, Storey JM (2004) Metabolic rate depression in animals: transcriptional and translational controls. Biol Rev 79(1): 207-233.

Storey KB, Storey JM (2010) Metabolic rate depression: the biochemistry of mammalian hibernation. Clin Chem [in press]

Streicher JM, Ren S, Herschman H, Wang Y (2010) MAPK-activated protein kinase-2 in cardiac hypertrophy and cyclooxygenase-2 regulation in heart. Circ Res 106(8): 1434-1443.

Sun W, Wei X, Kesavan K, Garrington TP, Fan R, Mei J, Anderson SM, Gelfand EW, Johnson GL (2003) MEK kinase 2 and the adaptor protein Lad regulate extracellular signalregulated kinase 5 activation by epidermal growth factor via Src. Mol Cell Biol 23(7): 2298-2308.

Taegtmeyer H, Sen S, Vela D (2010) Return to the fetal gene program: a suggested metabolic link to gene expression in the heart. Ann NY Acad Sci 1188: 191-198.

Temsah R, Nemer M (2005) GATA factors and transcriptional regulation of cardiac natriuretic peptide genes. Regul Pept 128(3):177-85.

Tinker DB, Harlow HJ, Beck TD (1998) Protein use and muscle-fiber changes in free-ranging, hibernating black bears. Physiol Zool 71(4): 414-424.

Vong LH, Ragusa MJ, Schwarz JJ (2005) Generation of conditional Mef2cloxP/loxP mice for temporal- and tissue-specific analyses. Genesis 43(1): 43-48. 
Wang LCH, Lee TF (1996) Torpor and hibernation in mammals: metabolic, physiological, and biochemical adaptations. In: Fregley MJ, Blatteis CM (eds) Handbook of Physiology: Environmental Physiology. Oxford University Press, New York, sect 4, vol 1, pp 507532.

Wang SQ, Lakatta EG, Cheng H, Zhou ZQ (2002) Adaptive mechanisms of intracellular calcium homeostasis in mammalian hibernators. J Exp Biol 205(Pt 19): 2957-2962.

Watkins H, McKenna WJ, Thierfelder L, Suk HJ, Anan R, O'Donoghue A, Spirito P, Matsumori A, Moravec CS, Seidman JG, et al. (1995) Mutations in the genes for cardiac troponin and alpha-tropomyosin in hypertrophic cardiomyopathy. N Engl J Med 332(16): 10581064.

Wei JQ, Shehadeh LA, Mitrani JM, Pessanha M, Slepak TI, Webster KA, Bishopric NH (2008) Quantitative control of adaptive cardiac hypertrophy by acetyltransferase p300. Circulation 118(9): 934-946.

Wickler SJ, Hoyt DF, van Breukelen F (1991) Disuse atrophy in the hibernating golden-mantled ground squirrel, Spermophilus lateralis. Am J Physiol 261(5 Pt 2): R1214-R1217.

Woods AK, Storey KB (2005) Effects of hibernation on multicatalytic proteinase complex in thirteen-lined ground squirrels, Spermophilus tridecemlineatus. Mol Cell Biochem 271(12): $205-213$.

Wright DC (2007) Mechanisms of calcium-induced mitochondrial biogenesis and GLUT4 synthesis. Appl Physiol Nutr Metab 32(5): 840-845.

Yacoe M (1983) Maintenance of the pectoralis muscle during hibernation in the big brown bat Eptesicus fuscus. J Comp Physiol 152: 137-144.

Yang SH, Galanis A, Sharrocks AD (1999) Targeting of p38 mitogen-activated protein kinases to MEF2 transcription factors. Mol Cell Biol 19(6): 4028-4038.

Yang XJ, Seto E (2008) Lysine acetylation: codified crosstalk with other posttranslational modifications. Mol Cell 31(4):449-61. 
Yoon SC, Ahn YM, Jun SJ, Kim Y, Kang UG, Park JB, Kim YS (2005) Region-specific phosphorylation of ERK5-MEF2C in the rat frontal cortex and hippocampus after electroconvulsive shock. Prog Neuropsychopharmacol Biol Psychiatry 29(5): 749-753.

Yu YT, Breitbart RE, Smoot LB, Lee Y, Mahdavi V, Nadal-Ginard B (1992) Human myocytespecific enhancer factor 2 comprises a group of tissue-restricted MADS box transcription factors. Genes Dev 6(9): 1783-1798.

Zakharova NM, Nakipova OV, Averin AS, Tikhonov KG, Solomonov NG (2008) Changes in force-frequency relationships in cardiac papillary muscles of hibernating ground squirrels under cooling. Dokl Biol Sci 424: 21-24.

Zuikova OV, Osipova DA, Vikhliantsev IM, Malyshev SL, Udal'tsov SL, Podlubnaia ZA (2005) Myosin light chains of skeletal and cardiac muscles of ground squirrels Citellus undulatus in different periods of hibernation. Biofiz 50(5): 797-802. 